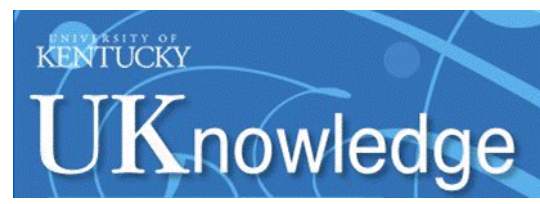

University of Kentucky

UKnowledge

\title{
Identifying the Trauma Recovery Needs of Maltreated Children: An Examination of Child Welfare Workers' Effectiveness in Screening for Traumatic Stress
}

Adrienne Whitt-Woosley

University of Kentucky, alwhit4@uky.edu

Digital Object Identifier: http://dx.doi.org/10.13023/ETD.2016.196

Right click to open a feedback form in a new tab to let us know how this document benefits you.

\section{Recommended Citation}

Whitt-Woosley, Adrienne, "Identifying the Trauma Recovery Needs of Maltreated Children: An Examination of Child Welfare Workers' Effectiveness in Screening for Traumatic Stress" (2016). Theses and Dissertations--Social Work. 11.

https://uknowledge.uky.edu/csw_etds/11

This Doctoral Dissertation is brought to you for free and open access by the College of Social Work at UKnowledge. It has been accepted for inclusion in Theses and Dissertations--Social Work by an authorized administrator of UKnowledge. For more information, please contact UKnowledge@lsv.uky.edu. 


\section{STUDENT AGREEMENT:}

I represent that my thesis or dissertation and abstract are my original work. Proper attribution has been given to all outside sources. I understand that I am solely responsible for obtaining any needed copyright permissions. I have obtained needed written permission statement(s) from the owner(s) of each third-party copyrighted matter to be included in my work, allowing electronic distribution (if such use is not permitted by the fair use doctrine) which will be submitted to UKnowledge as Additional File.

I hereby grant to The University of Kentucky and its agents the irrevocable, non-exclusive, and royalty-free license to archive and make accessible my work in whole or in part in all forms of media, now or hereafter known. I agree that the document mentioned above may be made available immediately for worldwide access unless an embargo applies.

I retain all other ownership rights to the copyright of my work. I also retain the right to use in future works (such as articles or books) all or part of my work. I understand that I am free to register the copyright to my work.

\section{REVIEW, APPROVAL AND ACCEPTANCE}

The document mentioned above has been reviewed and accepted by the student's advisor, on behalf of the advisory committee, and by the Director of Graduate Studies (DGS), on behalf of the program; we verify that this is the final, approved version of the student's thesis including all changes required by the advisory committee. The undersigned agree to abide by the statements above.

Adrienne Whitt-Woosley, Student

Dr. David Royse, Major Professor

Dr. Chris Flaherty, Director of Graduate Studies 


\section{IDENTIFYING THE TRAUMA RECOVERY NEEDS OF MALTREATED CHILDREN: AN EXAMINATION OF CHILD WELFARE WORKERS' EFFECTIVENESS IN SCREENING FOR TRAUMATIC STRESS}

\section{DISSERTATION}

A dissertation submitted in partial fulfillment of the requirements for the degree of Doctor of Philosophy in the College of Social Work at the University of Kentucky

By

Adrienne Whitt-Woosley, MSW, LCSW

Lexington, Kentucky

Co-Directors: Dr. David D. Royse, Professor of Social Work and Dr. Mary V. Sprang, Professor of Medicine

Lexington, Kentucky

Copyright (C) Adrienne Whitt-Woosley 2016 


\section{ABSTRACT OF DISSERTATION}

\section{IDENTIFYING THE TRAUMA RECOVERY NEEDS OF MALTREATED CHILDREN: AN EXAMINATION OF CHILD WELFARE WORKERS' EFFECTIVENESS IN SCREENING FOR TRAUMATIC STRESS}

Children in the child welfare system comprise a group largely defined by their exposure to trauma via experiences of maltreatment, under circumstances presenting multiple risk factors for traumatic stress. High rates of posttraumatic stress have been observed in this population. However, there is currently no standard for the universal screening of children in child welfare for trauma exposure and traumatic stress. The purpose of this study was to analyze the trauma experiences of a sample of maltreated children and examine whether child welfare workers are effective screeners of traumatic stress symptoms with children from their caseloads. Method: A sample of children $(\mathrm{N}=131)$ with trauma screenings completed by their child welfare workers and clinical measures of traumatic stress symptoms based on self or caregiver report was analyzed. Descriptive and correlational analyses were conducted. Hypotheses were tested with a series of four hierarchical regression models to determine whether workers' screening information regarding child age, trauma exposure history and symptoms of traumatic stress were predictive of outcomes on the clinical measures completed. Results: Findings from the analyses revealed complex trauma exposure histories and high rates of traumatic stress symptoms among this generally younger sample of maltreated children. Additionally, the models tested supported workers' efficacy in screening for symptoms of total posttraumatic stress and specific trauma symptoms of intrusion and avoidance. Workers were less effective in screening for the traumatic stress symptoms associated with arousal. Implications: These findings support the importance of identifying the trauma recovery needs of maltreated children and the utility of child protection workers in assisting with the trauma screening process. Implications are provided for associated practices, policies and training efforts regarding the implementation of a trauma screening protocol in child welfare. This would serve as a critical pathway for creating trauma-informed systems that better address the needs of maltreated children and their families. 
KEYWORDS: Trauma, Posttraumatic Stress, Children, Screening, Maltreatment, Child Welfare

Adrienne Whitt-Woosley

April 25, 2016 


\section{IDENTIFYING THE TRAUMA RECOVERY NEEDS OF MALTREATED CHILDREN: AN EXAMINATION OF CHILD WELFARE WORKERS' EFFECTIVENESS IN SCREENING FOR TRAUMATIC STRESS}

\section{By}

Adrienne Whitt-Woosley

Dr. David D. Royse

Co-Director of Dissertation

Dr. Mary V. Sprang

Co-Director of Dissertation

Dr. Christopher Flaherty

Director of Graduate Studies

April 25, 2016

Date 
This dissertation is dedicated to my family and all of the children from the child welfare system that I have known professionally. 


\section{ACKNOWLEDGEMENTS}

There are many people to thank and acknowledge for their support. First, my cochairs, Dr. David Royse and Dr. Ginny Sprang, have both been invaluable teachers and mentors. Dr. Royse's balance of support and at times heroic efforts to keep me moving through the program were exactly what I needed. Thanks for not giving up on me! As for Dr. Sprang, words are simply not enough to express my gratitude for all of her generosity in terms of sharing her time, knowledge, support and the numerous opportunities extended to me over the years. Thanks for taking a chance on me all of those years ago, and thanks for sharing the data for this dissertation.

I am also extremely grateful for the support of the rest of my dissertation committee: Dr. Hoffman and Dr. Sar, who both provided me with crucial feedback, insights and took the time from their busy schedules to assist me with this endeavor.

In addition, I want to express my appreciation for my colleagues at the Center on Trauma and Children and professors and fellow students at the College of Social Work. Special thanks to Jessica, Stefana and Miriam for their support. I am grateful to so many of my fellow students from various cohorts for their encouragement and for keeping me laughing through all of this. I also appreciate my colleagues at the Center on Trauma and Children and at DCBS for their support and assistance with the data collection process. Lastly, I want to express my appreciation to all of the children and families who completed the measures for the study, and shared with us their life experiences.

Most importantly, I am eternally grateful for the support of my family. Greg and my girls have made enormous sacrifices for many years to help me through this process. I am thankful for Emmy and Lily, who were my biggest cheerleaders, and who occasionally 
highlighted the statistically significant relationships on my correlation table printouts. You are the best! Greg has been our rock and I could not have done this without him. I am also grateful to my parents who always believed in me and to so many others: Pruette, Polly, Brenda, Cokie, and my sisterhood and family of friends who have truly been there for me. I promise to talk about something else from now on! Thanks for keeping me going. Mwah! 


\section{TABLE OF CONTENTS}

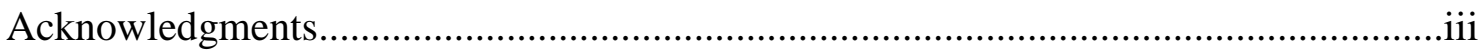

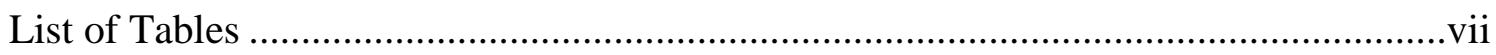

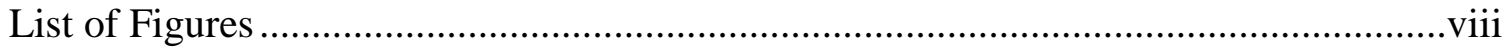

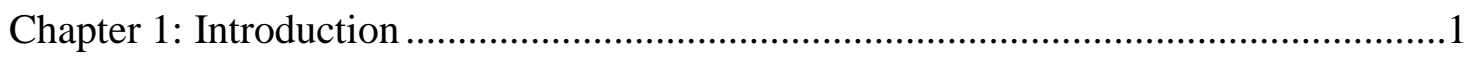

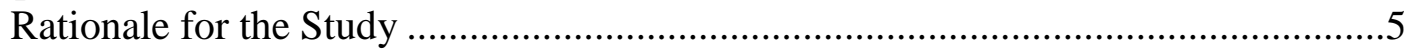

Theoretical Context for the Study ...................................................................6

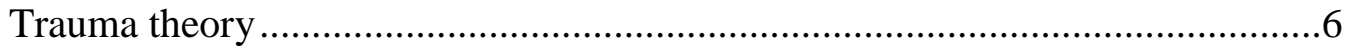

Developmental perspectives on trauma ………………….............................10

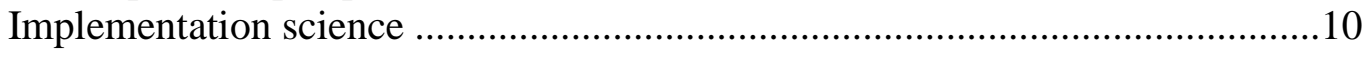

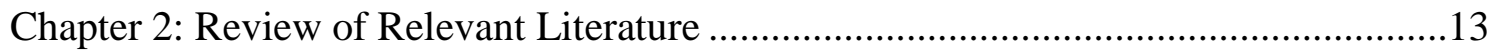

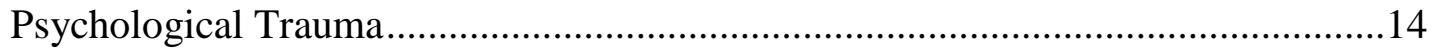

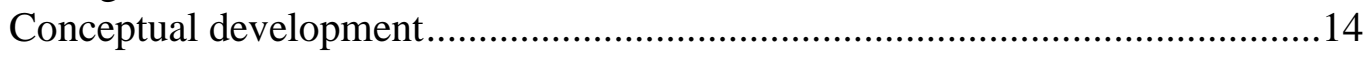

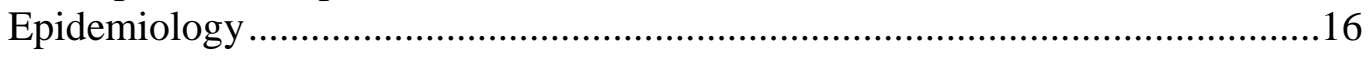

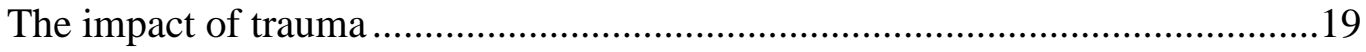

Risk factors for traumatic stress.................................................................21

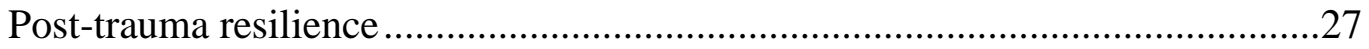

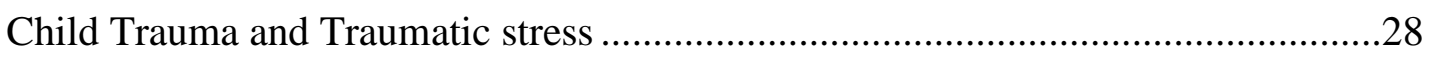

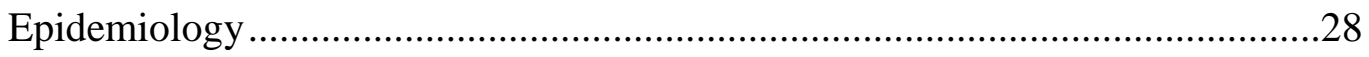

Impact of trauma on children and adolescents....................................................30

Maltreatment-Related Trauma and the Child Welfare System....................................34

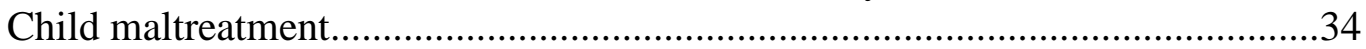

The child welfare system's role in identifying children's mental health needs...35

Screening for trauma and traumatic stress in child welfare..................................37

Creating trauma-informed child welfare systems .................................................41

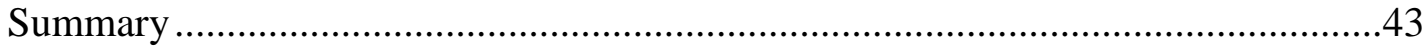

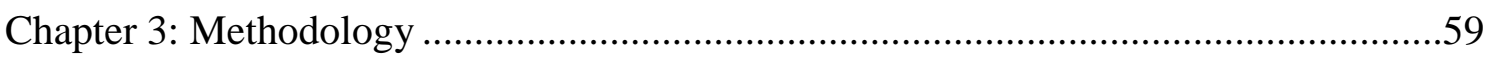

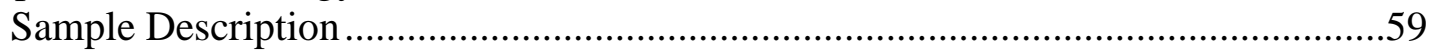

Conceptual and Operational Definitions..................................................................61

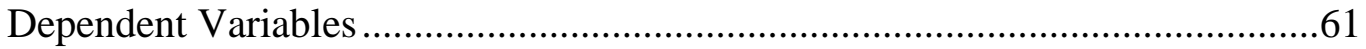

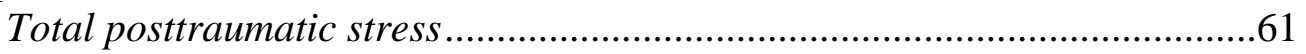

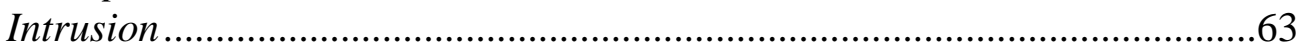

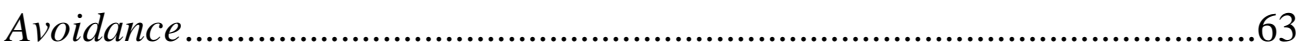

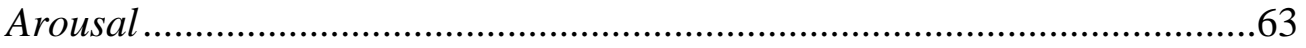

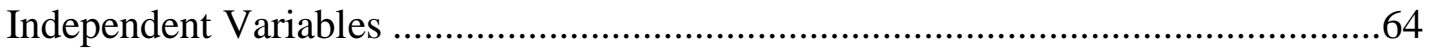

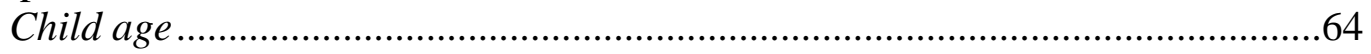

Trauma exposure history ...............................................................................64

Child welfare worker observations/information-total posttraumatic stress........65

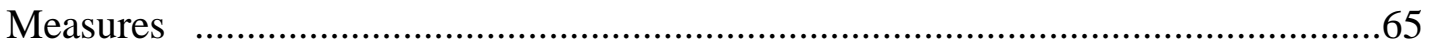

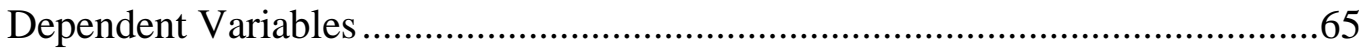


Trauma Symptom Checklist for Children-Alternate Form.........................65

Trauma Symptom Checklist for Young Children .......................................67

Independent Variables ..................................................................................69

Child Welfare Trauma Referral Tool.....................................................69

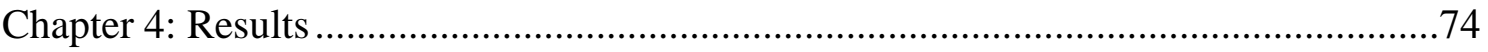

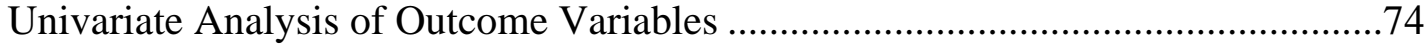

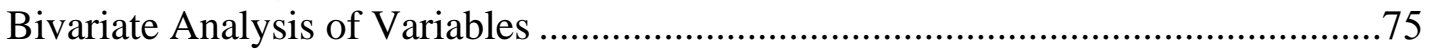

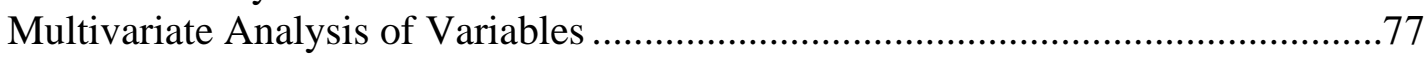

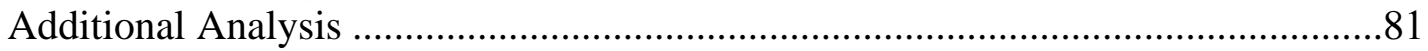

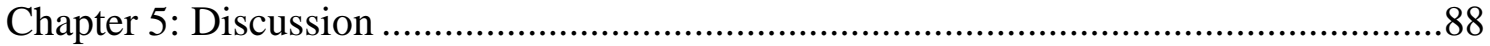

Experiences of Traumatic Stress in Children from the Sample ...............................88

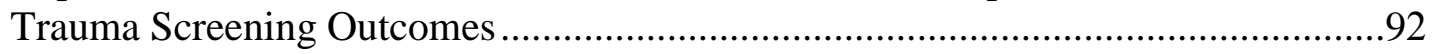

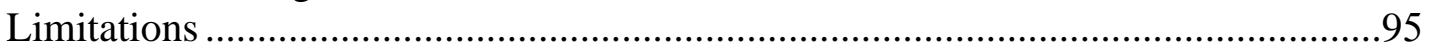

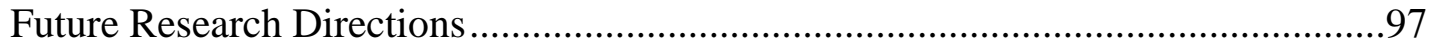

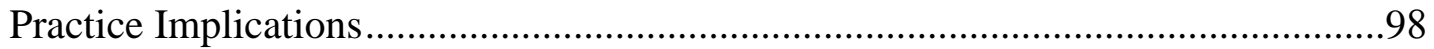

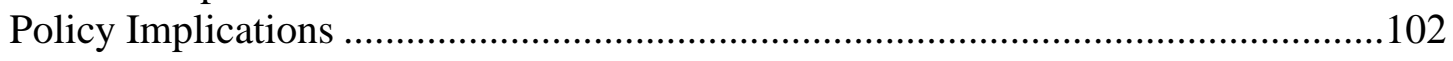

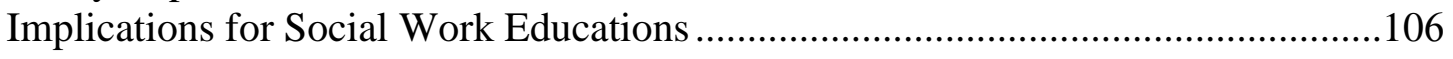

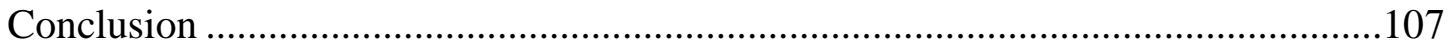

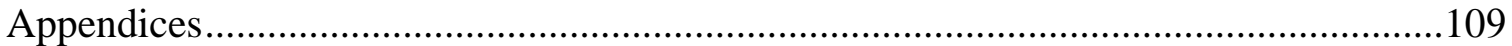

Appendix A: Child Welfare Trauma Referral Tool ...............................................109

Appendix B: TSCC-A and TSCYC Permission Letter.......................................113

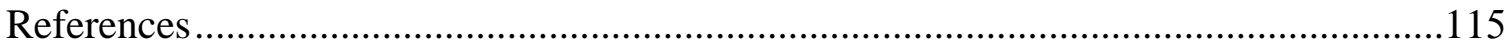

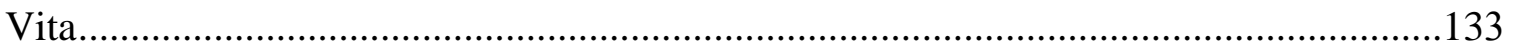




\section{LIST OF TABLES}

Table 2.1, Measurement of Traumatic Stress in Child Welfare Samples .......................46

Table 2.2, Observations Regarding Traumatic Stress and Related Factors ....................50

Table 2.3, Descriptive Summary of Child Welfare Samples Screened for

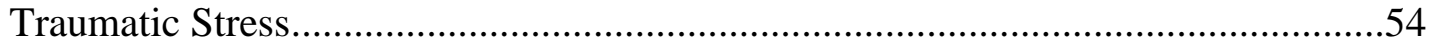

Table 3.1, CBCL Scores for Children in the Sample ....................................................73

Table 4.1, Description of TPS and Related Symptoms by Child, Caregiver and

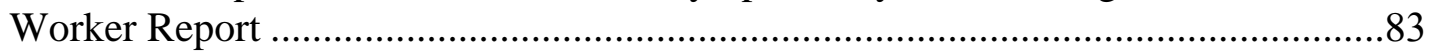

Table 4.2, Bivariate Correlations Between the Independent and Outcome Variables

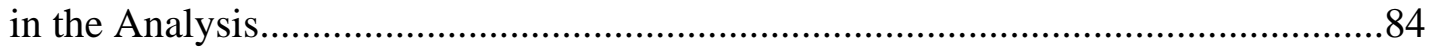

Table 4.3, Hierarchical Regression of Total PTS from Child Welfare Workers' Trauma Screening Information

Table 4.4, Hierarchical Regression of PTS-Intrusion from Child Welfare Workers'

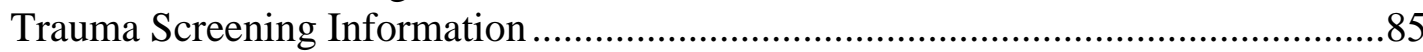

Table 4.5, Hierarchical Regression of PTS-Avoidance from Child Welfare Workers'

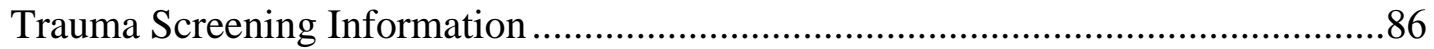

Table 4.6, Hierarchical Regression of PTS-Arousal from Child Welfare Workers' Trauma Screening Information

Table 4.7, Comparison of Children with Elevated Arousal Scores on the TSCYC to the Rest of the Sample 


\section{LIST OF FIGURES}

Figure 2.1, Conceptual Model ............................................................................45 


\section{Chapter 1}

Anything that is human is mentionable, and anything that is mentionable

can be more manageable.

Fred Rogers

\section{Introduction}

Children in the child welfare system comprise a group characterized by its exposure to trauma via experiences of maltreatment, under circumstances presenting multiple risk factors for traumatic stress and other associated mental health concerns. In 2012, approximately 679,000 children in the United States were found to be victims of maltreatment, with a child maltreatment victim rate of 9.2 per 1,000 children in the general population, and approximately 638,000 children entered foster care that year (U.S. Department of Health and Human Services, 2014). Studies reveal rates of maltreatment-related trauma in children in foster care as ranging from 80 to 93 percent (Lipschitz, Winegar, Hartnick, Foote, \& Southwick, 1999; Stein et al., 2001; U.S. Department of Health and Human Services, 2013). The vast numbers of children maltreated and subsequently involved in the child welfare and foster care systems present a significant public health problem in this country, especially given the associated negative effects of these experiences (Jamora et al., 2009).

The impact of child maltreatment is evident in the growing body of related research including the Adverse Childhood Experiences study and others that demonstrate the deleterious, long-term consequences of early trauma such as mental health disorders, substance abuse and serious physical health problems such as heart disease, obesity and even shortened life expectancy (Anda et al., 2006; Felitti et al., 1998). One study indicates that childhood maltreatment presents a ten-fold increase in the lifetime risk for 
Posttraumatic Stress Disorder and other anxiety, mood and substance abuse disorders (Scott, Smith, \& Ellis, 2010). The short-term impact of child maltreatment can also be severe. Studies demonstrate significantly higher rates of Posttraumatic Stress Disorder and various other mental health diagnoses in samples of maltreated children versus the general population (Jamora et al., 2009; Keller, Salazar, \& Courtney, 2010; Pecora, White, Jackson, \& Wiggins, 2009; White et al., 2007). Exposure to child abuse and neglect, particularly the early polyvictimization experiences known as complex trauma exposure frequently seen in treatment foster care, residential and juvenile justice populations, leads to disruptions in numerous domains of functioning including important core self-regulatory and attachment capacities (Ford, Chapman, Connor, \& Cruise, 2012). Maltreated children often exhibit notable emotional, behavioral, social and academic challenges as a result. Fusco and Cahalane (2013) cite the following as primary domains of potential impairment associated with complex trauma: affect regulation problems, information processing problems, struggles with self-concept, behavioral control challenges, difficulty with interpersonal relationships, and problems with biological processes (p. 38).

Because of the potential for adverse reactions and the long-term consequences of maltreatment-related trauma, screening and assessment are critical elements in the determination of whether a child is experiencing traumatic stress and requires intervention. Fortunately, there are many evidence-based trauma interventions that can interrupt the cascade of potential problems cited in the literature. Yet in spite of these facts, there is currently no standard for the universal screening for traumatic stress and related mental health problems in most child welfare systems, though some states are 
making some progress toward this goal (Griffin et al., 2012). This standard has also not yet been fully implemented in spite of the growing trend toward providing traumainformed care in child welfare and other child-serving systems. Trauma-informed practice promotes the development of routine screenings for trauma, referrals for comprehensive trauma assessments when indicated by screenings, utilization of evidence based practices for the treatment of identified traumatic stress, increased access to trauma-related information and increased continuity of care (Ko et al., 2008). The use of trauma screening and assessment tools has been recommended as an important pathway for the development of trauma conceptualizations and incorporation of this information into child welfare decision making and treatment planning (Henry et al., 2011). All of these initiatives and recommendations are designed to improve outcomes for trauma exposed youth.

Child welfare workers represent an important resource for addressing problems associated with the under-identification of maltreated children's trauma recovery needs. Not only are child welfare workers mandated by policy to assess the mental health and other basic needs of children as part of the case planning and family intervention process, but they also have access to a unique database that should prove useful in screening for traumatic stress and related concerns. McCrae \& Barth (2008) argue that the information typically collected during a maltreatment investigation including the age, frequency and intensity of exposures to maltreatment; parental history of mental illness and substance misuse; and other environmental risks are critical elements of assessing mental health and trauma recovery needs in children. Given child welfare workers' access to this information and the epidemiology of mental health and trauma related problems in 
maltreated children, these authors and others including the American Academy of Child and Adolescent Psychiatry and the Child Welfare League of America have called for universal screening of children's mental health as standard elements of the case planning process (Romanelli et al., 2009). Other organizations including the National Child Traumatic Stress Network have gone a step further to recommend universal screening specifically for traumatic stress in the child welfare system (Chadwick Trauma Informed Systems Project, 2013; Conradi, Wherry, \& Kisiel, 2011). The failure to implement these recommendations is generally attributed to workers being overburdened, having little time to assess needs and make referrals, having limited awareness of their role in the process of identifying children's mental health and emotional recovery needs as part of promoting child safety and well-being, poor coordination with the mental health sector and correspondingly limited training and awareness of how to assess or identify traumarelated needs (Burns et al., 2004; Hurlburt et al., 2004).

The current movement toward creating trauma-informed systems of care for at-risk children is motivated by recognition that early identification of trauma recovery needs and timely intervention can substantially reduce risks for mental health and other related problems (Conners-Burrow et al., 2013; Ko et al., 2008). It has been recommended that child welfare workers receive specific training on the effects of trauma and how to screen children for related problems in order to prevent misinterpretations of children's symptoms, particularly disruptive behaviors, and to appropriately identify their service needs, promote a sense of safety and help them and their caregivers manage symptoms of distress (Conners-Burrow et al., 2013; Kramer, Sigel, Conners-Burrow, Savary, \& 
Tempel, 2013). Implementation of these practices would help create an appropriate environment for trauma recovery and improve outcomes for maltreated children.

\section{Rationale for the Study}

This study was designed to address the research questions of whether child welfare workers are able to effectively screen children from their caseloads for traumatic stress, and whether there are notable differences in their abilities to screen for specific manifestations of trauma symptoms such as intrusion, avoidance and arousal. The purpose of this study was to contribute to the literature regarding the utilization of child welfare workers in the role of screening for traumatic stress in maltreated children, and to make implications regarding increasing their effectiveness in this role. There are no prior studies that examine child welfare workers' trauma screening abilities and compare their identification of child traumatic stress symptoms to those of caregivers or the children's self-reports. Additionally, this study aimed to describe the trauma experiences of the sample in order to further examine the nature of traumatic stress observed in children from the child welfare population. There are existing studies that report on rates of trauma exposure and whether children are exhibiting traumatic stress, but little specificity has been provided in these reports. The specific symptoms observed by the child welfare workers were compared to the clinical measures administered with children and caregivers as informants to further analyze what aspects of trauma screening may be more or less challenging. Implications for training and the implementation of trauma screening protocols in child welfare are provided based on the results of this analysis. 


\section{Theoretical Context for the Study}

There are a few prominent theories that are applicable to this investigation. Trauma theory is perhaps the most critical to forming the basis for understanding how and why children are affected by maltreatment-related trauma. A discussion of trauma theory and relevant neuroscience is provided to inform the conceptual basis of this research and to illustrate the individual nature of trauma responses underscoring the need for screening and assessment in populations with high rates of exposure. Additionally, a developmental trauma perspective is discussed given that this research focuses on the effects of trauma in children and adolescents. Finally, a discussion of implementation science is provided as a framework for considerations of how to effectively integrate best practice recommendations regarding trauma-informed care including trauma screening protocols into the child welfare system.

\section{Trauma Theory}

While trauma is by definition an overwhelming stressor, responses to maltreatment and other trauma exposures vary and are individual in nature. Some trauma-exposed individuals develop trauma symptoms while many others do not, and the exact reasons for this are not always apparent. It is clear that trauma exposure nearly always leads to some acute stress reaction or "normal response to an abnormal event," but the development of ongoing traumatic stress is not a foregone conclusion (van der Kolk, Macfarlane, \& Weisaeth, 2012, p. 78). Traumatization occurs "when both internal and external resources are inadequate to cope with external threat" (Van der Kolk, 1989, p. 393). Trauma theory explains that an individual's response to a traumatic event is shaped by characteristics of the individual, event specific factors, meaning of the event and 
challenges to the individual's assumptive world, developmental processes, and sociocultural factors (Substance Abuse and Mental Health Services Administration, 2014). It is the complex interaction of these individual, event and contextual variables that ultimately shape the trauma response (Briere \& Scott, 2006). Even within a single category of trauma exposure such as child maltreatment there are various sub-types and different experiences of the same event that influence one's response. Understanding the concept of the dose-response relationship further illustrates this phenomenon (Norris, 2002). As an individual's dose of exposure increases via proximity, duration, impact and other event-specific variables, the likelihood of a distress response increases accordingly.

Broader consideration of trauma theory sheds light on the effects that significant and random life events can have on one's life course and behavioral adaptations, and the potential for the development of psychopathology. Epidemiological studies on trauma exposure indicate that these experiences are more frequent than rare over the course of the lifespan, with prevalence rates between 60-70 percent and even higher for certain types of trauma among subgroups of the population (Norris, 1992; Resnick et al., 1993). Therefore, consideration of the influence of traumatic experiences on the development of personality, psychopathology and capacities for change is necessary given that trauma exposure is a relatively expected part of the human condition. Trauma theory asserts that these events which by definition involve exposure to actual or threatened death, serious injury or sexual violence can overwhelm human capacities to cope, resulting in significant responses in the acute phase and potentially more long-term alterations especially when events are severe, chronic in nature or occur during the formative years of childhood (American Psychiatric Association, 2013; Chu, 2011). 
Essentially, when trauma occurs, these events are sufficiently atypical and dramatic in nature to overwhelm ordinary adaptive responses to stressors. In part, this is due to the physiological as well as psychological responses elicited by traumatic events. Traumatic stressors produce excessive external stimuli and corresponding over-excitation in the brain meant to alert individuals to external threats and activate the necessary response systems for survival (Teicher et al., 2003). The brain is not able to fully process the event under these conditions including excessive secretions of stress hormones such as adrenaline and cortisol, and may respond through various mechanisms of psychological numbing, shutting down of normal emotional responses or dissociation (Herman, 1992). These responses may be highly adaptive during the acute phases of trauma exposure, but often trauma-exposed individuals continue to utilize them after the threat has ended, which can be counterproductive. Chu (2011) asserts that there are both primary and secondary psychological responses to traumatic events meaning that the primary issues are direct effects of the trauma, as previously mentioned, and the secondary issues are the strategies developed by traumatized individuals to manage their lingering distress. Both sets of responses can be equally significant and impact the development of personality and human behavior in negative ways.

In spite of innate human capacities for resilience in the aftermath of trauma, traumatic stress and depressive symptomatology are common among survivors of repeated, severe or early trauma, as are certain characterological issues including those associated with Borderline Personality Disorder. Trauma theorists assert that these conditions have a known etiology (the traumatic event or events) and the symptoms are the individual's adaptations to the trauma, with varying degrees of functionality. For example, feelings of 
shame and a tendency toward secrecy may be adaptive for an abused child in terms of survival and keeping in the good favor of a volatile parent, but these cognitions may also lead to distress and dysfunctional relational dynamics as the child develops (Chu, 2011). Additionally, dissociation during trauma exposure is when an individual disconnects from the full experiencing of an event, which promotes survival in the acute phase and tends to numb both psychological and physiological pain, but also leads to a lack of integration in conscious awareness if utilized as a means of coping long-term (ISSTD, 2015). Chu (2011) also describes how childhood trauma exposure can alter the development of personality through the failure of parental attachment and nurturance. $\mathrm{He}$ asserts that abusive conditions during the formative years of identity and relational expectations can lead to the instability of mood, overvaluing/devaluing of relationships, abandonment issues and poorly developed sense of self that are hallmark features of Borderline Personality Disorder.

In sum, trauma theorists assert that psychopathology and characterological problems in the trauma-exposed individual should be viewed as adaptations to trauma exposure. Accordingly, interventions to promote change should be implemented from this traumainformed, adaptation-oriented perspective. Modern treatments utilized are typically phased approaches that include ego-supportive, stabilizing interventions followed by the use of abreaction, processing of the traumatic event and integration of the experience into a coherent life narrative. Cognitive processing and desensitization of specific fear responses associated with the trauma are major intervention goals. All of these interventions are meant to be delivered in the context of a supportive and validating therapeutic relationship in order to provide a corrective experience for the trauma 
survivor in which healthier or more adaptive relational patterns can be learned (Chu, 2011).

\section{Developmental Perspectives on Trauma}

Further complicating matters is the issue of development when considering individual responses to childhood maltreatment or other types of trauma. Given that perception of threat and interpretation of meaning are important factors in shaping an individual's response to trauma, one's developmental stage, associated needs and capacities are important determining factors as well (Friedman, 2006; Weathers \& Keene, 2007). For example, very young children may not have fully developed capacities to comprehend the meaning of an event and they rely heavily on caregivers to appraise threats, whereas older children and adolescents become more sophisticated in their abilities to comprehend meanings of trauma and are increasingly independent in their appraisals (Ciccheti \& Toth, 1997). Developmental trauma theorists note that knowledge, language development, memory, emotional regulation, and social cognitions as well as family contextual factors are all important influences on the varying trauma responses observed in children and adolescents, and these capacities are all determined by developmental stage and progress (Margolin, 2005; Salmon \& Bryant, 2002). In sum, trauma and developmental theory illustrate the individuality of responses particularly in children whose resources to cope with traumatic stressors are continually evolving.

\section{Implementation Science}

Implementation science and relevant theoretical understandings of how evidencebased practices are adopted, implemented in organizations and reflected in individual behavior is an emerging field. It has been defined as the scientific analysis and 
understanding of "methods to promote the systematic uptake of research findings and other evidence-based practices into routine practice, and, hence, to improve the quality and effectiveness of health services" (Eccles \& Mittman, 2006, p. 1). Associated theories and models for research and interventions address individual, interpersonal and system characteristics as possible explanations for why evidence based practices are or are not effectively implemented. Individual factors may include cognitive, educational, and motivational factors; social context factors may include issues of social learning, organizational culture and client characteristics; and systems factors frequently identified include economics, leadership, organizational innovation and opportunities for learning (Grol \& Grimshaw, 2003; Grol \& Wensing, 2004).

Dissemination and implementation research and related theoretical models are particularly relevant to the mental health, healthcare and social services sectors. Through research, the knowledge base available to inform practice in these areas is rapidly expanding, and practitioners have an ethical obligation to integrate the best available knowledge into their clinical practice (American Psychological Association, 2005). However, there are numerous barriers to achieving evidence-based practice in these systems. Dissemination and implementation research supports that increasing practitioner knowledge of evidence based practices via quality training programs is an essential element to changing practitioner behavior and improving client care, yet there are other critical factors that affect the uptake of this information (Cabana et al., 1999; Proctor et al., 2009; Grol \& Grimshaw, 2003). The systems-contextual perspective is a primary approach to understanding the role of training in the implementation process given that these activities take place within the systemic environment (Beidas \& Kendall, 2010). 
This model indicates that training effects interact with practitioner behavior, practitioner characteristics, organizational support, client factors and the quality of the training program to produce the outcomes observed.

Copyright @ Adrienne Whitt-Woosley 2016 


\section{Chapter 2}

\section{Review of Relevant Literature}

This section includes a summary of the literature relevant to the screening and assessment of traumatic stress in children in the child welfare population, as well as literature regarding the emergence of trauma-informed care in this system. The beginning of this section regarding psychological trauma contains a review of the historical development of this concept, epidemiological findings, and the literature regarding various factors associated with traumatic stress as well as resiliency. This section largely relies on adult-focused models and research given that this was the early emphasis of traumatic stress studies, and child models and investigations emerged from this context. Next, information regarding the differential impact of trauma on children is reviewed, followed by a discussion of the proximal and distal effects of maltreatment-related trauma exposures in childhood.

The subsequent sections of the literature review focus on the child welfare system. A description is provided of the system itself, its goals of promoting safety as well as child well-being, and the findings of studies regarding the mental health needs of children in this population. Then, a synopsis of the literature regarding the trauma experiences and reactions of children in child welfare and the need for trauma-informed care is provided.

The final section of this literature review synthesizes findings from the existing conceptual and empirical literature regarding the assessment and screening for traumatic stress in the child welfare population, and related training and implementation issues for child welfare workers. This includes discussion of a comprehensive training model with empirical support for training child welfare workers on trauma-informed care. 


\section{Psychological Trauma}

\section{Conceptual Development}

Depending upon the context, the term trauma can take on various meanings. Often, what its being referenced is medical trauma or physical injury, which is not unrelated to the concept of psychological trauma. The term psychological trauma, frequently also referred to simply as trauma, references the impact of experiencing a traumatic rather than merely stressful or unwanted life event (Kammerer \& Mazelis, 2006). While trauma responses are stress reactions, traumatic events are by nature overwhelming stressors outside the range of daily experience. However, defining what constitutes a potentially traumatic event is complicated and often shaped by cultural and individual expectations and beliefs, which results in clinicians facing the arduous task of assessing both stress reactions as well as the nature of various stressors when determining the presence of traumatic stress (Briere, 2004; Jones \& Wessely, 2006).

The current Diagnostic and Statistical Manual of Mental Disorders-V(DSM-V) defines a potentially traumatic exposure as "exposure to actual or threatened death, serious injury, or sexual violence" that can be experienced either directly, by witnessing in person, learning of these events occurring to a loved one or via exposure to "aversive details of the traumatic event" (p. 271, American Psychiatric Association, 2013). Such events are determined to be traumatizing when the exposed individual experiences stress response symptoms of intrusion, avoidance, alterations in cognition and mood, or arousal, and functioning is notably impaired. This is how the condition of Posttraumatic Stress Disorder is described in the DSM-V, which demonstrates the uniqueness of this condition 
because of the great importance placed on the etiologic agent- the traumatic stressor (Friedman, 2014). However, it is important to note that individual differences and interpretations influence the nature of experience. It is widely held that the emotional responses and subjective perceptions of the individual exposed to the event are what determine whether it is traumatic in nature (Friedman, 2006; Weathers \& Keene, 2007).

These current definitions of trauma exposure and posttraumatic stress are relatively new in spite of a long and changing history of recognizing the effects of trauma in mental health and the social sciences. As early as the 1800 's, psychoanalysts recognized the impact of childhood trauma. Freud and Breuer theorized that hysterical reactions were related to early traumatic experiences, and they developed methods of intervention including the retelling of traumatic events and promoting emotional release in a manner quite similar to methods still used in modern trauma therapies (Monson, Friedman, \& La Bash, 2007). War related distress observed among combat veterans furthered discussion of trauma related issues into the $19^{\text {th }}$ and $20^{\text {th }}$ centuries, and resulted in awareness of conditions such as shell shock, combat fatigue and the physiological as well as psychological effects of trauma as exemplified in individuals with an exaggerated startle response as part of their trauma reaction (Jones \& Wessely, 2006; Hyams, Wignall, \& Roswell, 1996; Monson, Friedman, \& La Bash, 2007). However, conceptualizations of psychological trauma and associated reactions did not begin to more fully resemble current models until the era of the Vietnam War when many soldiers were returning with traumatic stress related to combat. The DSM-III published in 1980 recognized the growing awareness of this phenomenon in clinical arenas by including the diagnosis of Posttraumatic Stress Disorder for the first time. 


\section{Epidemiology}

The emergence of Posttraumatic Stress Disorder (PTSD) as a diagnosis was an important point in the history of traumatic stress research and intervention because it created a construct for further investigation and development of the concept of psychological trauma. Trauma research has progressed rapidly since this time yet the ever changing definitions and measurement approaches present challenges to interpretation and underscore the need to evaluate findings in context of the operational definitions and measurement techniques applied (Norris \& Slone, 2007). While most epidemiological studies have focused on the incidence of PTSD as the primary means of measuring traumatic stress, there are many other manifestations of trauma responses documented in the literature including changes in worldview and even resiliency and posttraumatic growth, which will be discussed in more detail in subsequent sections of this review. Older definitions prior to the DSM-IV tend to underestimate the risk of trauma exposure and associated stress responses (Norris \& Slone, 2013). Overall, in spite of this variability, the existing literature depicts considerable information regarding the incidence and effects of trauma exposure.

There have been several general, adult population studies regarding trauma exposure and traumatic stress in Western or developed societies, as well as others in non-developed countries. In Breslau's (2009) review of epidemiologic studies of trauma and PTSD, she reports that most United States residents have experienced one or more traumatic events as indicated by a prevalence rate of approximately 80 percent, and similar rates have been found in Canada though lower rates of exposure are documented in developed European countries. Earlier studies using more narrow definitions of trauma exposure tended to 
establish lower prevalence rates ranging from 36 to 73 percent (Breslau, Davis, Andreski, \& Peterson, 1991; Norris, 1992; Kessler, Sonnega, Bromet, Hughes, \& Nelson, 1995). In studies of non-Western or developing countries, various rates of trauma exposure are observed. In a study conducted in Mexico, similar rates to those found in North America were observed, whereas epidemiological studies of war afflicted countries and those with rampant political violence such as Cambodia, Croatia and Bosnia found rates of trauma exposure at or near 100 percent (Mollica, Poole, \& Tor, 1998; Goldstein, Wampler, \& Wise, 1995). In sum, exposures to potentially traumatic events appear to be common. Based on their analysis of the literature, Norris and Slone (2007) concluded that by onset of adulthood, 25 percent of the population will have been exposed to at least one potentially traumatic event, and by age 45 , nearly all adults will have been exposed.

Exposure to potentially traumatic events can occur in a variety of circumstances and may occur repeatedly across the lifespan. A considerable segment of the traumatic stress literature notes that many individuals experience multiple trauma exposures either via repeated exposure to the same events or to different types of traumatic stressors. The potentially traumatic stressors that are most frequently cited include physical abuse/assault, sexual abuse/assault, combat, natural or other disasters, exposure to violence domestically or in the community, and life threatening accidents (Breslau, 2009; Norris \& Slone, 2013). A recent study by Kilpatrick and colleagues (2013) found that estimates of trauma exposure based on the DSM-IV criteria produce similar rates to studies using the new DSM-V criteria in spite of omitting the non-violent death of a loved one as meeting Criterion A, which outlines what may constitute a traumatic stressor. Additionally, many studies have found that individuals exposed to any one of 
these traumatic events are more likely than not to have been exposed to other types of trauma as well (Creamer, Burgess, \& McFarlane, 2001; Kilpatrick et al., 2013). Kessler and colleagues (1995) found that 34 percent of men and 25 percent of women in their study had experienced two or more traumatic events. A study by Resnick and colleagues (1993) confirmed the frequency of repeat victimizations for trauma survivors. The most frequently experienced trauma types noted across studies include witnessing someone being injured or killed, disasters, physical or sexual assault and being involved in a life threatening accident (Creamer, Burgess, \& McFarlane, 2001; Kessler et al., 1995; Kilpatrick et al., 2013).

Studies regarding rates of traumatic stress reactions or PTSD present fairly consistent findings since the introduction of the DSM-III-R definition (Norris \& Slone, 2013). While epidemiological studies find that most individuals are exposed to traumatic events at some point, lifetime prevalence rates for PTSD identified in studies conducted in the U.S. range from 7 to 12 percent (Breslau et al., 1998; Breslau et al., 2004; Kessler, Sonnega, Bromet, Hughes, \& Nelson, 1995). Prevalence rates of PTSD are typically lower in other parts of the world, with rates cited as low 1 to 4.8 percent in countries such as Colombia, Israel, Italy, Spain, South Africa, China and Ukraine (Kessler \& Ustun, 2008). However, a study in Mexico by Norris and colleagues (2003) found the lifetime rate of PTSD to be approximately 11 percent, which is more similar to findings in the U.S. While the linguistic challenges of these studies were carefully managed, there may be cultural and definitional issues affecting the differential rates of PTSD observed internationally (Norris \& Slone, 2013). 
What can be inferred from all of these studies, irrespective of the variability in findings, is that PTSD or functionally impairing traumatic stress reactions are not likely in spite of exposure to trauma being a common experience. Researchers have studied the conditional risk for PTSD associated with the various types of trauma exposures and found that certain stressors carry more risk for the disorder (Breslau, 2009). For example, acts of interpersonal violence, childhood abuse and criminal victimization present higher risk for PTSD than accidents, disasters and witnessing traumatic events (Breslau, 1998; Kessler et al., 1995, Resnick et al., 1993). However, it has been asserted that the determination of trauma responses and potential for PTSD or any other form of posttraumatic stress is the result of a complex interaction of event-specific as well as numerous individual and contextual factors. Factors associated with shaping individual trauma responses are discussed further in subsequent sections of this review.

\section{The Impact of Trauma}

Trauma, as understood as a stressor that is overwhelming by nature, always results in an acute stress response of varying intensity, but does not always result in the development of psychopathology. In fact, as the epidemiological literature demonstrates, clinically significant posttraumatic stress occurs in only a small percentage of trauma survivors overall. Most of the literature regarding post-trauma psychopathology focuses on PTSD or symptoms of traumatic stress including the intrusive, avoidant, cognitive, mood, arousal and numbing or dissociative symptoms that comprise this diagnosis. Reexperiencing the trauma via intrusive thoughts or memories and associated distress responses are hallmark features of the disorder (Cahill \& Foa, 2007). Avoidant, numbing and dissociative responses are frequently employed as means of managing the 
overwhelming nature of these experiences and intense emotions. However, no one diagnosis can adequately describe the full effects of a traumatic experience. While the symptoms of PTSD are unique in that they have more obviously direct connections to the individual's history of trauma exposure, other commonly experienced forms of psychopathology for trauma-exposed individuals include depression, grief, symptoms of psychosis, panic and anxiety (Briere \& Scott, 2006; Falsetti \& Resnick, 1997; Freedman et al., 2002; Kessler et al., 1995; Shear \& Smith-Caroff, 2002). Also, substance misuse disorders are associated outcomes of trauma exposure as many individuals rely on substances to numb or mask overwhelming symptoms of arousal and re-experiencing (Reynolds et al., 2005; Stewart et al., 1998).

It is important to consider other impacts on trauma survivors not captured by the diagnostic categorization of mental health conditions. A primary example is the existential impact of trauma and the challenges to one's basic assumptions about themselves, others, safety and the world in general that often occur. Studies have shown that even years later, survivors may still be struggling to incorporate traumatic experiences into their basic schemas, particularly those regarding issues of self-worth, the benevolence of the world and chance (Dekel, Solomon, Elklit, \& Ginzburg, 2004; JanoffBulman, 1989). Crossley (2000) also noted that trauma survivors frequently experience a state of existential crisis that results from the event's disruptions of the connections between their plans, fears, expectations and memories, which then challenge their ability to sustain a coherent concept of their lives. All of this occurs within the context of an intense physiological response to the traumatic event or events that involves the oversecretion of stress hormones that affect important brain functions related to emotional 
regulation, as well as the encoding of memories (van der Kolk, 1996). These physiological responses include activation of numerous areas of the brain, hormone and neurotransmitter systems, and while designed to help individuals respond to physical threats, can lead to significant challenges with integrating, processing and regulating emotional responses to trauma (Southwick et al., 2007). As a result, trauma-exposed individuals often experience poorly regulated stress responses in general. This is particularly true if the exposure to the traumatic stressor is repeated, prolonged, particularly severe or occurs in childhood when the brain is still developing (Southwick et al., 2007; Teicher et al., 2003).

\section{Risk Factors for Traumatic Stress}

There are a number of individual, event and contextual factors that interact to shape one's response to trauma exposure. The response is one that develops uniquely, i.e. two people may share the same experience and have two vastly different responses, and an individual's response to the traumatic event is one that likely changes considerably over time (Briere \& Scott, 2006). As McFarlane \& Yehuda (1996) explain in their conceptual framework for the development of PTSD, an initial distress response to a traumatic event is normal, expected and typically resolves; yet for some, chronic symptoms emerge and develop out of the pattern of acute stress initiated by the event. The longitudinal stress response is shaped by the presence of numerous risk and protective factors. Because of this unfolding over time, many models of traumatic stress categorize the associated risk and protective factors as individual/pre-existing factors, event factors including peritraumatic responses, and post-trauma factors (Keane, Marshall, \& Taft, 2006). The complexity of interactions of these variables renders it difficult if not impossible to fully 
determine the unique contributions of each to the post-trauma response as they all have potential to moderate or mediate the effects of the other (Briere, 2004; Vogt, King, \& King, 2007). However, recognition of the influential nature of these factors aids in the assessment of trauma reactions, which should ultimately form the basis for indicated interventions.

There is considerable literature regarding individual or pre-existing factors that influence one's trauma response and increase the risk for traumatic stress. The metaanalysis from Brewin, Andrews \& Valentine (2000) identified consistent support across studies for the pre-existing risk factors of prior psychiatric history, childhood abuse and familial psychiatric history for the development of posttraumatic stress. Each of these factors are discussed as contributing to risk because of the potential for compromised coping in individuals due to increased stress from other sources, poor modeling of coping behaviors early in life or vulnerability related to prior traumatic experiences (Briere, 2004; Halligan \& Yehuda, 2000). Prior trauma history has been found to be an especially strong determinant of traumatic stress, particularly if the previous exposures occurred at an early age and involved assaultive violence (Breslau, 2009; Davidson et al., 1991; McCauley et al., 1997; Ozer et al., 2003).

Cognitive factors represent yet another category of pre-existing risks for traumatic stress. Studies have shown that lower intellectual functioning is a significant risk factor (Macklin et al., 1998), as well as HPA axis abnormalities resulting in lower cortisol levels (Resnick et al., 1995; Yehuda et al., 1998). Additionally, tendencies toward maladaptive cognitions such as catastrophic thinking have been found to be important risk factors (Bryant \& Guthrie, 2005). 
Several demographic variables are associated with an increased risk for posttraumatic stress. Gender, or rather female status in particular, has consistently been found to present increased risk for traumatic stress, nearly double the risk for men (Brewin, Andrews, \& Valentine, 2000; Kessler et al., 1995; Breslau et al., 1999). Breslau and colleagues (1999) found that this female vulnerability was both consistent with findings of increased risks for other psychiatric disorders, as well as a certain susceptibility to severely assaultive violence and earlier trauma exposures. These factors of early trauma exposure and interpersonal violence present higher risks for distress irrespective of gender status. Women also typically have higher trauma exposure rates. When trauma exposure rates are equal, risk for PTSD has been found to be equivalent between men and women (Yehuda, 2004).

Race or ethnicity also presents a similarly complicated presentation of risk. While minority status is generally found to be a weak yet significant risk factor for posttraumatic stress across studies (Breslau et al., 1998; Brewin, Andrews, \& Valentine, 2000; Kessler et al., 1995), many investigators have found that ethnic differences interact with other factors that may account for its effects (Norris, 1992). For example, Brewin and colleagues (2000) found larger effect sizes for socioeconomic status and education which are factors typically associated with ethnicity in western countries, and studies regarding the experiences of those in combat or living in high crime environments have found that once trauma exposure was controlled for, minority status was no longer a significant risk factor (MacDonald, Chamberlain, \& Long, 1997; Breslau et al., 1998).

A few additional demographic factors are noted in the literature. Marital status has been found to be a significant factor in some studies. Being currently married is cited as 
serving a protective function with being previously married or single posing risks for posttraumatic stress, along with having a lower level of education and socioeconomic status (Halligan \& Yehuda, 2000; Kessler et al., 1995). In general, studies indicate that the less support and more prior life adversity experienced by individuals via issues of poverty, limited resources, marginalization or higher levels of trauma exposure, the more susceptible they are to posttraumatic stress (Lloyd \& Turner, 2003; Ozer et al., 2003). This same pattern generally holds true for the issue of age, with older individuals presenting higher risks for traumatic stress related to increased likelihood of cumulative exposures (Kessler et al., 1995), yet the very young also seem to be vulnerable to posttraumatic stress as well (Keane, Marshall, \& Taft, 2006). Individuals in the midrange of life tend to be the least susceptible to traumatic stress reactions perhaps due to less cumulative exposure yet more developed means of coping with traumatic stressors (Koenen et al., 2002).

The literature regarding risk factors for traumatic stress indicates that different events or types of traumatic stressors convey differing degrees of risk. The nature of the event is a central determinant of response. In general, studies indicate that acts of interpersonal violence, such as rape, convey the highest degree of risk for traumatic stress reactions as opposed to non-interpersonal traumas like natural disasters (Briere \& Elliott, 2000; Green et al., 2000; Resnick et al., 1993). Also, sexual victimization rather than non-sexual trauma tends to pose higher levels of risk (Breslau et al., 1991). In the National Comorbidity Study (Kessler et al., 1995), rape presented the highest risk for traumatic stress of all events analyzed for both men and women. In this study, the traumatic stressors found to present the highest conditional risk for PTSD all involved interpersonal 
violence, e.g. rape, childhood abuse, sexual assault and combat. The lower risk stressors included natural disasters, accidents and witnessing traumatic events.

These findings regarding event-related risks suggest not only the significance of interpersonal victimization, but also the importance of severity of impact. Trauma severity has been found to be a significant risk factor for PTSD across studies, and one that has demonstrated a positive correlation with PTSD severity (Brewin et al., 2000; Norris et al., 2002). In a similar manner, studies have shown that traumatic events resulting in physical injury also present increased risks for traumatic stress (Briere \& Elliott, 2000; Tucker et al., 2000). Thus, it seems logical that the events presenting the most conditional risk for traumatic stress are those with higher likelihoods of being both severe and resulting in physical harm. Other event-specific risk factors cited in the literature similarly present increased likelihood for a more severe or intense experience of the trauma. These include witnessing death, especially grotesque means of death, direct life threat and loss of a loved one (Briere \& Elliott, 2000; Epstein, Fullerton, \& Ursano, 1998; Ozer et al., 2003; Ullman \& Fillipas, 2001).

Also relevant to this discussion is the considerable evidence that having a prior trauma history greatly increases not only risks for traumatic stress, but also increased symptom severity (Breslau, Chilcoat, \& Davis, 1999; Green et al., 2000). It has been posited that individuals who have experienced multiple traumatic events may experience a "kindling" effect where biological memories of prior traumatic experiences result in increasing susceptibility to distress responses to subsequent exposures (McFarlane \& Yehuda, 2007). Multiple exposures to trauma, therefore, present risks for a complex trauma response that can significantly impair functioning. 
Certain aspects of peri-traumatic reactions also serve as risk factors for subsequent traumatic stress. Dissociation at the time of trauma exposure is perhaps the response that has received the most attention in the literature. In general, studies indicate that acute dissociation predicts poorer long-term psychological adjustment and the development of PTSD (Halligan et al., 2003;Ozer et al., 2003; Shalev, Peri, Canetti, \& Schreiber, 1996). It is explained that dissociation at the time of the trauma can interrupt the normal encoding and processing of memories necessary to prevent the development of psychopathology. Yet, not all studies have replicated this finding. It has been proposed that there may be some confounding of variables in these studies, and it is really whether dissociation continues beyond the peri-traumatic phase that is the true risk factor for PTSD (Briere, 2004).

Post-trauma variables have also been analyzed for their potential as risk factors for traumatic stress, though with much less frequency. Social support is noted as being of significance in predicting outcomes for trauma survivors, with those having less perceived social support being at greater risk for PTSD (Brewin et al., 2000; Ozer et al., 2003). Other secondary variables such as post-trauma stigmatization or a lack of acceptance or validation of the survivor's experiences have been found to be risk factors (Herek, Gillis, \& Cogan, 1999; Konen et al., 2003). Increased acceptance and support of individuals exposed to less socially controversial types of traumas such as natural disasters has been associated with improved post-trauma adjustment (Armenian et al., 2002). 


\section{Post-Trauma Resilience}

The opposite or absence of many of the risk factors cited can serve as protective factors against the development of traumatic stress in many instances. Yet there are additional factors associated specifically with resiliency that are gaining attention in the literature. While most clinical and research efforts are focused on traumatic stress and how to effectively intervene with traumatized individuals, there is a need to understand what leads to resilience in the aftermath of trauma and loss as this may also lead to more targeted prevention and intervention models. Resilience has been defined in many ways, but generally in the context of trauma survivors refers to the tendency to rebound from and cope well when exposed to extreme adversity (Agaibi \& Wilson, 2005). Most research in this area has focused on the processes that promote the development of resiliency, the characteristics or traits of resilient individuals, and the specific cognitive functions and strategies that promote resilient adaptations (Richardson, 2002).

In Bonanno’s (2004) article, he discusses how there are seemingly multiple pathways to resilience or posttraumatic growth, and he provides evidence that certain characteristics such as hardiness, employment of self-enhancing biases, positive emotion and humor, and repressive coping styles are associated with long-term resilience and positive adjustment after experiences of trauma and loss. A study of sexual abuse survivors by Bogar and Hulse-Killacky (2006) identified several key resiliency determinants (interpersonal skills, competence, high self-regard, spirituality, positive life circumstances) and processes (coping strategies, refocusing, active healing, achieving closure). These authors note the need for further research on the processes of resilience rather. 


\section{Child Trauma and Traumatic Stress}

\section{Epidemiology}

While trauma research has traditionally focused on adult populations, there is a growing body of research regarding the incidence of trauma exposure and traumatic stress reactions found in children worldwide that has been informed by previous adult studies. The findings of these child focused studies sufficiently indicate that child trauma is a serious public health issue (Harris, Putnam, \& Fairbank, 2006). Research has documented an array of potentially traumatic events commonly experienced by children that include child maltreatment, domestic violence, war, disasters, accidents, community and school violence and medical trauma (Fairbank, Putnam \& Harris, 2007). The most common type of trauma exposures leading to traumatic stress in children are interpersonal traumas such as child abuse, domestic violence, war or terrorism and community violence, and most of these experiences occur within their immediate home or social environments (DeBellis, \& Van Dillen, 2005; Schmid, Petermann, \& Fegert, 2013; Spinnazola et al., 2005). Estimating rates of trauma exposure in children is challenging due to complications with reporting and identifying the experiences of children particularly the very young, yet the findings of studies conducted to date are concerning. General population studies of children and adolescents in the U.S. have found that by age 16, 25 percent to two-thirds of children have experienced at least one trauma exposure, with rates of being exposed to multiple traumatic events being nearly three times higher for urban versus rural youth (Copeland, Keeler, Angold, \& Costello, 2007; Costello, Erkanli, Fairbank, \& Angold, 2002; Hoven et al., 2002).Children exposed to four or more traumatic events have been found to be at much greater risk for 
psychiatric disorders than children exposed to two or fewer traumas (Copeland, Keeler, Angold, \& Costello, 2007).

Studies of the prevalence of child trauma exposure from other countries continue to follow a pattern similar to the one observed in studies of adult populations. Rates of trauma exposure have been found to be lower in industrialized European nations, at around 20 percent, but higher in less developed and war-affected countries where rates of trauma exposure are near 80 percent for children and adolescents (Perkonigg, Kessler, Storz, \& Wittchen, 2000; Seedat et al., 2004). Several studies have found adolescence to be a peak time for trauma exposure, which may be related to the increase in risk taking behaviors associated with this stage of development (Breslau et al., 2004;Elklit \& Frandsen, 2014; Mizuta et al., 2005).

Epidemiological studies of traumatic stress or PTSD have also been conducted with child and adolescent populations. These findings are generally thought to provide an underestimate of children's traumatic stress reactions given the diagnostic challenges of using criteria based on the presentation of traumatic stress in adults, which has for many years prompted controversial discussions of creating alternative diagnostic criteria that more accurately reflect the developmentally influenced presentation of traumatic stress in childhood and adolescence (Schmid, Petermann, \& Fegert, 2013). Studies have found that children experiencing posttraumatic stress that does not meet full criteria for the disorder also have clinically significant distress and impaired functioning that should not be overlooked (Carrion, Weems, Ray, \& Reiss, 2002). However, the studies conducted to date have generally relied upon the criteria established in the various versions of the 
DSM, and in spite of the limitations acknowledged, have found notable rates of traumatic stress in affected populations of children and adolescents.

While most children exposed to trauma do not develop PTSD, many do and certain groups appear to be at higher risk. Most prevalence studies have been conducted with older children or adolescents. General population studies have reported low rates of lifetime PTSD, generally between 3 and 6 percent (DeBellis \& Van Dillen, 2005). A study of adolescents in Germany found the lifetime rate of PTSD to be 7.8 percent (Perkonigg et al., 2000), and a community study of rural American youth found PTSD to be rare overall (less than 1 percent), but nearly 50 percent for youth who had experienced more than one traumatic event (Copeland, Keeler, Angold, \& Costello, 2007). Older adolescents have been found to have higher rates of PTSD, suggesting an age effect related to exposure with rates ranging from 8.8 to 14.5 percent (Breslau et al., 2004; Giaconia et al., 1995).

What is known from studies of child trauma is that some groups are more vulnerable to trauma exposures and consequently to poorer outcomes associated with significant, negative impacts in multiple domains of physical and mental health. Studies have found that children living in poverty, violent communities, and war-affected areas, as well as those involved in the child welfare, juvenile justice and mental health systems are at greatly increased risks for multiple trauma exposures (Fairbank \& Fairbank, 2009; Fairbank, Putnam, \& Harris, 2007; Trickey et al., 2012). Important research from the Adverse Childhood Experiences Study by Felliti and colleagues (1998) demonstrates the major consequences of increased exposure to traumatic and highly stressful events early in life including emotional abuse, physical abuse, parental substance abuse, parental 
mental illness, domestic violence, criminal behavior in the household and parental separation or divorce. In over 50 subsequent studies of this data, extremely elevated risks for a number of health and mental health conditions have been found to increase with cumulative exposures to these events, especially for those experiencing four or more childhood adversities. These include increased risks for substance abuse, mental health problems, obesity, heart disease, suicide attempts, sexually transmitted diseases, cancer, stroke and even early death (Anda et al., 2002; Felliti et al., 1998).

\section{Impact of Trauma on Children and Adolescents}

Traumatic stress reactions have been described as the dysregulation of emotional responses to traumatic reminders that manifest as symptoms of hyperarousal, emotional numbing, hypervigilance and other disturbances of mood and cognition, which for children occurs within the context of their changing developmental processes and abilities (Cloitre et al., 2009). Another salient difference when considering child versus adult trauma, is the importance of familial context. Not only has it been established that the majority of traumatic exposures for children happen in their immediate home or social setting, but childhood traumas are often inflicted by the very caregivers upon whom they rely to cope with adversity. Caregivers' responses and roles in the trauma exert considerable influence on the child's subjective experience even to the point of defining what may be traumatic or not, and caregiver responses to the stressor model for children how they should interpret and cope with the event (Scheeringa \& Zeanah, 2001; Schwarz \& Perry, 1994). Capacities for interpreting threat and the meaning of traumatic events, which are important determinants of the trauma response, and the degree of 
reliance on caregivers for this function are largely influenced by developmental stage (Friedman, 2006; Weathers \& Keene, 2007).

The impact of trauma on children and adolescents has been conceptualized in terms of acute and long-term responses. Models of child trauma reactions suggest that short-term responses are influenced by interactions of event specific factors (dose of exposure, nature of the event), child intrinsic factors (developmental stage, temperament, coping, history of emotional problems), ecology of the child (parental impact, adjustment, functioning, functionality of the familial/social environment) and proximal stresses and reminders (Lieberman \& Knorr, 2007; Pynoos, Steinberg, \& Piacentini, 1999). According to these models, long-term responses and the child's post-trauma adjustment are further shaped by interactions among secondary stressors and losses, continued exposure to trauma reminders, secondary or subsequent traumatization, familial/social stability and access to helping professionals. Risk factors affecting trauma responses are similar to those found in studies of adults, with the addition of the developmental and familial issues included in the models cited above and peri- and post-trauma factors including the degree of support received and caregivers' responses to the stressor (National Center for PTSD, 2015; Trickey, Siddaway, Meiser-Stedman, Serpell, \& Field; 2012).

Another important factor when considering the differential impact of trauma on children as compared to adult responses is the context of the developing brain. Schwarz \& Perry (1994) cite evidence that the "plasticity of the developing brain" renders it more vulnerable to prolonged disruptions of the stress response mechanisms and neural networks being formed that regulate emotions and lead to the development of certain characteristics of the individual (p. 313). Chronic neglect can result in under-stimulation 
of the brain inhibiting development, as well. This plasticity of the brain in childhood underscores why the effects of early trauma can be so deleterious and persist well into adulthood. Physiologic effects of early trauma exposure can include abnormalities in the immune systems of individuals, related to disproportionate responses to stress and associated physiological reactivity and subsequently higher rates of physical health problems (NCTSN, 2015). Emerging research on biologic and genetic effects of childhood trauma exposure has even found increased risks for aging and early death as evidenced by shorter leukocyte telomere length, a marker of biologic age (Donovan et al., 2011; Tyrka et al., 2010).

Due to the differential factors shaping trauma responses in children, traumatic stress reactions tend to take on other presentations than those observed in adults. Adolescents and older children may exhibit symptom profiles more similar to adults, though they tend to include increased likelihood of aggression and impulsivity as part of their trauma response. However, developmental differences are especially apparent in very young and latency aged children. Younger children, notably the very young (0-6), often have difficulty regulating their behavioral and emotional responses following trauma exposures. As a result, they can become clingy, fearful, aggressive, and experience sleep disturbances and significant regression with regard to developmental milestones previously achieved (National Child Traumatic Stress Network, 2015). Further, latency aged children may have difficulty remembering the trauma coherently, which can lead to hypervigilance and misinterpretation of potential threats and cues in their environments, as well as tendencies to reenact aspects of the trauma in their play (National Center for PTSD, 2015). The often behavioral manifestations of traumatic stress in children 
combined with developmental differences in presentation pose significant assessment challenges (Cohen, 2009).

\section{Maltreatment-Related Trauma and the Child Welfare System}

\section{Child Maltreatment}

As stated in the introductory chapter, the significant number of maltreated children presents a major public health issue in this country given the myriad health and mental health problems associated with these maltreatment experiences (Jamora et al., 2009). As expected, studies of traumatic stress in children actively involved in the child welfare system reveal much higher rates than those observed in the general population however, there is limited empirical research on traumatic stress that is specific to the child welfare population. The majority of studies regarding measures of traumatic stress in children have been conducted with clinical samples that are not child welfare specific or entirely limited to this population. A systematic review was conducted of all studies including trauma assessments or screenings of child welfare samples since 2000. Table 2.1 summarizes the findings of the 14 studies that met these criteria. Three of these studies reported the lifetime rate of PTSD in the samples, which ranged from 13.4 to 15.1 percent (Keller, Salazar, \& Courtney, 2010; McMillen et al., 2005; White, Havalchak, Jackson, O'Brien, \& Pecora, 2007). These statistics are concerning given that the lifetime rate for PTSD among adolescents in the general population is cited as 5 percent (Hamblen \& Barnett, 2015). This indicates that the incidence of PTSD in child welfare samples is nearly 3 times that of the general population of children. More concerning is the extremely high rate (61 percent) of PTSD reported from a residential facility for children 
in the child welfare system (Brown et al., 2013). However, this sample is indicative of the experiences of some of the most psychologically fragile children in child welfare.

Other studies did not conduct assessments of whether these children and adolescents met criteria for diagnosis of PTSD, but rather screened for clinically significant levels of traumatic stress and specific symptoms of the disorder. Most studies that reported on clinically significant levels of posttraumatic stress reported similar rates that ranged from 22 to 27.3 percent (Collin-Vezina et al., 2011; Fusco \& Cahalane, 2013; Greeson et al., 2011). A few studies reported on other related symptoms of clinical significance that were present at high rates including sexual concerns, dissociation, arousal and depression.

Studies of traumatic stress with children actively involved in the child welfare system also revealed the significance of various factors associated with poorer outcomes in this population. These studies revealed numerous risk factors for traumatic stress including increased trauma exposure, gender (i.e. female status), age (i.e. very young, older adolescence), exposure to violence in the home, and ethnicity (i.e. Caucasian, African American) (Collin-Vezina et al., 2011; Fusco \& Cahalane, 2013; Greeson et al., 2011; Griffin et al., 2012; Keller, Salazar, \& Courtney, 2010; Kolko et al., 2010; White et al., 2007). Other factors associated with the development of traumatic stress including some potentially protective factors are summarized in Table 2.2.

\section{The Child Welfare System's Role in Addressing Children's Mental Health Needs}

Since the passage of the Adoption and Safe Families Act (ASFA) in 1997, the goals of the child welfare system in the United States and its associated intervention or case planning process are to achieve safety, permanency and well-being for maltreated children (DePanfilis \& Salus, 2003). Child welfare workers are expected to create 
conditions that facilitate change for the parents and promote family well-being, yet ASFA clearly established an emphasis on the needs of the child. Plans are meant to be initiated at the onset of child welfare involvement, and they are expected to be revised and evolve over time according to the needs of the children and their caregivers.

Case plans are developed based on child welfare workers' assessments of risks for maltreatment and individual needs for intervention and stabilization. There is an assumption that current maltreating behavior is predictive of future maltreating behavior in the absence of such interventions (English \& Pecora, 1994). Therefore, child welfare workers engaged in case planning with maltreating caregivers must assess risks accurately, identify target outcomes, set measurable goals and identify tasks and services to meet those goals (DePanfilis \& Salus, 2003; Rittner, 2002). Decisions are made not only about placement (i.e. whether children remain with parents or are placed in foster care, or whether families are reunified or children are placed for adoption), but also about the basic service needs of the individual adult and child family members in order to reinstitute their health and well-being (Crossen-Tower, 2009). Studies of child welfare case planning components note that important services for children include relational, mental health, physical and developmental therapies (Brook, McDonald, \& Yan, 2012; Estefan et al., 2012).

While it has been recognized that addressing the mental health needs of children in this system is a critical issue and important component of promoting child well-being, there is a significant gap between those who need mental health services and those who receive them (Levitt, 2009). One national study of children with completed investigations for maltreatment found that approximately 75 percent of children with evidence of mental 
health problems were unlikely to receive treatment, and another study found that only 23 to 38 percent of children in foster care were receiving any mental health services (Burns et al., 2004; Rosenbach, Lewis, \& Quinn, 2000). These findings are evidence of the continued lack of case planning that directly focuses on the needs of children. Glisson and Green (2005) cite numerous barriers related to organizational and bureaucratic climate and culture that interfere with access to needed mental health services for children in child welfare including limited resources and knowledge of how to properly identify mental health needs, pressure to focus on parental issues, worker turnover and burnout, and limited collaboration with other child serving systems.

\section{Screening for Trauma and Traumatic Stress in Child Welfare}

As discussed, an important component of child welfare case planning involves the identification of children's health and mental health needs, including screening for traumatic stress. There are numerous screening and assessment measures available to identify children who are in need of evidence based interventions as a result of their maltreatment experiences. Conradi and colleagues (2011) conducted a review of the literature and compiled a summary of commonly utilized trauma screening tools for children who have experienced maltreatment. This list of instruments includes the Child and Adolescent Needs and Strengths- Trauma Version (Kiesiel, Blaustein, Fogler, Ellis, \& Saxe, 2009), the Child Welfare Trauma Referral Tool (Taylor, Steinberg, \& Wilson, 2006), the Trauma Symptom Checklist for Children (Briere, 1996), the Trauma Symptom Checklist for Young Children (Briere, 2005), the Traumatic Events Screening InventoryParent Report (Ribbe, 1996), and the UCLA Posttraumatic Stress Disorder Reaction Index for DSM-IV (Steinberg, Brymer, Decker, \& Pynoos, 2004). These instruments have 
been widely utilized and most have demonstrated sufficient validity and reliability with samples of children who have been maltreated. This collection of instruments also depicts the range of options available for trauma screening in terms of the child ages they are designed to assess and who may serve as the informant.

In studies of traumatic stress screenings with child welfare specific samples, high rates of trauma exposure and traumatic stress symptoms are consistently observed. A summary of the descriptions of the samples and trauma exposure information is provided in Table 2.3 , and findings regarding rates of traumatic stress are summarized in the previously referenced Table 2.1. The highest rates were found in children in residential and foster care settings. This was an expected finding given that these children have presumably experienced higher risk maltreatment necessitating their placement in out of home care, and that the residentially placed children have impaired functioning to a degree necessitating more restrictive placements. However, it was notable that even the children receiving lower levels of child welfare intervention, including those in the investigative stage, as well as children remaining in the care of their biological families, were still exhibiting significant rates of traumatic stress. This is an important distinction because it highlights the need for screening for all children in the system, not just those presumed to be higher risk.

The review of this literature highlighted some additional key findings regarding the administration of trauma screenings. First, there were no studies found where the child welfare workers were administering the screenings. However, it was notable that many of the studies involved child welfare worker identification of cases for screening even if they were not necessarily more involved in the process. Of the measures utilized in the 
studies, only one was designed for use solely by non-clinical professionals, and the others would require some assistance from specially trained child welfare professionals or the mental health sector for interpretation and use. It was notable that none of the studies utilized the Child Welfare Trauma Referral Tool (Taylor, Steinberg, \& Wilson, 2006), a screening instrument with an associated structured decision making guide designed for child welfare workers by authors from the National Child Traumatic Stress Network (NCTSN). This instrument is included as part of a trauma-informed care curriculum developed by the NCTSN specifically for child welfare, which is described in a subsequent section of this review. More studies on the use of this instrument and the CANS, which has a similar decision making component for child welfare, are needed to explore the potential of workers as trauma screeners and ways to enhance their role in providing trauma-informed care. This would address notable gaps in the literature on the implementation of trauma-informed practices in child welfare.

Another significant issue observed in the review of this literature was a seeming overreliance on the construct of PTSD. While many children in the child welfare system experience numerous trauma exposures, associated symptoms of traumatic stress and disruptions in functioning, not all of these children will meet full criteria for PTSD, especially younger children (Kolko et al., 2010). Therefore, studies that relied on this standard for measurement likely provided an underestimate of the actual number of children needing trauma-focused intervention. Current practice standards recommend that all youth with clinically impairing trauma symptoms should be provided evidence-based interventions regardless of diagnosis in order to prevent the development of negative 
psychosocial consequences long-term (Ai, Jackson Foster, Pecora, Delaney, \& Rodriguez, 2013).

The goal of the trauma screening process is to identify those children in need of comprehensive trauma assessments with clinicians capable of providing evidence-based trauma interventions. Conradi and colleagues (2011) make the important distinction between trauma screening tools that are designed to be universal and trauma assessments. Trauma assessments are explained as being much more comprehensive in nature, completed by a trauma-trained clinician, and include more specific information about the child's functioning in multiple domains, as well as how they relate to the supportive systems in their lives, specifically with regard to caregivers and family. Trauma assessments typically rely on multiple informants and collateral sources of data that are integrated to develop a complete picture of the child's individual trauma response. This is meant to specifically guide the treatment planning process.

The positive outcome and ultimate goal of identifying children with these impairments is that there are numerous evidence-based, developmentally appropriate interventions for the treatment of traumatic stress. Some of the more commonly utilized interventions demonstrate the range of options available including the relationally-based Child-Parent Psychotherapy (Lieberman \& Van Horn, 2009) and Trauma-Focused Cognitive Behavioral Therapy (Cohen, Mannarino, \& Deblinger, 2006), which is targeted more toward the individual but also includes caregivers in the process. Additionally, Trauma Systems Therapy (Saxe, Ellis, \& Kaplow, 2007) is a systems level intervention designed to improve the child's emotional regulation capacity through the creation of a traumainformed therapeutic milieu, Child and Family Traumatic Stress Intervention (Marans, 
Epstein, \& Berkowitz, 2011) is a brief early intervention with growing empirical support, and Cognitive Behavioral Intervention for Trauma in Schools (Schultz et al., 2010) is a group model designed for administration in a school setting. These are only some examples of the various empirically supported and effective interventions for treating traumatic stress reactions in children and adolescents.

\section{Creating Trauma-Informed Child Welfare Systems}

Creating trauma-informed child welfare systems has been cited as a necessary condition to prevent system-induced trauma, address maltreated children's recovery needs and decrease risks for mental health problems in affected children (ConnersBurrow et al., 2013). Trauma-informed child serving systems have been described as those capable of integrating the trauma-perspective into practice, screening children for trauma exposure and associated stress reactions, referring them for trauma-focused interventions and promoting continuity of care (Ko et al., 2008; NCTSN, 2008). Implementation of these new practice parameters presents numerous challenges. In order to achieve this conceptual shift, significant system-wide training efforts are required. Quality, comprehensive training programs have been cited as a critical component in the process of adopting evidence-based practices in child welfare, among other necessary conditions (Aarons \& Palinkas, 2007).

Numerous training initiatives are underway nationally to address this need for the development of trauma-informed child welfare systems. The National Child Traumatic Stress Network (NCTSN) has undertaken a leadership role in making recommendations for the various child serving systems on how to implement trauma-informed care. The NCTSN is a group of clinical and research centers funded by the federal Substance and 
Mental Health Services Administration (SAMSHA) that aims to improve access to evidence-based services for trauma-exposed children in a variety of settings and promote collaboration among systems serving these children (NCTSN, 2015). In accordance with this mission, the NCTSN developed perhaps the most comprehensive trauma-training program to date for child welfare, entitled The Child Welfare Trauma Training Toolkit (NCTSN, 2008). This training curriculum is designed to increase child welfare workers' knowledge of the effects of trauma on children's development in all domains, promote evidence-based approaches to screening and assessment for trauma and traumatic stress (including training on the use of the Child Welfare Trauma Referral Tool), and to increase use of trauma-informed practices to promote psychological safety and placement stability for children in out of home care.

A few studies have evaluated the effectiveness of The Child Welfare Trauma Training Toolkit curriculum and found significant improvements in the use of trauma-informed practices (Conners-Burrow et al., 2013; Kramer et al., 2013). However, notable barriers were cited that prevent full implementation of trauma-informed care in child welfare in spite of receiving effective training. These included high caseloads, worker stress, time constraints, limited resources/providers for children and families in need of intervention, the need to prioritize crisis management over mental health or trauma screening, the need to reinforce learning of new strategies and information, and worker discomfort with talking to children about trauma-sensitive matters. Beyond providing effective training, addressing these challenges via alternative strategies such as supervisory and organizational support is critical to the success of achieving trauma-informed systems of care (Antle, Barbee, \& van Zyl, 2008). 


\section{Summary}

This review of the literature supports the significance of evaluating the impact of psychological trauma in affected populations, particularly with individuals who have experienced childhood maltreatment. There is considerable research to confirm the high trauma exposure and traumatic stress rates among children in the child welfare population, and there are indications that these children are largely underserved in terms of their receipt of mental health services. Because of these findings, universal screening for trauma exposure and traumatic stress with children in the child welfare system has been recommended as a best practice approach, and is an integral component of creating a trauma-informed system that can improve outcomes for youth. However, this practice has not been fully implemented, and child welfare workers' effectiveness in this role has not yet been empirically investigated. This study aims to fill this notable gap in the literature.

The empirical literature and theoretical models reviewed support the importance of considering child age and history of trauma exposure when assessing traumatic stress reactions in children. Child welfare workers possess knowledge of these two critical categories of information as part of their routine case work with children; first learning basic information such as the age of a child, then acquiring historical information including a child's history of trauma exposure. Workers then accumulate observational and collateral data regarding a child's functioning during the course of service provision. Therefore, for the primary research question regarding whether child welfare workers can effectively screen for traumatic stress in children, the following hypothesis statement was tested: 
$\mathrm{H}_{1}$ : Utilizing knowledge of a child's age, trauma exposure history and a child's emotions and behaviors, child welfare workers are able to effectively predict posttraumatic stress scores indicated on clinical measures.

A secondary question was also examined regarding whether there are differences in child welfare workers' abilities to screen for certain types of traumatic stress symptoms. Information regarding the nature of these symptoms, how they manifest in children, and challenges regarding the assessment of child traumatic stress was used to guide the development of the second hypothesis. For example, intrusive or re-experiencing symptoms are more directly connected to traumatic experiences, and may be more clearly reported by children or observed to be effects of their trauma history. Avoidance is less visible or difficult to observe, and the nature of successful avoidance prevents children from talking about it (Cohen, 2009). Screening or assessing for arousal in children is complicated by these symptoms being more easily confused with other emotional and behavioral conditions. As a result, children with traumatic stress are often misdiagnosed with or experience co-morbid conditions such as Separation Anxiety Disorder, Attention Deficit Hyperactivity Disorder and Oppositional Defiant Disorder, and the overlap of symptoms associated with these disorders and trauma-related arousal specifically is considerable (Cohen, 2009; Kessler et al., 1995). Consequently, for the secondary research question regarding whether there are differences in child welfare workers' abilities to screen for certain types of traumatic stress symptoms, the following hypothesis statement was tested:

$\mathrm{H}_{2}$ : Child welfare workers are more effective at identifying symptoms of intrusion than avoidance and arousal in trauma-exposed children. 
Figure 2.1. Conceptual Model

Child Welfare Workers' Process of Utilizing Information to Screen for Traumatic Stress in Children

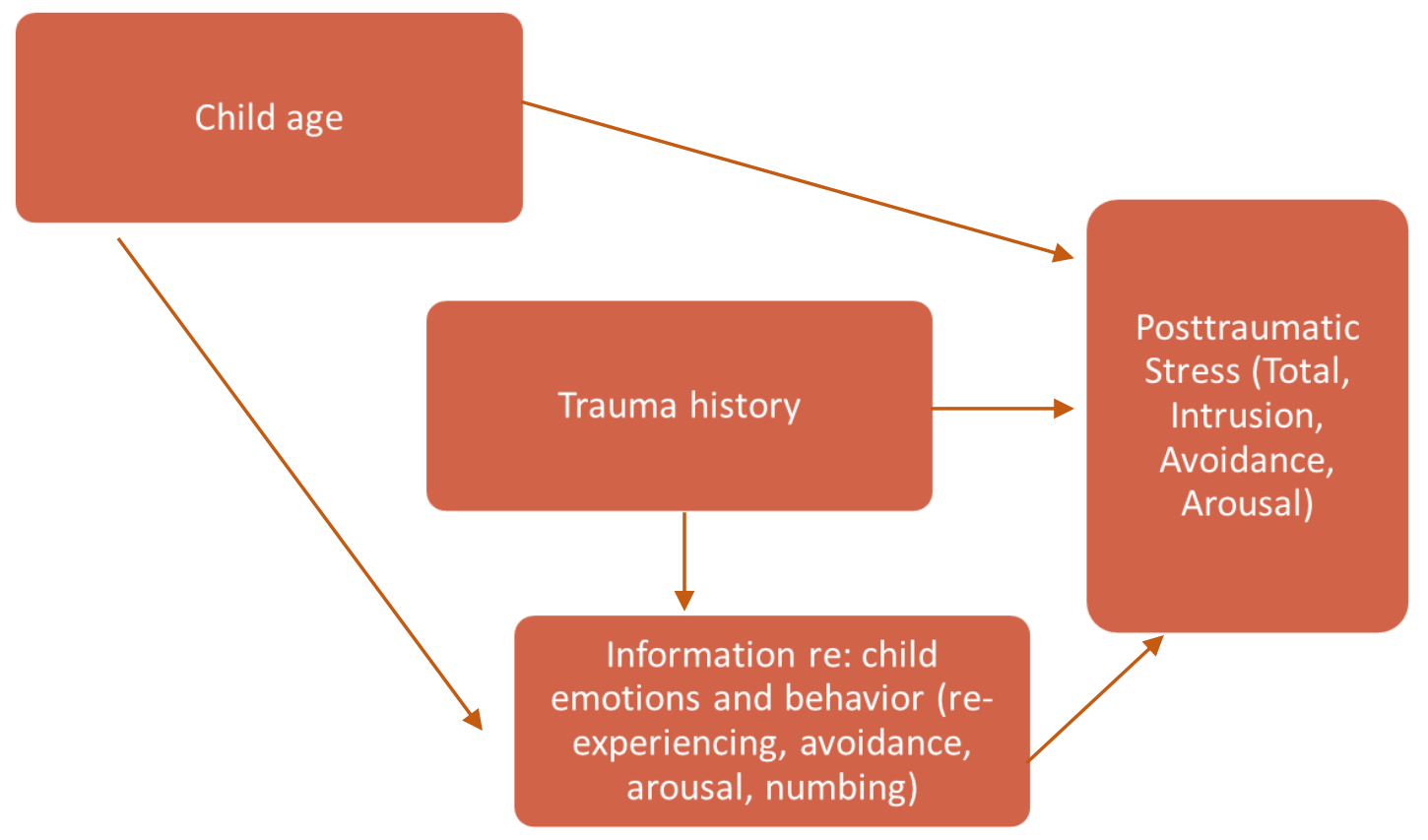


Table 2.1. Measurement of Traumatic Stress in Child Welfare Samples

\begin{tabular}{|c|c|c|c|c|}
\hline Author & Trauma Measure & Informant & Data Collection & Rates of Traumatic Stress Observed \\
\hline Brown et al. (2013) & $\begin{array}{l}\text { UCLA PTSD- Reaction } \\
\text { Index for DSM-IV } \\
\text { (UCLA PTSD-RI) } \\
\text { (Steinberg et al., 2004) }\end{array}$ & child & $\begin{array}{l}\text { residential treatment } \\
\text { facility }\end{array}$ & $\begin{array}{l}61 \% \text { met criteria for PTSD } \\
25 \% \text { met partial criteria } \\
14 \% \text { did not meet criteria }\end{array}$ \\
\hline $\begin{array}{l}\text { Collin-Vezina et al. } \\
\text { (2011) }\end{array}$ & $\begin{array}{l}\text { Trauma Symptom Checklist } \\
\text { for Children (TSCC) } \\
\text { (Briere, 1996) }\end{array}$ & child & $\begin{array}{l}\text { residential treatment } \\
\text { facility }\end{array}$ & $\begin{array}{l}\% \text { of clinically significant symptoms: } \\
34 \% \text { sexual concerns } \\
28.3 \% \text { dissociation } \\
26.4 \% \text { depression } \\
24.5 \% \text { posttraumatic stress } \\
18.9 \% \text { anger } \\
11.3 \% \text { anxiety }\end{array}$ \\
\hline $\begin{array}{l}\text { Fusco \& Cahalane } \\
\text { (2013) }\end{array}$ & $\begin{array}{l}\text { Trauma Symptom Checklist } \\
\text { for Young Children } \\
\text { (TSCYC) } \\
\text { (Briere, 2005) }\end{array}$ & $\begin{array}{l}\text { biological } \\
\text { mother }\end{array}$ & $\begin{array}{l}\text { in-home, researchers } \\
\text { CPS referred }\end{array}$ & $\begin{array}{l}\% \text { of clinically significant symptoms: } \\
27.3 \% \text { total posttraumatic stress } \\
24.3 \% \text { arousal } \\
13.7 \% \text { avoidance } \\
15.2 \% \text { intrusion }\end{array}$ \\
\hline $\begin{array}{l}\text { Goldstein et al. } \\
\text { (2011) }\end{array}$ & $\begin{array}{l}\text { TSCC } \\
\text { (Briere, 1996) }\end{array}$ & child & $\begin{array}{l}\text { multi-site (on laptop } \\
\text { at CPS office, home } \\
\text { or public location), } \\
\text { researchers } \\
\text { CPS referred }\end{array}$ & $\begin{array}{l}\% \text { of clinically significant symptoms } \\
\text { not reported, only T-score means; } \\
\text { dissociation \& sexual concerns } \\
\text { highest }(47.98 / 11.01 ; 51.67 / 19.61)\end{array}$ \\
\hline
\end{tabular}


Table 2.1. Measurement of Traumatic Stress in Child Welfare Samples (continued)

\begin{tabular}{|c|c|c|c|c|}
\hline Author & Trauma Measure & Informant & Data Collection & Rates of Traumatic Stress Observed \\
\hline $\begin{array}{l}\text { Greeson et al. } \\
(2011)\end{array}$ & $\begin{array}{l}\text { UCLA PTSD-RI } \\
\text { (Steinberg et al., 2004) }\end{array}$ & child & $\begin{array}{l}\text { treatment setting, } \\
\text { clinicians }\end{array}$ & $\begin{array}{l}22 \% \text { in clinical range for } \\
\text { posttraumatic stress }\end{array}$ \\
\hline $\begin{array}{l}\text { Griffin et al. } \\
(2012)\end{array}$ & $\begin{array}{l}\text { Child and Adolescent } \\
\text { Needs and Strengths } \\
\text { (CANS) } \\
\text { (Lyons et al., 2008) }\end{array}$ & $\begin{array}{l}\text { multi-informant } \\
\text { (child, collaterals, } \\
\text { records) }\end{array}$ & $\begin{array}{l}\text { CPS office, } \\
\text { clinicians }\end{array}$ & $\begin{array}{l}\% \text { of children reporting: } \\
38 \% \text { at least } 1 \text { trauma symptom } \\
24.02 \% \text { adjusting to trauma } \\
8.08 \% \text { reexperiencing } \\
8.69 \% \text { avoidance } \\
6.13 \% \text { numbing } \\
2.12 \% \text { dissociation } \\
5.98 \% \text { potential PTSD (ages } 13-17 \text { ) } \\
6.87 \% \text { potential PTSD (age } 17 \text { ) }\end{array}$ \\
\hline $\begin{array}{l}\text { Haight, Black, \& } \\
\text { Sheridan (2010) }\end{array}$ & $\begin{array}{l}\text { Child Behavior } \\
\text { Checklist- PTSD- } \\
\text { Dissociation subscale } \\
\text { (Sim et al., 2005) }\end{array}$ & caregiver & $\begin{array}{l}\text { treatment setting, } \\
\text { clinicians } \\
\text { CPS referred }\end{array}$ & $\begin{array}{l}\% \text { above clinical cutoff: } \\
60 \% \text { pre-intervention } \\
40 \% \text { post-intervention }\end{array}$ \\
\hline $\begin{array}{l}\text { Keller, Salazar, \& } \\
\text { Courtney (2010) }\end{array}$ & $\begin{array}{l}\text { Composite } \\
\text { International } \\
\text { Diagnostic } \\
\text { Interview (CIDI)- } \\
\text { PTSD subscale } \\
\text { (WHO, 1997) }\end{array}$ & child & $\begin{array}{l}\text { setting not reported, } \\
\text { researchers } \\
\text { CPS referred }\end{array}$ & $\begin{array}{l}15.1 \% \text { met PTSD criteria (lifetime) } \\
\text { PTSD most commonly indicated } \\
\text { diagnosis }\end{array}$ \\
\hline
\end{tabular}


Table 2.1. Measurement of Traumatic Stress in Child Welfare Samples (continued)

\begin{tabular}{|c|c|c|c|c|}
\hline Author & Trauma Measure & Informant & Data Collection & Rates of Traumatic Stress Observed \\
\hline $\begin{array}{l}\text { Kolko et al. } \\
(2010)\end{array}$ & $\begin{array}{l}\text { TSCC } \\
\text { (Briere, 1996) }\end{array}$ & child & $\begin{array}{l}\text { setting not reported, } \\
\text { researchers } \\
\text { identified via CPS } \\
\text { records }\end{array}$ & $\begin{array}{l}\% \text { of clinically significant symptoms: } \\
11.7 \% \text { total posttraumatic stress } \\
19.2 \% \text { for children in OOHC } \\
10.7 \% \text { for children in home }\end{array}$ \\
\hline $\begin{array}{l}\text { Leon et al. } \\
(2008)\end{array}$ & $\begin{array}{l}\text { TSCC } \\
\text { (Briere, 1996) }\end{array}$ & child & $\begin{array}{l}\text { setting not reported, } \\
\text { researchers } \\
\text { utilized laptops } \\
\text { CPS referred }\end{array}$ & $\begin{array}{l}\% \text { of clinically significant symptoms } \\
\text { not reported, extracted } 3 \text { factors from } \\
\text { TSCC: negative affect, sexually } \\
\text { ruminative thoughts, non-sexual }\end{array}$ \\
\hline & & & & $\begin{array}{l}\text { rumination; reported these as } \\
\text { significant. No additional } \\
\text { information provided. }\end{array}$ \\
\hline $\begin{array}{l}\text { McMillen et al. } \\
(2005)\end{array}$ & $\begin{array}{l}\text { Diagnostic Interview } \\
\text { Schedule for DSM-IV- } \\
\text { PTSD subscale } \\
\text { (Robbins et al., 1995) }\end{array}$ & child & $\begin{array}{l}\text { in-home, } \\
\text { researchers } \\
\text { CPS referred }\end{array}$ & $\begin{array}{l}\text { 14\% met PTSD criteria (lifetime) } \\
42 \% \text { PTSD prior to foster care } \\
8 \% \text { PTSD past year } \\
\text { mean age of onset }=10.48(3.54)\end{array}$ \\
\hline $\begin{array}{l}\text { Tarren-Sweeney } \\
\text { (2013) }\end{array}$ & $\begin{array}{l}\text { Assessment Checklist } \\
\text { for Adolescents } \\
\text { (Tarren-Sweeney, 2007) }\end{array}$ & caregiver & $\begin{array}{l}\text { foster care, } \\
\text { researchers }\end{array}$ & $\begin{array}{l}\text { clinically significant symptoms } \\
\text { not reported (psychometric study) }\end{array}$ \\
\hline
\end{tabular}


Table 2.1. Measurement of Traumatic Stress in Child Welfare Samples (continued)

\begin{tabular}{lllll}
\hline Author & Trauma Measure & Informant & Data Collection & Rates of Traumatic Stress Observed \\
\hline $\begin{array}{l}\text { Tarren-Sweeney } \\
(2013)\end{array}$ & $\begin{array}{l}\text { Brief Assessment Checklist } \\
\text { for Children \& Adolescents } \\
\text { (Tarren-Sweeney, 2013) }\end{array}$ & caregiver & $\begin{array}{l}\text { in-home/mail survey } \\
\text { identified from CPS } \\
\text { records }\end{array}$ & $\begin{array}{l}\text { clinically significant symptoms } \\
\text { not reported (psychometric study); } \\
\text { 2 trauma-specific items endorsed by } \\
28 \% \text { and 33\% respectively: } \\
\text { "distressed by traumatic memories" } \\
\text { \& "startles easily (jumpy)" }\end{array}$ \\
$\begin{array}{l}\text { White et al. } \\
(2007)\end{array}$ & $\begin{array}{l}\text { CIDI- PTSD subscale } \\
\text { (WHO, 1997) }\end{array}$ & child & $\begin{array}{l}\text { foster care, in-person } \\
\text { interviews, } \\
\text { researchers }\end{array}$ & $13.4 \%$ met PTSD criteria (lifetime)
\end{tabular}


Table 2.2. Observations Regarding Traumatic Stress and Related Factors

\begin{tabular}{|c|c|c|}
\hline Author & Additional Factors Investigated & Relationships Observed with Traumatic Stress \\
\hline Brown et al. (2013) & child functioning & $\begin{array}{l}\text {-high rates of PTSD associated with significantly impaired } \\
\text { functioning } \\
\text {-significant decrease in levels of functional impairment } \\
\text { after receiving trauma intervention }\end{array}$ \\
\hline $\begin{array}{l}\text { Collin-Vezina et al. } \\
\text { (2011) }\end{array}$ & $\begin{array}{l}\text { trauma history } \\
\text { resilience }\end{array}$ & $\begin{array}{l}\text {-high rates of multiple traumas } \\
\text {-higher number of traumas associated with lower resilience } \\
\text {-females had higher rates of sexual abuse and } \\
\text { traumatic stress related to sexual concerns and dissociation }\end{array}$ \\
\hline $\begin{array}{l}\text { Fusco \& Cahalane } \\
\text { (2013) }\end{array}$ & $\begin{array}{l}\text { OOHC history } \\
\text { maternal factors } \\
\text { violence in the home } \\
\text { race } \\
\text { maltreatment type }\end{array}$ & $\begin{array}{l}\text {-very high rates of traumatic stress in young children (age 3-5) } \\
\text {-biracial status, history of neglect, IPV in the home all contributed } \\
\text { to increased traumatic stress }\end{array}$ \\
\hline $\begin{array}{l}\text { Goldstein et al. } \\
\text { (2011) }\end{array}$ & $\begin{array}{l}\text { maltreatment type } \\
\text { frequency of maltreatment } \\
\text { substance abuse }\end{array}$ & $\begin{array}{l}\text {-all maltreatment types positively, significantly associated with } \\
\text { TSCC subscale scores } \\
\text {-more frequent maltreatment associated with increased trauma } \\
\text { symptoms } \\
\text {-child maltreatment and dissociation associated with substance } \\
\text { abuse } \\
\text {-higher anger and dissociation associated with increased alcohol } \\
\text { abuse }\end{array}$ \\
\hline
\end{tabular}


Table 2.2. Observations Regarding Traumatic Stress and Related Factors (continued)

\begin{tabular}{lll}
\hline Author & Additional Factors Investigated & Relationships Observed with Traumatic Stress \\
\hline $\begin{array}{l}\text { Greeson et al. } \\
(2011)\end{array}$ & $\begin{array}{l}\text { complex trauma } \\
\text { demographics }\end{array}$ & $\begin{array}{l}\text {-White children in foster care more likely to have complex trauma } \\
\text {-complex trauma histories associated with significantly higher }\end{array}$
\end{tabular}

PTSD symptoms

$\begin{array}{ll}\text { Griffin et al. } & \text { age } \\ & \text { trauma exposure variables } \\ & \text { other mental health diagnoses } \\ \text { child strengths }\end{array}$

Haight, Black, \& intervention effects Sheridan (2010)

Keller, Salazar, \& Courtney (2010) demographics mental health substance abuse placement -for each additional trauma, average number of trauma symptoms increased by $41 \%$, other mental health symptoms by $34 \%$

-with each additional strength, trauma symptoms decreased by $18 \%$

-PTSD risk increased with age

-post-intervention reduction in PTS and externalizing symptoms observed (Life Story Intervention; Gambrill, 2005)

-females had significantly greater risks for PTSD and depression, which were the most common diagnoses observed -type of OOHC placement significantly associated with other mental health and substance abuse disorders, but not PTSD -onset of PTSD prior/post OOHC placement was equivalent except for African American youth (more likely post removal) 
Table 2.2. Observations Regarding Traumatic Stress and Related Factors (continued)

\begin{tabular}{|c|c|c|}
\hline Author & Additional Factors Investigated & Relationships Observed with Traumatic Stress \\
\hline $\begin{array}{l}\text { Kolko et al. } \\
(2010)\end{array}$ & $\begin{array}{l}\text { placement } \\
\text { age } \\
\text { maltreatment } \\
\text { mental health }\end{array}$ & $\begin{array}{l}\text {-younger child age, abuse by non-biological parent, violence } \\
\text { in the home, and child depression all contributed to increased } \\
\text { trauma symptoms }\end{array}$ \\
\hline $\begin{array}{l}\text { Leon et al. } \\
(2008)\end{array}$ & $\begin{array}{l}\text { placement } \\
\text { demographics } \\
\text { personal/social variables } \\
\text { sexual behavior problems }\end{array}$ & $\begin{array}{l}\text {-sexual abuse history significantly associated with negative affect } \\
\text { and rumination } \\
\text {-better parenting, increased competence, increased foster parent } \\
\text { support all associated with decreases in trauma symptoms } \\
\text { related to sexual concerns }\end{array}$ \\
\hline $\begin{array}{l}\text { McMillen et al. } \\
(2005)\end{array}$ & $\begin{array}{l}\text { placement } \\
\text { demographics } \\
\text { mental health } \\
\text { age of onset }\end{array}$ & $\begin{array}{l}\text {-high rates of lifetime psychiatric disorder }(61 \%) \text { and in the past } \\
\text { year }(37 \%) \\
-62 \% \text { reported the onset of their earliest disorder occurring prior to } \\
\text { placement in foster care } \\
\text {-number of types of maltreatment most significant predictor of } \\
\text { psychiatric disorder } \\
\text {-no significant differences between children placed in foster versus } \\
\text { kinship care }\end{array}$ \\
\hline $\begin{array}{l}\text { Tarren-Sweeney } \\
\text { (2013) }\end{array}$ & psychometric study & $\begin{array}{l}\text {-relevant trauma symptom clusters confirmed in this sample } \\
\text { included trauma-related dissociation symptoms, PTSD/trauma- } \\
\text { related anxiety symptoms, and emotional dysregulation } \\
\text { symptoms }\end{array}$ \\
\hline
\end{tabular}


Table 2.2. Observations Regarding Traumatic Stress and Related Factors (continued)

\begin{tabular}{|c|c|c|}
\hline Author & Additional Factors Investigated & Relationships Observed with Traumatic Stress \\
\hline $\begin{array}{l}\text { Tarren-Sweeney } \\
(2013)\end{array}$ & psychometric study & $\begin{array}{l}\text {-relevant trauma symptom clusters confirmed in this sample } \\
\text { included behavioral/emotional dysregulation and trauma-related } \\
\text { anxiety and dissociation } \\
\text {-effectiveness supported as a screening tool for children in child } \\
\text { welfare system in various placement settings \& administered by } \\
\text { non-clinicians }\end{array}$ \\
\hline $\begin{array}{l}\text { White et al. } \\
\text { (2007) }\end{array}$ & $\begin{array}{l}\text { mental health } \\
\text { demographics } \\
\text { sexuality } \\
\text { spirituality }\end{array}$ & $\begin{array}{l}\text {-controlling for other demographics and placement history, females } \\
\text { had significantly higher rates of lifetime and past year } \\
\text { internalizing disorders including depression, panic disorder and } \\
\text { PTSD } \\
\text {-the lifetime rate of PTSD for females was } 21.4 \% \text { compared to } \\
5.1 \% \text { for males }\end{array}$ \\
\hline
\end{tabular}


Table 2.3. Descriptive Summary of Child Welfare Samples Screened for Traumatic Stress

\begin{tabular}{|c|c|c|c|c|}
\hline Author & Age & Gender/Ethnicity & Maltreatment Type & Placement Information \\
\hline Brown et al. (2013) & 70 adolescents & $100 \%$ male, ethnicity not reported & $\begin{array}{l}\text { Average of } 4 \text { traumas- } \\
\text { PA, DV, SA and } \\
\text { community violence } \\
\text { "most common" forms }\end{array}$ & residential treatment facility \\
\hline $\begin{array}{l}\text { Collin-Vezina et al. } \\
\text { (2011) }\end{array}$ & $\begin{array}{l}53 \text { adolescents } \\
\text { aged } 14-17\end{array}$ & $\begin{array}{l}55 \% \text { male } \\
38 \% \text { Caucasian } \\
19 \% \text { Black } \\
21 \% \text { Aboriginal } \\
22 \% \text { mixed or other }\end{array}$ & $\begin{array}{l}60 \% \text { physical abuse } \\
68 \% \text { emotional abuse } \\
38 \% \text { sexual abuse } \\
\text { (63\% girls, } 17 \% \text { boys) } \\
98 \% \text { neglect }\end{array}$ & residential treatment facility \\
\hline $\begin{array}{l}\text { Fusco \& Cahalane } \\
\text { (2013) }\end{array}$ & $\begin{array}{l}100 \text { children } \\
\text { aged } 3-5\end{array}$ & $\begin{array}{l}\text { 56.3\% male } \\
\text { 16.2\% African American } \\
\text { 77.5\% White } \\
6.3 \% \text { Biracial } \\
3.6 \% \text { Hispanic }\end{array}$ & $\begin{array}{l}13.1 \% \text { physical abuse } \\
1.6 \% \text { sexual abuse } \\
25.4 \% \text { neglect }\end{array}$ & $\begin{array}{l}\text { in child welfare system, } \\
\text { open cases but in biological } \\
\text { mothers' care } \\
36.8 \% \text { prior placement in } \\
\text { OOHC }\end{array}$ \\
\hline $\begin{array}{l}\text { Goldstein et al. } \\
\text { (2011) }\end{array}$ & $\begin{array}{l}253 \text { adolescents } \\
\text { aged } 14-17\end{array}$ & $\begin{array}{l}\text { 61\% female } \\
\text { 27.3\% Caucasian } \\
\text { 24.9 African Canadian } \\
\text { 31.3\% multiple ethnicities }\end{array}$ & $\begin{array}{l}36.6 \% \text { physical abuse } \\
19.0 \% \text { sexual abuse } \\
34.3 \% \text { emotional abuse } \\
36.6 \% \text { neglect }\end{array}$ & $\begin{array}{l}65.7 \% \text { Crown Ward status } \\
\text { (post TPR, wards of state) }\end{array}$ \\
\hline
\end{tabular}


Table 2.3. Descriptive Summary of Child Welfare Samples Screened for Traumatic Stress (continued)

\begin{tabular}{|c|c|c|c|c|}
\hline Author & Age & Gender/Ethnicity & Maltreatment Type & Placement Information \\
\hline $\begin{array}{l}\text { Greeson et al. } \\
(2011)\end{array}$ & $\begin{array}{l}2,251 \text { children } \\
\& \text { adolescents } \\
\text { aged } 0-21, \\
\text { mean age }=9.5 \text { yrs } \\
(\mathrm{SD}=4.3)\end{array}$ & $\begin{array}{l}52.2 \% \text { female } \\
38.6 \% \text { Black } \\
\text { 49.1\% White } \\
15.7 \% \text { Hispanic/Latino }\end{array}$ & $\begin{array}{l}68 \% \text { neglect } \\
54.2 \% \text { DV exposure } \\
51.4 \% \text { emotional abuse } \\
48.4 \% \text { physical abuse } \\
32.0 \% \text { sexual abuse }\end{array}$ & $\begin{array}{l}54.1 \% \text { currently in foster } \\
\text { care; all had prior history in } \\
\text { OOHC }\end{array}$ \\
\hline & & & $\begin{array}{l}\text { mean number traumas }=4.7 \\
(\mathrm{SD}=2.5)\end{array}$ & \\
\hline $\begin{array}{l}\text { Griffin et al. } \\
(2012)\end{array}$ & $\begin{array}{l}14,103 \text { children } \\
\& \text { adolescents } \\
\text { aged } 0-17 \\
59.9 \% \text { aged } 0-6 \\
19.9 \% \text { aged } 7-13 \\
20.2 \% \text { aged } 13-17\end{array}$ & $\begin{array}{l}50.7 \% \text { male } \\
\text { 46.9\% African American } \\
\text { 46.9\% White } \\
5.7 \% \text { Hispanic }\end{array}$ & $\begin{array}{l}46.1 \% \text { neglect } \\
29.3 \% \text { family violence } \\
20.7 \% \text { physical abuse } \\
13.4 \% \text { emotional abuse } \\
8.6 \% \text { sexual abuse }\end{array}$ & in CPS custody \\
\hline $\begin{array}{l}\text { Haight, Black, \& } \\
\text { Sheridan (2010) }\end{array}$ & $\begin{array}{l}15 \text { children \& } \\
\text { adolescents aged } \\
7-14\end{array}$ & $\begin{array}{l}60 \% \text { male } \\
100 \% \text { Caucasian }\end{array}$ & $\begin{array}{l}73 \% \text { neglect } \\
27 \% \text { sexual and/or } \\
\text { physical abuse }\end{array}$ & in foster care \\
\hline
\end{tabular}


Table 2.3. Descriptive Summary of Child Welfare Samples Screened for Traumatic Stress (continued)

\begin{tabular}{|c|c|c|c|c|}
\hline Author & Age & Gender/Ethnicity & Maltreatment Type & Placement Information \\
\hline $\begin{array}{l}\text { Keller, Salazar, \& } \\
\text { Courtney (2010) }\end{array}$ & $\begin{array}{l}732 \text { adolescents } \\
59 \% 17 \text { years old } \\
41 \% 18 \text { years old }\end{array}$ & $\begin{array}{l}51.5 \% \text { female } \\
57.3 \% \text { African American } \\
\text { 31.0\% Caucasian } \\
9.8 \% \text { mixed ethnicity }\end{array}$ & not reported & $\begin{array}{l}\text { in } \mathrm{OOHC} \text { at least } 1 \text { year, } \\
\text { transitioning to independent } \\
\text { living } \\
\text { age entry in } \mathrm{OOHC}=10.8 \mathrm{yrs} \\
30.5 \% \text { kinship care } \\
35.8 \% \text { foster care } \\
18.1 \% \text { group/residential care } \\
8.6 \% \text { independent living } \\
.7 \% \text { foster-adoptive home } \\
6.3 \% \text { other placement }\end{array}$ \\
\hline $\begin{array}{l}\text { Kolko et al. } \\
(2010)\end{array}$ & $\begin{array}{l}1,848 \text { children } \& \\
\text { adolescents } \\
\text { aged } 8-14\end{array}$ & $\begin{array}{l}53 \% \text { female } \\
\text { 46.1\% Caucasian } \\
30.1 \% \text { African American } \\
\text { 15\% Hispanic }\end{array}$ & $\begin{array}{l}\text { ages } 8-11 \text { : } \\
12.1 \% \text { sexual abuse } \\
10.4 \% \text { emotional abuse } \\
38.3 \% \text { physical abuse } \\
54.3 \% \text { neglect } \\
\text { ages } 12-14: \\
15.6 \% \text { sexual abuse } \\
40.9 \% \text { physical abuse } \\
12.4 \% \text { emotional abuse } \\
49.0 \% \text { neglect }\end{array}$ & $\begin{array}{l}\text { under child welfare } \\
\text { investigation } \\
88.4 \% \text { with biological family } \\
11.6 \% \text { in OOHC }\end{array}$ \\
\hline $\begin{array}{l}\text { Leon et al. } \\
(2008)\end{array}$ & $\begin{array}{l}142 \text { children \& } \\
\text { adolescents }\end{array}$ & $\begin{array}{l}73 \% \text { male } \\
88 \% \text { African American }\end{array}$ & $23 \%$ sexual abuse & $\begin{array}{l}\text { in foster care } \\
\text { mean number placements= } \\
7.0(\mathrm{SD}=4.0)\end{array}$ \\
\hline
\end{tabular}


Table 2.3. Descriptive Summary of Child Welfare Samples Screened for Traumatic Stress (continued)

\begin{tabular}{|c|c|c|c|c|}
\hline Author & Age & Gender/Ethnicity & Maltreatment Type & Placement Information \\
\hline $\begin{array}{l}\text { McMillen et al. } \\
(2005)\end{array}$ & 373,17 year olds & $\begin{array}{l}56 \% \text { female } \\
52 \% \text { African American } \\
42 \% \text { White } \\
4 \% \text { mixed ethnicity }\end{array}$ & $\begin{array}{l}48 \% \text { physical abuse } \\
48 \% \text { neglect } \\
35 \% \text { sexual abuse } \\
17 \% \text { all } 3 \text { types } \\
23 \% 2 \text { types } \\
32 \% 1 \text { type }\end{array}$ & $\begin{array}{l}\text { in OOHC } \\
31 \% \text { in foster care } \\
20 \% \text { kinship care } \\
41 \% \text { group/residential care }\end{array}$ \\
\hline $\begin{array}{l}\text { Tarren-Sweeney } \\
(2013)\end{array}$ & $\begin{array}{l}372 \text { children \& } \\
\text { adolescents } \\
\text { aged } 11-18\end{array}$ & $\begin{array}{l}54 \% \text { male } \\
\text { ethnicity not reported }\end{array}$ & not reported & $\begin{array}{l}\text { in } \mathrm{OOHC} \\
83 \% \text { foster care } \\
13 \% \text { kinship care } \\
4 \% \text { adoptive } \\
\text { mean age of entry into } \\
\text { OOHC }=6.2 \text { yrs } \\
\text { mean time spent in } \mathrm{OOHC}= \\
8.6 \mathrm{yrs}\end{array}$ \\
\hline
\end{tabular}


Table 2.3. Descriptive Summary of Child Welfare Samples Screened for Traumatic Stress (continued)

\begin{tabular}{|c|c|c|c|c|}
\hline Author & Age & Gender/Ethnicity & Maltreatment Type & Placement Information \\
\hline $\begin{array}{l}\text { Tarren-Sweeney } \\
\text { (2013) }\end{array}$ & $\begin{array}{l}347 \text { children \& } \\
\text { adolescents } \\
\text { aged } 4-11\end{array}$ & $\begin{array}{l}51 \% \text { female } \\
\text { ethnicity not reported }\end{array}$ & $\begin{array}{l}\text { average of } 3 \\
\text { maltreatment events }\end{array}$ & $\begin{array}{l}\text { in } \mathrm{OOHC} \\
86 \% \text { foster care } \\
14 \% \text { kinship care } \\
\text { mean age of entry into } \\
\text { OOHC }=3.5 \text { yrs } \\
\text { mean time spent in } \mathrm{OOHC}= \\
4.3 \text { yrs } \\
\text { mean number of placements= } \\
3.1\end{array}$ \\
\hline $\begin{array}{l}\text { White et al. } \\
\text { (2007) }\end{array}$ & $\begin{array}{l}188 \text { adolescents } \\
\text { aged } 14-17\end{array}$ & $\begin{array}{l}51.1 \% \text { female } \\
67.7 \% \text { "youth of color" }\end{array}$ & not reported & in foster care \\
\hline
\end{tabular}




\section{Chapter 3}

\section{Methodology}

\section{Sample Description}

This study examined child welfare workers' effectiveness in screening for traumatic stress in a sample of maltreated children from their caseloads. The study utilized secondary data analysis of cross-sectional data collected at the University of Kentucky Center on Trauma and Children since 2011. Data collection is ongoing. Approval from the University of Kentucky Institutional Review Board was received for this analysis.

A sample of children with substantiated cases of maltreatment was screened for traumatic stress in this study. The children were all referred by their ongoing services, child welfare workers to a university-based assessment clinic for families with high-risk cases of maltreatment. This clinic serves the entire child welfare system in a predominantly rural state. Evaluation data from the assessment clinic indicates that the families served are rated on average as being in the highest category or extreme range according the child protection risk rating anchors used to assess cases following a substantiation of maltreatment (Sprang, Silman, Whitt-Woosley, \& Mau, 2015). Each child's worker completed a trauma screening on their behalf as part of the assessment process. Depending on the child's age, a clinical trauma measure was also completed for each child by either self-report and/or a caregiver. The number of children in the sample with both completed trauma screenings from their child welfare worker and at least one clinical trauma measure was 131. 
The sample of children included in the analysis ranged from 3 to 17 years of age (mean $=7.75, \mathrm{SD}=3.90$ ), with 76 of the children being eligible to complete their own trauma measures (ages 8 to 17 ) and 55 (ages 3 to 7 ) requiring caregivers to report trauma symptoms. The children had spent an average of 8.51 months $(\mathrm{SD}=8.01)$ in their placement at the time of data collection. Data regarding their histories of trauma exposure was also collected from their child welfare workers. The children had reportedly experienced an average of 4.36 different types of traumas ( $\mathrm{SD}=1.99$ ), with the most frequently endorsed type of trauma being neglect (96.4 percent) followed by exposure to domestic violence (77.5 percent). The next most frequently experienced types of traumatic events were emotional abuse (53.3 percent), physical abuse (44.4 percent) and sexual abuse (44.3 percent). Rates of exposure to extreme interpersonal violence, traumatic loss and systems-induced trauma ranged from 26.2 to 36 percent. The remaining trauma types including disasters, war/terrorism, community violence and serious accidents or medical trauma were reportedly experienced at lower rates ranging from .8 to 7.1 percent.

Some additional information was available regarding the emotional and behavioral functioning of the children in the sample. The children's caregivers had completed a Child Behavior Checklist (Achenbach, 2004) that reports on how true items are regarding various emotional, behavioral, social and developmental problems for each child. The Child Behavior Checklist (CBCL) is an empirically derived measure with established norms and psychometric properties that has been used extensively to study the mental health status of children in child welfare settings (Heflinger, Simpkins, \& Combs-Orme, 2000; McIntyre \& Kessler, 1986; Pecora, 1997; Silver et al., 1992). Two CBCL versions 
are available for children ages 1.5-5 and ages 6-18. For this study, scores were available regarding the clinical problem scales only. A summary of these findings is provided in Table 3.1. Overall, caregivers described the children in this sample as experiencing the highest rates of clinically significant $(T \geq 70)$ problems in the areas of conduct (17.1 percent), emotionally reactive (16.9 percent) and attention problems (14.9 percent). Among the younger children in the sample, pervasive developmental problems were the most prominent with 20 percent of the children being reported by caregivers to have clinically significant concerns in this domain.

\section{Conceptual and Operational Definitions}

As indicated in the literature review, there are many manifestations of trauma responses, particularly in children. Given the focus of the analysis, variables were defined using clinical terminology associated with the diagnosis of Posttraumatic Stress Disorder. This supports the purpose of this study, which was to determine whether child welfare workers can adequately screen children for traumatic stress symptoms.

\section{Dependent Variables}

\section{Total Posttraumatic Stress}

This variable represents a cluster of symptoms consistent with the diagnosis of Posttraumatic Stress Disorder. This disorder underwent considerable revision between the DSM-IV and the most recent edition of the DSM-V, though the general symptoms required to meet criteria for diagnosis are largely the same (National Center for PTSD, 2015). Notable changes include the three clusters of DSM-IV symptoms (reexperiencing, arousal and avoidance with numbing) being divided into four clusters in DSM-V: intrusion, avoidance, negative alterations in mood and alterations in arousal 
(American Psychiatric Association, 2000; American Psychiatric Association, 2013).

Factor analytic studies prompted this reorganization and studies indicated the need to require one symptom of avoidance specifically (National Center for PTSD, 2015). Therefore, this variable was conceptually defined as the combined psychological distress reaction resulting from exposure to a traumatic event (or events) including symptoms of intrusion, arousal, avoidance, and associated affective disturbance.

This variable was operationally defined as $T$-scores on either the Posttraumatic Stress (PTS) clinical scale of the Trauma Symptom Checklist for Children-Alternate Form (TSCC-A) (Briere, 1996) or on the Posttraumatic Stress Total clinical scale of the Trauma Symptom Checklist for Young Children (TSCYC) (Briere, 2005). These measures were used interchangeably to assess the dependent variable in the first model given that they measure the same concepts. Child age determined the administration of these measures, i.e. only children aged 8 and older could complete the TSCC-A while children aged 3-12 were eligible for administration of the TSCYC.

In the three subsequent models, clinical scale scores from only the TSCYC were utilized for the dependent variables given that this measure provides scores for additional symptom categories of traumatic stress including intrusion, avoidance and arousal. This allowed for further analysis of workers' effectiveness in screening for specific types of trauma symptoms beyond total traumatic stress. The TSCC-A relies on a different structure that includes reporting on levels of anxiety, depression and other related symptoms but only provides a total score regarding symptoms of posttraumatic stress. Therefore, no child self-report measure was available for the dependent variables in the latter three models. 


\section{Intrusion}

Intrusion was conceptually defined as traumatic stress symptoms that include involuntary and distressing memories of the trauma, distressing dreams of the event, flashbacks, and/or extreme psychological or physical distress when presented with cues or reminders of the trauma (American Psychiatric Association, 2013). In children, trauma reenactment in play and intense nightmares regarding the trauma are common manifestations of intrusive symptoms, which are often experienced as highly distressing, sensory based experiences (American Psychiatric Association, 2013; Briere, 1992).

This variable was operationally defined as the $T$-scores on the Posttraumatic StressIntrusion scale on the TSCYC.

\section{Avoidance}

Avoidance was defined as either emotional or behavioral avoidance of reminders of the traumatic event (National Center for PTSD, 2015). Emotional avoidance includes avoiding distressing thoughts, feelings and conversations associated with the trauma and employing cognitive coping strategies to suppress these experiences, whereas behavioral avoidance involves changing one's behavior to avoid exposure to trauma reminders such as people, places and activities (APA, 2000, APA, 2013).

Avoidance was operationally defined as the $T$-scores on the Posttraumatic StressAvoidance scale of the TSCYC.

\section{Arousal}

Arousal was defined as experiencing an increased state of alertness and activation of an individual's "fight or flight" response following a trauma that can include hypervigilance, exaggerated startle response, aggression, difficulty sleeping and impaired 
concentration (APA, 2000; APA, 2013). Arousal often includes a sense that the individual is in danger, and those affected are hyper-responsive to potential threats or cues in their environments.

Arousal was operationally defined as the $T$-scores on the Posttraumatic Stress-Arousal scale of the TSCYC.

\section{Independent Variables}

\section{Child Age}

When considering the impact of traumatic experiences on children, it has been established that age and developmental stage exert significant influences (Ciccheti \& Toth, 1997; Margolin, 2005). A child's age likely affects not only the manifestation of a child's response, but knowledge of a child's age may also influence the way others observe and contextualize their behavior and expressions of distress. Therefore, the models tested included child age, which was conceptually defined as the child's chronological age at the time of the trauma screening.

This variable was operationally defined as the child's chronological age in years as reported by the child welfare worker on the Child Welfare Trauma Referral Tool (CWTRT) (Taylor, Steinberg, \& Wilson, 2006).

\section{Trauma Exposure History}

Numerous studies confirm the significance of trauma exposure history and number of traumas experienced as risk factors for traumatic stress (Breslau, Chilcoat, Kessler, \& Davis, 2014; Green et al., 2000). Knowledge of what traumatic events a child has been exposed to should provide context for how one interprets their emotional and behavioral responses. For this study, trauma exposure history was conceptually defined as the 
accumulation of events experienced that involved exposure to actual or threatened death, serious injury, or sexual violence either directly or indirectly (American Psychiatric Association, 2013).

This variable was operationalized by the number of trauma types experienced by the child as reported by the child welfare worker on the CWTRT. Fourteen different types of trauma are listed on the screening.

\section{Child Welfare Worker Observations/Information- Total Posttraumatic Stress}

The variable Child Welfare Worker Observations/Information-Total Posttraumatic Stress was conceptually defined as stated previously in the description of the dependent variable of Total Posttraumatic Stress. As a predictor in the models, Child Welfare Worker Observations/Information-Total Posttraumatic Stress was operationally defined as the combined score derived from the child welfare workers' ratings regarding the presence of symptoms of posttraumatic stress on the CWTRT. This trauma screening tool asks workers to rate their observations of the presence of child traumatic stress symptoms according to the DSM-IV categories of re-experiencing, avoidance, numbing and arousal. A composite variable was created to obtain a total score from the workers' ratings of the presence of each symptom on the CWTRT as no (0), suspected (1) or yes (2). Possible scores ranged from 0 to 8 . Higher scores reflected increased endorsement of child traumatic stress symptoms.

\section{Measures}

\section{Dependent Variables}

Trauma Symptom Checklist for Children-Alternate Form (TSCC-A). The Trauma Symptom Checklist for Children-Alternate Form (TSCC-A) was the instrument used to 
measure the children's self-reported traumatic stress reactions in this study (Briere, 1996). The 44-item altered version of the original Trauma Symptom Checklist (TSCC) was developed for the assessment of children ages 8-17 as a self-report measure of posttraumatic distress and related symptomatology. It is intended to be administered to children with known exposures to traumatic events including physical abuse, sexual abuse, disasters, witnessing of violence and other forms of victimization. The alternate form of the original instrument omits the sexual concerns subscale, but otherwise remains the same. The measure contains two validity scales measuring under-response and hyperresponse, as well as five clinical scales that assess anxiety, depression, anger, posttraumatic stress, and dissociation (with two subscales). This measure includes anxiety, depression and anger in addition to the measurement of traumatic stress symptoms given the frequency of which these related symptoms are experienced by traumatized children and adolescents (Briere, 1996).

The measure was designed to be administered to children by presenting them with a list of feelings, thoughts and behaviors, and they are asked to report on how often they experience them (Briere, 1996). Each item has a corresponding 4-point scale ranging from 0 (never) to 3 (almost all of the time). The responses on each scale are summed to obtain the raw score. Then, raw scores are converted to their corresponding $T$ scores determined by age group and gender. All scores 1.5 standard deviations at or above the mean $(T=65)$ are considered clinically significant, though $T$ scores in the range of 60 to 65 are considered indicative of subclinical but significant symptomatology (Briere, 1996). The interpretation of scores is based on normative data from a sample of 3,008 children from the general population. Extensive analyses of reliability and validity have 
been conducted for this measure. It has been found to have good construct and predictive validity in numerous studies with both clinical and non-clinical samples (Elliott \& Briere, 1994; Lanktree et al., 2008; Wherry, Graves, \& Rhodes, 2008). Alpha coefficients reported for the clinical subscales range from .82 to .89 (Briere, 1996).

The 10-item Posttraumatic Stress clinical scale was utilized as the dependent variable for the first model in this study. Raw scores range from 0 to 30 . This scale contains items relating to "classic posttraumatic stress symptoms including intrusive thoughts, sensations and memories of past events; nightmares; fears of men or women; and cognitive avoidance of negative thoughts and memories" (Briere, 1996, p. 13). Sample items include, "Scary ideas or pictures just pop into my head," "Feeling scared of men," and "Can't stop thinking about something bad that happened to me."1

Trauma Symptom Checklist for Young Children (TSCYC). The TSCYC is another instrument used to measure traumatic stress reactions in children in this study via caregiver report (Briere, 2005). The 90-item item checklist is also intended to be administered to children with known exposures to traumatic events including physical abuse, sexual abuse, disasters, witnessing of violence and other forms of victimization. It contains two validity scales and nine clinical scales that measure traumatic stress in terms of intrusion, avoidance, arousal, dissociation and total posttraumatic stress, as well other symptoms frequently experienced by traumatized children including anxiety, depression, anger/aggression, and sexual concerns.

\footnotetext{
${ }^{1}$ Adapted and reproduced by special permission of the Publisher, Psychological Assessment Resources, Inc., 16204 North Florida Avenue, Lutz, Florida 33549, from the Trauma Symptom Checklist for Children by John Briere, PhD, Copyright 1989, 1995 by PAR. Further reproduction is prohibited without permission from PAR.
} 
The measure was designed to be administered to caregivers by presenting them with a list of things children often feel, think or do, and they are asked to report on how often their children appear to have these experiences (Briere, 1996). Each item has a corresponding 4-point scale ranging from 1 (not at all) to 4 (very often). The responses on each scale are summed to obtain the raw score. Then, raw scores are converted to their corresponding $T$ scores determined by age group and gender. For all scores except the Posttraumatic Stress-Total score, $T$ scores between 65 and 69 are interpreted as potentially problematic, and scores at 70 or above indicate clinically significant distress (Briere, 2005). Posttraumatic Stress-Total $T$ scores in the 65 to 69 range indicate mild to moderate posttraumatic stress, and scores of 70 or above indicate "relatively severe posttraumatic disturbance" (Briere, 2005, p. 15). The interpretation of scores is based on normative data from a sample of 750 children from the general population. Extensive analyses of reliability and validity have been conducted for this measure. It has been found to have good construct, predictive and discriminant validity in numerous studies with both clinical and non-clinical samples (Briere et al., 2001; Finkelhor, Ormrod, \& Turner , 2004; Gilbert, 2004). Alpha coefficients reported for the clinical subscales range from .78 to .92 (Briere et al., 2001; Gilbert, 2004).

The Posttraumatic Stress-Total clinical scale was utilized as the dependent variable for the first model in this study. Raw scores range from 27 to 108 because the Total score is the sum of the three other Posttraumatic Stress scales (intrusion, avoidance, and arousal). This summary scale evaluates the combination of posttraumatic symptoms experienced by children. 
The 9-item Posttraumatic Stress-Intrusion clinical scale was also utilized as a dependent variable for one of the models. Raw scores range from 9 to 36 . This scale measures experiences of "Nightmares, posttraumatic play, flashbacks, fear in response to trauma-reminiscent events, and being upset by traumatic memories" (Briere, 2005, p. 2). "Bad dreams or nightmares" is a sample item from this scale. ${ }^{2}$

The 9-item Posttraumatic Stress-Avoidance clinical scale was utilized as another dependent variable for one of the models. Raw scores range from 9 to 36 . This scale measures experiences of "Avoiding people, places, and situations reminiscent of a traumatic event, emotional numbing, unwillingness to speak about a traumatic event, and difficulties fully remembering a trauma" (Briere, 2005, p. 2). "Not wanting to go somewhere that reminded him or her of a bad thing from the past" is a sample item from this scale.

The 9-item Posttraumatic Stress-Arousal clinical scale was also utilized as a dependent variable for one of the models. Raw scores range from 9 to 36 . This scale measures experiences of "Posttraumatic stress symptoms associated with autonomic hyperarousal, including jumpiness, tension, attention and concentration problems, and sleep problems" (Briere, 2005, p. 2). "Watching out everywhere for possible danger" is a sample item from this scale.

\section{Independent Variables}

Child Welfare Trauma Referral Tool (CWTRT). The CWTRT (Taylor, Steinberg, \& Wilson, 2006) was utilized to measure child welfare workers' reports regarding trauma

\footnotetext{
${ }^{2}$ Adapted and reproduced by special permission of the Publisher, Psychological Assessment Resources, Inc., 16204 North Florida Avenue, Lutz, Florida 33549, from the Trauma Symptom Checklist for Young Children by John Briere, PhD, Copyright 1999, 2005 by PAR. Further reproduction is prohibited without permission from PAR.
} 
history, traumatic stress and related distress in children from their caseloads. This measure can be reviewed in Appendix A (public domain, authors' permission received). It contains 35 trauma-related and clinical items, as well as two basic information questions regarding the child's age and number of months in current placement. This measure is completed by the workers based on their knowledge of the child from direct observation, record review and caregiver and other collateral reports. It is designed for use with children and adolescents aged 1-20. The tool contains a related decision-making structure to connect the child's experiences and reactions to the level of mental health services indicated (Taylor, Steinberg, \& Wilson, 2006). This measure has not been tested in a normative sample, and there is no associated scoring mechanism. It is designed to be a screening tool meant to guide decision-making.

The CWTRT contains 14 trauma exposure items. Workers are asked to rate whether the child has experienced any of these events by responding yes, suspected, no or unknown. They are then asked to endorse what ages the child experienced each event. The list of possible traumatic events includes sexual abuse, physical abuse, emotional abuse, neglect, serious accident or illness, witness to domestic violence, victim/witness to community violence, natural or manmade disasters, war/terrorism/political violence, traumatic grief and systems-induced trauma.

The CWTRT asks workers to rate whether children have experienced four types of traumatic stress symptoms. For each item, they are asked to report on the presence of these symptoms as yes, suspected, no or unknown.

The measure defines re-experiencing for the workers as symptoms consisting of "difficulties with intrusive memories or reminders of traumatic events, including 
nightmares, flashbacks, intense reliving of the events and repetitive play with themes of specific traumatic experiences. Also included is pronounced reactivity to trauma or loss reminders" (Taylor, Steinberg, \& Wilson, 2006, p. 3).

This measure defines Avoidance for the workers as symptoms including "efforts to avoid stimuli associated with traumatic experiences. The child may avoid certain places or people, or avoid discussing the specifics of the trauma" (Taylor, Steinberg, \& Wilson, 2006, p. 3).

This measure defines Numbing for the workers as symptoms including "feelings of detachment or estrangement from others, restricted range of emotion (e.g. unable to have loving feelings, feeling out of sync with others, or having sense of a foreshortened future)" (Taylor, Steinberg, \& Wilson, 2006, p. 3).

This measure defines Arousal for the workers as symptoms consisting of "difficulties with hypervigilance (an exaggerated awareness of potential dangers), difficulty concentrating, exaggerated startle reactions, difficulties falling or staying asleep, and irritability or outbursts of anger. Children with these symptoms often seem distractible, impulsive and inattentive, leading to a common misdiagnosis of ADHD” (Taylor, Steinberg, \& Wilson, 2006, p. 3).

The CWTRT also contains several additional items measuring related symptoms often observed in traumatized children and adolescents. The workers are directed to rate their observations of these items as yes, suspected, no or unknown. The remaining scale contains one attachment item, four behavioral items requiring immediate stabilization (suicidal intent, substance abuse, eating disorder, and serious sleep disturbance), and twelve items measuring current reactions/behaviors/functioning (anxiety, depression, 
affect dysregulation, dissociation, somatization, attention/concentration, suicidal behavior, self-harm, regression, impulsivity, oppositional behaviors, and conduct problems). These items were not included in the proposed analysis due to this study's specific focus on workers' abilities to predict traumatic stress symptomatology. 
Table 3.1. CBCL Scores for Children in the Sample.

\begin{tabular}{|c|c|c|}
\hline Problem scale & Mean/SD & $\%$ above clinical cutoff \\
\hline Emotionally-reactive & $57.54 / 12.18$ & 16.9 \\
\hline Anxious-depressed & $55.42 / 7.54$ & 7.1 \\
\hline Somatic complaints & $54.76 / 6.66$ & 5.4 \\
\hline Withdrawn & $57.11 / 8.95$ & 10.8 \\
\hline Sleep problems & $55.98 / 10.08$ & 7.7 \\
\hline Social problems* & $57.52 / 7.69$ & 12.5 \\
\hline Thought problems* & $57.41 / 8.41$ & 13.3 \\
\hline Attention problems & $58.45 / 10.17$ & 14.9 \\
\hline Rule-breaking behavior* & $57.88 / 8.06$ & 11.4 \\
\hline Aggressive behavior & $58.23 / 11.27$ & 13.3 \\
\hline Affective problems & $56.44 / 8.44$ & 12.5 \\
\hline Anxiety problems & $56.75 / 8.49$ & 12.6 \\
\hline Pervasive developmental problems $* *$ & $58.78 / 10.35$ & 20.0 \\
\hline ADHD problems & $57.02 / 8.17$ & 8.9 \\
\hline Oppositional-defiant problems & $57.32 / 8.70$ & 12.5 \\
\hline Conduct problems* & $59.10 / 9.42$ & 17.1 \\
\hline \multicolumn{3}{|c|}{ *Scale only included on the CBCL for ages 6-18 } \\
\hline
\end{tabular}

Copyright (C) Adrienne Whitt-Woosley 2016 


\section{Chapter 4}

\section{Results}

PASW 21.0 was utilized for data analysis. The data set was visually examined and frequency distributions were obtained in order to identify missing data. Univariate analyses were conducted to examine the factors and outcome variables for this sample. Correlational analysis was also conducted to examine bivariate relationships between the independent and dependent variables. A series of four hierarchical regressions were run to test the hypotheses. A priori power analysis indicated that a sample size of 76 would be sufficient to achieve a medium effect at 80 percent power $(p=.05)$.

Bivariate and multivariate analyses were conducted with and without the inclusion of outliers. Following examination of the results, 8, 9, 9, and 6 cases were removed to omit outliers from the analyses regarding models one through four respectively. These cases included those with $T$ scores on the dependent variable $\geq 110$. Additional cases were omitted due to missing data (less than 5 percent), resulting in final sample sizes for the models testing outcomes of total posttraumatic stress, intrusion, avoidance and arousal being 117, 97, 97, and 97 respectively.

\section{Univariate Analysis of Outcome Variables}

Descriptive analyses found that the children in this sample were experiencing high rates of distress as indicated by their self-reported responses, as well as the reports from their caregivers and child welfare workers. The children self-reported the lowest rate of clinically concerning (potentially problematic-clinically significant) total posttraumatic

stress at 21.1 percent, followed by caregiver reports at 40.6 percent and worker reports at 40.8 percent. Examination of specific symptoms of posttraumatic stress indicated that 
both caregivers and child welfare workers observed the presence of concerning levels of arousal in the children more frequently than the other symptoms at rates of 38.4 and 49.4 percent respectively. The TSCC-A provides scoring for only total posttraumatic stress, dissociation and related conditions, which prevented comparisons of caregiver and worker reports on specific trauma symptoms to child reports. Table 4.1 provides more detail regarding the symptoms of posttraumatic stress observed in the sample by reporting source and rates of children experiencing these conditions at or above the cutoff for clinical concern (TSCC-A, $T \geq 60$; TSCYC, $T \geq 65$ ). The cutoffs for clinical concern or potential problems rather than clinical significance were applied to this descriptive analysis given research suggesting that any observation of clinically concerning trauma symptoms warrants full assessment and/or intervention, especially with younger children given the assessment challenges with regard to child traumatic stress (Ai et al., 2013; Kolko et al., 2010).

\section{Bivariate Analysis of Variables}

Bivariate analyses were conducted to examine potential relationships among the variables conceptually indicated for inclusion in the models designed to test the two hypotheses. Additional correlational analysis was conducted regarding these variables and other variables from the data set regarding trauma exposure typology and the related conditions included on the TSCC-A. This additional analysis was included to provide further context for understanding the sample and implications of findings. The analyses

revealed several significant relationships among the variables, particularly between child welfare worker and caregiver observations of traumatic stress. Moderate, significant relationships were noted regarding their reports of total posttraumatic stress $(r=.340, p \leq$ 
$.001)$, intrusion $(r=.438, p \leq .001)$ and avoidance $(r=.340, p \leq .001)$ in the sample. A significant but weak relationship was observed between worker reports of total posttraumatic stress and caregiver reports on measures of arousal $(r=.194, p \leq .05)$ in the children sampled. A moderate and significant relationship was observed between child and caregiver reports of total posttraumatic stress $(r=.302, p \leq .001)$, but the relationship between worker and child reports was not significant.

Additionally, it was notable that child age did not relate significantly to the other variables. Child age was observed to have inverse relationships, though insignificant, with all variables regarding trauma symptoms and trauma history. Trauma history was found to have a moderate, significant correlation with both worker $(r=.419, p \leq .001)$ and caregiver $(r=.271, p \leq .001)$ reports of total posttraumatic stress, but there was not a significant relationship observed with regard to child reports of total posttraumatic stress. Table 4.2 provides a summary of the correlations observed between the independent and outcome variables.

Further correlational analysis including additional variables from the data set revealed several significant relationships, though most were weak. Some moderate, significant relationships observed included those between emotional abuse and physical abuse histories $(r=.384, p \leq .001)$, domestic violence and physical abuse $(r=.327, p \leq .001)$, emotional abuse and domestic violence $(\mathrm{r}=.308, p \leq .001)$, emotional abuse and systems induced trauma $(r=.321, p \leq .001)$, and community violence and school violence exposures $(r=.324, p \leq .001)$. With regard to relationships between trauma exposure history and reports of traumatic stress symptoms, only a few significant relationships were observed. Serious illness and medical procedures exhibited a moderate, significant 
relationship with depression as reported by children on the TSCC-A $(r=.374, p \leq .001)$.

Also, histories of sexual abuse were found to be significantly related to caregiver reports of child traumatic stress symptoms of intrusion $(r=.220, p \leq .05)$ and avoidance $(r=.234$, $p \leq .05)$

\section{Multivariate Analysis}

Multiple tests were completed to determine whether all necessary assumptions were met prior to conducting the four hierarchical regressions designed to test the hypotheses. Scatterplots, histograms, normal probability plots, correlation tables, residual plots, collinearity diagnostics and results from additional tests (tests of normality, Levene's, Durbin-Watson) were examined to determine if assumptions regarding linearity, normality, homoscedasticity, independent errors and absence of multicollinearity were met. All assumptions were met with the exception of normality concerns regarding the dependent variables being negatively skewed as evidenced by analysis of histograms, values for skewness and kurtosis and tests of normality (Kolmogorov-Smirnov, ShapiroWilk), which were significant for all four dependent variables. Linearity with regard to child age and the dependent variables was another concern as evidenced by examination of residual plots. Log transformation of the dependent variables is a recommended strategy to optimize data with regard to meeting both of these assumptions, which was achieved for the analyses (Howell, 2007; Kutner, Nachtsheim, \& Neter, 2004;

Tabachnick \& Fidell, 2007). Next, the baseline models were run, followed by analyses utilizing the log transformations of the dependent variables and omission of outliers. The revised models resulted in more than a 2 percent increase in $R^{2}$. Therefore, it was determined to interpret the revised models for testing of both hypotheses. Other 
transformation models were not attempted. The dependent variables were not transformed for the univariate and bivariate analyses reported.

Hierarchical regression models were analyzed to examine relationships between child welfare workers' knowledge of child age, trauma history and total posttraumatic stress with child and caregiver reports of posttraumatic stress symptoms. Four models were tested to specifically examine outcomes regarding total posttraumatic stress, intrusion, avoidance and arousal.

\section{Testing of Hypothesis 1}

$\mathrm{H}_{1}$ : Utilizing knowledge of a child's age, trauma exposure history and a child's emotions and behaviors, child welfare workers are able to effectively predict posttraumatic stress scores indicated on clinical measures.

The first hierarchical regression model was designed to test this hypothesis. The predictors in the model included child age, trauma history and total posttraumatic stress reported by child welfare workers. They were entered in this order in three steps, which was meant to represent the chronology with which workers' acquire and utilize information regarding children from their caseloads. The dependent variable for the model was log total posttraumatic stress reported by the child (if available) or the caregiver (if child score was not available due to child age).

This hierarchical regression model revealed that at step one child age contributed significantly to the model, $F(1,115)=19.570, p \leq .001$. The inclusion of this factor accounted for 14.5 percent of the variance. The addition of trauma history into the model explained 3.8 percent more of the variance and this change in $R^{2}$ was significant, $F(1$, $114)=12.733, p \leq .001$. Including total posttraumatic stress reported by the child welfare 
workers explained an additional 3.5 percent of the variance and this change in $R^{2}$ was also significant, $F(1,113)=10.494, p \leq .001$. When all three independent variables were entered into the model in step three, trauma history was no longer a significant predictor. In combination, the three independent variables accounted for 21.8 percent of the variance in the dependent variable. Table 4.3 summarizes these findings.

\section{Testing of Hypothesis 2}

$\mathrm{H}_{2}$ : Child welfare workers are more effective at identifying symptoms of intrusion than avoidance and arousal in trauma-exposed children.

Three additional hierarchical regression models were designed to test this hypothesis by allowing for examination of child welfare workers' effectiveness in predicting three different symptom manifestations of traumatic stress as this may have important implications for training workers on the screening process. The predictors in each of these models remained the same as the initial model and were entered in the same order in three successive steps. Each of these hierarchical regression models has a different outcome variable of intrusion, avoidance or arousal as reported by the caregivers on the TSCYC.

The first of these hierarchical regression models examined the dependent variable log intrusion and revealed that at step one child age did not contribute significantly to the model, $F(1,95)=.003, p=.957$. The addition of trauma history into the model explained 6.4 percent of the variance and this change in $R^{2}$ was significant, $F(1,94)=3.204, p \leq .05$. Including total posttraumatic stress reported by the child welfare workers explained an additional 14.7 percent of the variance and this change in $R^{2}$ was also significant, $F(1$, $93)=8.266, p \leq .001$. When all three independent variables were entered into the model in 
step three, neither child age or trauma history remained significant predictors. In combination, the three independent variables accounted for 21.1 percent of the variance in the dependent variable. Table 4.4 summarizes these findings.

The next hierarchical regression model for this hypothesis examined the dependent variable log avoidance and revealed that at step one child age did not contribute significantly to the model, $F(1,95)=.350, p=.555$. The addition of trauma history into the model explained 12.5 percent of the variance and this change in $R^{2}$ was significant, $F$ (1, $94)=6.737, p \leq .01$. Including total posttraumatic stress reported by the child welfare workers explained an additional 7.2 percent of the variance and this change in $R^{2}$ was also significant, $F(1,93)=7.609, p \leq .001$. When all three independent variables were entered into the model in step three, only child age was not significant as a predictor. In combination, the three independent variables accounted for 19.7 percent of the variance in the dependent variable. Table 4.5 summarizes these findings.

The next hierarchical regression model for this hypothesis examined the dependent variable log arousal and revealed that at step one child age did not contribute significantly to the model, $F(1,95)=1.996, p=.161$. The addition of trauma history into the model was also not significant, $F(1,94)=2.649, p=.076$. Including total posttraumatic stress reported by the child welfare workers did result in a significant change in $R^{2}, F(1,93)=$ $3.120, p \leq .05$. When all three independent variables were entered into the model in step three, neither child age or trauma history was a significant predictor. In combination, the three independent variables accounted for 9.1 percent of the variance in the dependent variable. Table 4.6 summarizes these findings. 


\section{Additional Analysis}

Given the focus of this analysis as stated in the first hypothesis on examining whether child welfare workers are effective in screening for child traumatic stress, additional analyses were conducted to determine the effect sizes attributable to the addition of step 3 (workers' assessments of total posttraumatic stress) in each of the four models. For the

first model testing $\mathrm{H}_{1}$, Cohen's effect size value $\left(f^{2}=.05\right)$ indicated a small effect. For the second model testing $\mathrm{H}_{2}$, Cohen's effect size value $\left(f^{2}=.19\right)$ indicated a medium effect. For the third model testing $\mathrm{H}_{2}$, Cohen's effect size value $\left(f^{2}=.09\right)$ indicated a small effect. For fourth model testing $\mathrm{H}_{2}$, Cohen's effect size value $\left(f^{2}=.04\right)$ indicated a small effect.

Analyses were also conducted to further explore the second hypothesis regarding child welfare workers' abilities to screen for different types of traumatic stress symptoms. Given that the workers appeared much less effective in their efforts to screen for symptoms of arousal as compared to intrusion and avoidance, further examination of the children with clinically significant arousal scores (TSCYC, $T \geq 70$ ) was indicated. A series of $t$-tests were conducted to examine differences between these children and the rest of the sample. The children with clinical levels of arousal were found to be younger on average though this difference was not statistically significant. The children in the arousal group had significantly more exposure to different trauma types, higher traumatic stress reported by caregivers in all domains and higher scores on all problem scales included on the CBCL. While child welfare workers reported more total posttraumatic stress for the children in the arousal group on average, this difference was not statistically significant. A summary of these group differences is provided in Table 4.7. 
Frequency distributions of the CBCL scores for the arousal group were also examined to determine what other problems these children may be presenting clinically that could potentially interfere with the workers' abilities to screen for traumatic stress. The highest rates (33.3 percent) of clinically significant problems for the group overall were in the domains of emotional-reactivity, conduct and thought problems. Rule-breaking behavior (29.6 percent), attention problems (26.4 percent), affective problems (26.4 percent) and aggression (26.0 percent) were also frequently reported as clinically significant issues for the arousal group. Clinically significant pervasive developmental problems in the younger children from the arousal group were reported at a higher rate than in the full sample (38.5 percent versus 20.0 percent). 
Table 4.1. Description of Posttraumatic stress (PTS) and Related Symptoms by Child, Caregiver and Worker Report.

\begin{tabular}{|c|c|c|c|}
\hline Source/Measure & Symptom & Mean/SD & $\begin{array}{l}\% \text { above cutoff/ } \\
\text { reported as present }\end{array}$ \\
\hline Child/TSCC-A & Total PTS & $47.37 / 11.21$ & 21.1 \\
\hline Child/TSCC-A & Anxiety & $47.88 / 12.07$ & 14.5 \\
\hline Child/TSCC-A & Depression & $45.89 / 10.56$ & 7.9 \\
\hline Child/TSCC-A & Anger/Aggression & $45.16 / 9.76$ & 9.2 \\
\hline Child/TSCC-A & Dissociation & $47.91 / 11.34$ & 11.8 \\
\hline Child/TSCC-A & Dissociation-Overt & $48.63 / 11.2$ & 14.5 \\
\hline Child/TSCC-A & Dissociation-Fantasy & $47.81 / 10.69$ & 13.3 \\
\hline Caregiver/TSCYC & Total PTS & $63.55 / 20.25$ & 40.6 \\
\hline Caregiver/TSCYC & Intrusion & $61.56 / 20.94$ & 34.1 \\
\hline Caregiver/TSCYC & Avoidance & $62.78 / 20.83$ & 37.0 \\
\hline Caregiver/TSCYC & Arousal & $61.04 / 17.79$ & 38.4 \\
\hline Worker/CWTRT & Total PTS & $5.84 / 2.75$ & 40.8 \\
\hline Worker/CWTRT & Re-experiencing & N/A & 37.4 \\
\hline Worker/CWTRT & Avoidance & N/A & 32.6 \\
\hline Worker/CWTRT & Numbing & N/A & 30.0 \\
\hline Worker/CWTRT & Arousal & N/A & 49.4 \\
\hline
\end{tabular}


Table 4.2. Bivariate Correlations Between the Independent and Outcome Variables in the Analysis.

\begin{tabular}{|c|c|c|c|c|c|c|c|c|}
\hline Variables & 1 & 2 & 3 & 4 & 5 & 6 & 7 & 8 \\
\hline $\begin{array}{c}\text { 1. Child age } \\
\text { (years) }\end{array}$ & & - & & & & & & \\
\hline $\begin{array}{l}\text { 2. Trauma history } \\
\text { (total) }\end{array}$ & -0.137 & - & & & & & & \\
\hline $\begin{array}{l}\text { 3. Total PTS } \\
\text { (worker) }\end{array}$ & -0.063 & $.419 * *$ & - & & & & & \\
\hline $\begin{array}{l}\text { 4. Total PTS } \\
\text { (TSCC-A) }\end{array}$ & -0.144 & 0.048 & -0.034 & - & & & & \\
\hline $\begin{array}{r}\text { 5. Total PTS } \\
(\mathrm{TSCYC})\end{array}$ & -0.059 & $.271 * *$ & $.340 * *$ & $.302 *$ & - & & & \\
\hline $\begin{array}{l}\text { 6. Intrusion } \\
\text { (TSCYC) }\end{array}$ & -0.035 & $.234^{*}$ & $.438 * *$ & 0.216 & $.894 * *$ & - & & \\
\hline $\begin{array}{l}\text { 7. Avoidance } \\
\text { (TSCYC) }\end{array}$ & -0.023 & $.317 * *$ & $.340 * *$ & 0.258 & $.916^{* *}$ & $.783 * *$ & - & \\
\hline $\begin{array}{l}\text { 8. Arousal } \\
\text { (TSCYC) }\end{array}$ & -0.162 & 0.144 & $.194^{*}$ & $.316^{*}$ & $.878 * *$ & $.672 * *$ & $.717 * *$ & - \\
\hline
\end{tabular}


Table 4.3. Hierarchical Regression of Total Posttraumatic Stress (TSCC-A/TSCYC) from Child Welfare Workers' Trauma Screening Information.

\begin{tabular}{llllll}
\hline Predictor & $B$ & $R^{2}$ & $\Delta R^{2}$ & $F$ & $\Delta F$ \\
\hline Step 1 & & & & & \\
Child age & $-.381 * *$ & .145 & .145 & $19.570^{* *}$ & $19.570^{* *}$ \\
Step 2 & & & & \\
Child age & $-.347 * *$ & & & & \\
Trauma history & $.196^{*}$ & .183 & .037 & $12.733^{* *}$ & $5.183^{*}$ \\
Step 3 & & & & \\
Child age & -.346 & & & & \\
Trauma history & .110 & & & & \\
Total PTS (worker) & $.207 *$ & .218 & .035 & $10.494 * *$ & $5.100^{*}$ \\
$* p \leq .05, * * p \leq .001$ & & & &
\end{tabular}

Table 4.4. Hierarchical Regression of Posttraumatic Stress-Intrusion (TSCYC) from Child Welfare Workers' Trauma Screening Information.

\begin{tabular}{llllll}
\hline Predictor & $B$ & $R^{2}$ & $\Delta R^{2}$ & $F$ & $\Delta F$ \\
\hline Step 1 & & & & & \\
Child age & -.006 & .000 & .000 & .003 & .003 \\
Step 2 & & & & \\
Child age & -.007 & & & & \\
Trauma history & $.253^{*}$ & .064 & .064 & $3.204 *$ & $6.405^{*}$ \\
Step 3 & & & & \\
Child age & -.025 & & & & \\
Trauma history & .083 & & & & \\
Total PTS (worker) & $.420 * *$ & .211 & .147 & & \\
$* p \leq .05$, * $p \leq .001$ & & & & &
\end{tabular}


Table 4.5. Hierarchical Regression of Posttraumatic Stress-Avoidance (TSCYC) from Child Welfare Workers' Trauma Screening Information.

\begin{tabular}{llllll}
\hline Predictor & $B$ & $R^{2}$ & $\Delta R^{2}$ & $F$ & $\Delta F$ \\
\hline Step 1 & & & & & \\
Child age & -.061 & .004 & .004 & .350 & .350 \\
Step 2 & & & & & \\
Child age & -.044 & & & & \\
Trauma history & $.349 * *$ & .125 & .122 & $6.737 *$ & $13.079 * *$ \\
Step 3 & & & & & \\
Child age & -.031 & & & & \\
Trauma history & $.230 *$ & & & & \\
Total PTS (worker) & $.294 *$ & .197 & & & \\
$* p \leq .05, * 072$ & & &
\end{tabular}

Table 4.6. Hierarchical Regression of Posttraumatic Stress-Arousal (TSCYC) from Child Welfare Workers' Trauma Screening Information.

\begin{tabular}{llllll}
\hline Predictor & $B$ & $R^{2}$ & $\Delta R^{2}$ & $F$ & $\Delta F$ \\
\hline Step 1 & & & & & \\
Child age & -.143 & .021 & .021 & 1.996 & 1.996 \\
Step 2 & & & & \\
Child age & -.135 & & & & \\
Trauma history & .181 & .053 & .033 & 2.649 & 3.255 \\
Step 3 & & & & \\
Child age & -.126 & & & & \\
Trauma history & .094 & & & & \\
Total PTS (worker) & $.214 *$ & .091 & & & \\
$* p \leq .05, * * p \leq .001$ & & & &
\end{tabular}


Table 4.7. Comparison of Children with Elevated Arousal Scores on the TSCYC to the Rest of the Sample.

\begin{tabular}{|c|c|c|c|}
\hline Variable & $\begin{array}{l}\text { Arousal Group } \\
\text { Mean/SD }\end{array}$ & $\begin{array}{l}\text { Non-Arousal Group } \\
\text { Mean/SD }\end{array}$ & $t$-scores \\
\hline Child age & $6.28 / 2.87$ & $6.67 / 2.98$ & -0.766 \\
\hline Trauma history (number, types) & $5.05 / 2.12$ & $4.13 / 1.89$ & $2.308 *$ \\
\hline TSCYC Intrusion & $76.22 / 21.66$ & $51.84 / 13.56$ & $7.435 * *$ \\
\hline TSCYC Avoidance & $77.44 / 21.77$ & $53.07 / 13.16$ & $7.446^{* *}$ \\
\hline TSCYC Total Trauma & $75.09 / 22.49$ & $49.26 / 9.89$ & $8.016 * *$ \\
\hline CWTRT Total Trauma & $6.38 / 3.09$ & $5.41 / 2.58$ & 1.787 \\
\hline CBCL Emotional-reactivity & $62.45 / 15.80$ & $53.58 / 5.94$ & $2.862 * *$ \\
\hline CBCL Anxious-depressed & $58.36 / 9.29$ & $53.98 / 5.93$ & $3.108 * *$ \\
\hline CBCL Somatic complaints & $56.91 / 8.08$ & $53.54 / 5.79$ & $2.649 * *$ \\
\hline CBCL Withdrawn & $59.35 / 9.99$ & $55.40 / 8.04$ & $2.444 *$ \\
\hline CBCL Sleep problems & $60.03 / 13.44$ & $52.72 / 4.10$ & $2.826 * *$ \\
\hline CBCL Social problems & $59.81 / 9.64$ & $55.58 / 5.87$ & $2.075^{*}$ \\
\hline CBCL Thought problems & $61.93 / 10.91$ & $54.88 / 6.45$ & $3.070 * *$ \\
\hline CBCL Attention problems & $62.15 / 11.41$ & $55.71 / 7.69$ & $3.665 * *$ \\
\hline CBCL Rule-breaking behavior & $62.59 / 9.98$ & $55.79 / 6.58$ & $3.174 * *$ \\
\hline CBCL Aggression & $62.50 / 14.59$ & $56.35 / 8.87$ & $2.739 * *$ \\
\hline CBCL Affective problems & $60.20 / 10.67$ & $54.36 / 6.47$ & $3.638 * *$ \\
\hline CBCL Anxiety problems & $60.00 / 10.29$ & $54.57 / 6.83$ & $3.435 * *$ \\
\hline CBCL Pervasive dev. Problems & $62.57 / 12.30$ & $55.92 / 7.57$ & $2.522 *$ \\
\hline CBCL ADHD problems & $59.36 / 8.74$ & $55.25 / 7.37$ & $2.977 * *$ \\
\hline CBCL ODD problems & $61.02 / 10.81$ & $55.43 / 6.59$ & $3.431 * *$ \\
\hline $\begin{array}{l}\text { CBCL Conduct problems } \\
*_{p} \leq .05, * *_{p} \leq .01\end{array}$ & $64.48 / 11.24$ & $57.29 / 8.08$ & $2.926 * *$ \\
\hline
\end{tabular}

Copyright (C) Adrienne Whitt-Woosley 2016 


\section{Chapter 5}

\section{Discussion}

The results from this study support the hypothesis postulated that child welfare workers can be an effective resource for identifying maltreated children's traumatic stress symptoms. This implication, if confirmed through further research, is of enormous practical significance given that all children in the system have access to a child welfare worker even when they may not have a mental health professional available to assist with the trauma screening process. Child welfare workers have generally not been utilized in the trauma screening role in most systems presumably because the systems have not yet acquired a trauma-informed perspective, as well as concerns that workers may not have sufficient knowledge of a child to assist with the screening process. Examining the utility of child welfare workers as trauma screeners sheds light on ways to develop resources to address the public health issue of trauma exposure and the consequences of adverse experiences among maltreated children. It also provides an opportunity to tailor training needs to improve workers' functionality in this role. The findings of this study supported the second hypothesis postulated that child welfare workers are most effective at identifying intrusive symptoms associated with traumatic stress. It was found that they were least effective in screening for symptoms of arousal, which suggests an avenue for targeted training of child welfare workers on the trauma screening process.

\section{Experiences of Traumatic Stress in Children from the Sample}

The analyses revealed a sample of children with high rates of trauma exposure and traumatic stress, which implies the need for trauma screening and underscores the 
complexity of trauma screening with this group especially given their younger age overall (mean $=7.75, \mathrm{SD}=3.90)$. Findings in this area seemed generally consistent with previous research on the trauma experiences of maltreated children. The children self-reported the lowest rate of clinically concerning posttraumatic stress symptoms at 21.1 percent, compared to the nearly identical rates reported for the sample by child welfare workers and caregivers which were approximately twice as high. Previous research has shown that younger children tend to underreport symptoms on self-reported trauma measures such as the TSCC-A (Butcher et al., 2013). This was likely a factor affecting the results from this sample. However, in spite of possible underreporting by the children themselves, this remains a high rate of posttraumatic stress symptoms, much greater than would be expected in a sample of children from the general population where rates of PTSD are estimated between 3 and 6 percent (DeBellis \& Van Dillen, 2005)..

In addition to the notable rates of posttraumatic stress symptoms observed, this sample was found to present with an overall pattern of chronic or complex trauma exposures historically. The sample had experienced on average 4 different types of trauma exposure, and correlational analysis revealed significant relationships between exposure to domestic violence, emotional abuse and physical abuse, thus presenting a particularly high risk context for the development of traumatic stress reactions. Correlational analysis also noted a subset of the sample with histories of injury or serious illness presenting with increased risks for depression, and those with sexual abuse exposures reporting higher levels of intrusive and avoidant symptoms. This suggests a possible need for more targeted screening with children with sexual abuse histories, including a need to screen for depression specifically for certain children in child welfare settings. Posttraumatic 
stress and depression have been found to commonly co-occur following trauma exposures in childhood and adolescence (Pecora et al., 2009; Thabet, Abed, \& Vostanis, 2004; Thienkrua et al., 2006; Widom, DuMont, \& Czaja, 2007).

Analysis of specific traumatic stress symptoms as reported by child welfare workers and caregivers revealed some interesting findings. Arousal was the symptom most frequently endorsed by both. However, child welfare workers endorsed this symptom approximately 11 percent more frequently than caregivers. It is possible that while arousal is a significant problem for children in this sample, child welfare workers may have been overestimating its occurrence due to difficulties distinguishing between the more observable behavioral indicators of arousal and symptoms of other disorders such as Attention Deficit Hyperactivity Disorder (ADHD). The Child Welfare Trauma Referral Tool (CWTRT), a less sensitive screening tool, defines arousal for workers in terms that may promote overestimations for this reason. The definition is as follows: "These symptoms consist of difficulties with hypervigilance (an exaggerated awareness of potential dangers), difficulty concentrating, exaggerated startle reactions, difficulties falling or staying asleep, and irritability or outbursts of anger. Children with these symptoms often seem distractible, impulsive and inattentive, leading to a common misdiagnosis of ADHD” (Taylor, Steinberg, \& Wilson, 2006, p. 3).

Further complicating matters, examination of the children with clinically elevated arousal scores revealed a complex picture. This group had significantly more trauma exposure types historically, higher rates of traumatic stress symptoms in other domains (total symptoms, intrusion, avoidance), and higher rates of symptoms reported on the problem 
scales of the CBCL. Similar to the sample overall, the arousal group presented a clinical profile of even more intensely emotional, inattentive, aggressive and behaviorally challenging children. Pervasive developmental issues were also significantly higher among the young children in this group.

Previous studies have documented the breadth of symptoms associated with childhood trauma, particularly in children with multiple trauma exposures (D’ Andrea, Ford, Stolbach, \& van der Kolk, 2012). Co-morbidity with PTSD has been estimated at 40 percent or higher for trauma-exposed youth, where co-occurring disruptive behavior, mood and anxiety disorders are common (Copeland et al., 2007; Ford et al., 2002). Differentiating between ADHD and traumatic stress has been shown to be particularly difficult, and it is not surprising that the least sensitive trauma screening tool utilized for this analysis produced higher rates in the domain of arousal (Becker-Blease \& Freyd, 2008; Conway, Oster, \& Szymanski, 2011; Syzmanski, Sapanski, \& Conway, 2011). Further, the definition of arousal on the CWTRT as cited above may increase the likelihood of endorsement of this symptom in the presence of many forms of behavioral dysregulation.

However, it is noteworthy that arousal is the specific trauma symptom most frequently reported by both caregivers and child welfare workers. The child self-report measure does not provide scores for arousal specifically, though it does look at related issues of anxiety, which along with dissociation, were reported at the highest rates of clinical concern on the TSCC-A. Anxiety and dissociation are both thought to present in trauma exposed children in ways that are difficult to distinguish from hyperarousal, ADHD and other disorders that include negative affectivity or that might overlap in symptomatic 
presentation (Cohen \& Scheeringa, 2009; D'Andrea, Ford, Stobach, Spinnazola, \& van der Kolk, 2012). It was also observed that caregiver reports of arousal and child reports of anxiety had a significant and positive correlation. It appears that arousal and associated difficulties are prominent issues of clinical concern for this sample as indicated by all reporting sources. All of these factors, result in trauma screening and assessment challenges, yet underscore the need to explore trauma as an underlying cause or comorbid condition in children with indications of externalizing behaviors, inattention, thought problems, and anxiety. The potential overlap between reported pervasive developmental problems and traumatic stress in maltreated children may present another area for targeted assessment.

\section{Trauma Screening Outcomes}

Findings from both bivariate and multivariate analyses confirmed many consistencies between the child welfare workers' and caregivers' screenings of child traumatic stress. While there were some significant relationships observed between caregiver and child reports of traumatic stress, there were not significant relationships noted between worker and child reports, which could be related in part to differences in the specificity of screening versus assessment measures. In general, child welfare workers were reporting the highest observations of distress while the children themselves were reporting the lowest rates. The discrepancy here was not unexpected especially given indications cited previously regarding underreporting on the TSCC-A, as well as previous research that demonstrates imperfect cross-informant overlap when assessing subtle internal states such as anxiety, depression and worry particularly with young children (Edelbrock et al., 1985; Silverman, Saavedra, \& Pina, 2001; Southam-Gerow, Fannery-Schroeder, \& 
Kendall, 2003). Due to these discrepancies in reporting and the potential for measurement effects, it has been suggested that using multiple informants likely provides the most clear clinical picture as different sources are more sensitive at assessing certain trauma symptom clusters (Lanktree et al., 2008). This may be what is reflected in the increased caregiver and worker reports of arousal symptoms which are more easily observed when manifested behaviorally, as opposed to the high rates of anxiety and dissociation reported by the children that are likely less discernible to outside observers.

The findings from the hierarchical regression models further indicate that if given an adequate screening mechanism that operationalizes traumatic stress terminology and organizes the workers' knowledge of a child's age, trauma exposure history and potential trauma symptoms indicated by the child's displays of emotion and behavior, child welfare workers appear similarly capable to caregivers at identifying traumatic stress in children from their caseloads. Child welfare workers demonstrated particular effectiveness with identifying symptoms of total posttraumatic stress, intrusion, and avoidance. The second hypothesis that workers would be most effective at identifying symptoms of intrusion compared to other manifestations of traumatic stress (avoidance, arousal) was supported. Results from the analyses suggested they were least effective in identifying symptoms of arousal. It may be that workers are equating arousal with some of the more externalizing symptoms reportedly displayed by the children in this sample, thus resulting in a tendency to over-endorse symptoms in this domain of traumatic stress. These findings suggest the need for a more sensitive screening tool and additional training in this area given the issues of co-morbidity and overlap with symptoms of behavioral disorders discussed previously. In terms of workers' abilities to predict 
symptoms of total posttraumatic stress, the domain where they appeared most effective, information regarding age and observations of potential trauma symptoms were the most significantly predictive factors. A negative relationship was noted with age, indicating that the younger children in the group were observed to be more symptomatic. This is consistent with some studies that have found age to be a risk factor for maltreated children with higher rates of traumatic stress being reported at both ends of the age continuum; in very young children and older adolescents (Fusco \& Cahalane, 2013; Kolko et al., 2010; Griffin et al., 2012). This was a younger sample of children overall, and a sample of children exhibiting high rates of clinically concerning problems in a variety of domains. The correlational and additional analyses conducted suggested that age not only had an inverse relationship with traumatic stress symptoms, but also with trauma exposure. This indicates that special attention to trauma screening is warranted for younger children with more complex trauma exposure histories.

Significant predictors in the subsequent models were noted as well. Following total posttraumatic stress, the child welfare workers were most effective at predicting symptoms of intrusion. Trauma history was a significantly predictive factor in this model, which is likely due to this category of symptoms being more directly linked to the child's particular history of exposure. Knowledge of the child's trauma history would plausibly improve the workers' abilities to correctly identify intrusive symptoms such as distressing images, thoughts or memories of traumatic events. Lastly, the workers were only slightly less effective at predicting symptoms of avoidance. Trauma history and potential trauma symptoms were significant factors. The importance of having knowledge of a child's trauma history was also likely critical here in that without this 
knowledge as context, it would be more difficult or even impossible to identify a child's efforts to avoid reminders of those events.

\section{Limitations}

While this study provides some useful insights into the experiences of a sample of children in the child welfare system and efforts to screen them for symptoms of traumatic stress, there are some notable limitations. First, this was not a randomly selected sample that can be assumed to be representative of the general child welfare population, thus generalizability is limited. The children included in the sample were all referred by their child welfare workers to an assessment clinic that serves high-risk families. Therefore, the findings from this sample may not be as representative of lower risk cases involved with child welfare that are receiving less intervention. It is possible those children may not have complex trauma histories or pose the same trauma screening challenges to workers, though previous studies have identified that trauma concerns are prevalent for children at all levels of child welfare involvement (Greeson et al., 2011; Kolko et al., 2010). The sample utilized for this study does, however, present a similar age profile of being younger with average ages between 6 and 8 years and the high rates of multiple trauma exposures confirmed by other surveys of the general child welfare population indicating similarities regarding factors known to affect traumatic stress outcomes (Child Welfare Information Gateway, 2015; Kolko et al., 2010).

The sample size was also limited due to many children being too young to complete their own trauma measures or for caregivers to complete a measure on their behalf for comparison to the child welfare workers' screenings. Also, adolescents were ineligible for inclusion in the three models testing outcomes of intrusion, avoidance and arousal due 
to the age cutoff for the measure utilized. While power analysis confirmed the sample sizes were sufficient for the models tested, the generally smaller sample prohibited the inclusion of additional variables that may have further enhanced the analyses such as interaction terms regarding age-trauma history and age-total PTS reported by workers. Also, the significant number of young children represented in the child welfare population does present challenges to data collection regarding mental health and traumatic stress in particular. Future development of additional trauma screening and assessment tools for younger children would be beneficial for both clinical and research endeavors, and seems indicated given findings of high rates of traumatic stress among younger maltreated children (Fusco \& Cahalane, 2013; Kolko et al., 2010). Additionally, increasing the number of children able to complete their own measures in future studies and including other self-report measures that report on specific symptoms of traumatic stress would assist with clarifying issues of accuracy in screening protocols.

The cross-sectional nature of the data analyzed for this study presents another limitation. Much has been written about the need to screen children in the child welfare system for trauma exposure and traumatic stress reactions at multiple points in time due to the complexity of their evolving reactions, situational factors that may interfere with the screening process and the potential for systems-induced trauma and re-victimization (Ai et al., 2013; Romanelli et al., 2009). Because chronic and complex trauma exposures appear to be common among this population, the functioning of these children is often quite unstable as are many influential family and contextual factors. The amount of placement disruptions and service provider turnover children in this system experience can be assumed to affect their functioning and potentially limit the accuracy of data 
obtained during the screening process. This study did not have a mechanism for controlling for the influence of these factors or the informants' depth of knowledge of the child. However, three reporting sources (child, caregiver, child welfare worker) were asked to reflect on the functioning of each participant in the study over time, which is consistent with best practice guidelines that underscore the need to rely on multiple informants and triangulation of methods to best identify the trauma experiences of children (NCTSN, 2016).

There were also limitations regarding the data available about the child welfare workers and caregivers conducting the screenings or completing clinical measures. Important factors regarding the workers' educational status, previous trauma training exposure, years of professional experience and length of the relationship with the child were unknown and may have influenced the manner in which they approached the screening process. Similarly, information regarding the caregivers who served as informants was unknown. Possible relevant factors include the nature of their relationship to the child (biologic parent, foster parent, relative caregiver), length of the relationship, and exposure to trauma training or related information.

\section{Future Research Directions}

Future research efforts should be made to increase the number of studies utilizing child welfare workers to screen for trauma exposure and traumatic stress in children from their caseloads. No other studies that specifically relied on child welfare workers as the informants and examined their effectiveness in this capacity were found in the existing literature. In order to better understand this phenomenon, additional studies should be conducted that examine child welfare workers' effectiveness as trauma screeners, various 
aspects of their screening process, attributes of the workers themselves that may influence the process, associated trauma training factors, the use of different screening tools, organizational support and outcomes for children who receive trauma screening services from their workers. Targeted research on the use of the CWTRT and other screening and decision-making tools designed for child welfare, such as the CANS, should be pursued in order to not only examine worker effectiveness with regard to trauma screening, but also the effects of screening on child welfare decision making and improving outcomes for children via trauma-informed care. Studies that are designed to control for caregiver informant variables would also be beneficial. Furthermore, additional studies that include larger sample sizes should be pursued in order to enhance the complexity of statistical analyses employed given that this was a limiting factor of the present study.

\section{Practice Implications}

The primary practice implications from this study include further support for the need for trauma screening with maltreated children and the potential that child welfare workers seem to possess to meet this need. Workers' access to information regarding the child's age, trauma exposure history and potential indicators of traumatic stress appears to be sufficient, if given an accurate structure or screening mechanism, to identify children requiring a more comprehensive trauma assessment and possible intervention. Although conducting universal trauma screenings in child welfare has been well established as a best practice recommendation given that it is the system serving the highest percentage of trauma-exposed youth, this has yet to be fully realized as a standard of care (Ko et al., 2008). In fact, recent studies show that most child welfare systems do not provide any 
form of universal mental health screening for children entering foster care in spite of the obvious maltreatment, loss and disruption they have experienced and the established literature regarding high rates of traumatic stress and other psychological conditions affecting this population (Levitt, 2009). Because of advancements in mental health technologies and the development of trauma-informed caregiving curriculums designed to promote the recovery of trauma-exposed youth, there are many resources available to assist maltreated children if they can be identified in a timely manner. Child welfare workers, mental health professionals, foster-adoptive parents and courts can serve important functions in promoting post-trauma recovery if operating from a traumainformed paradigm (Conners-Burrow et al., 2013; Henry et al., 2011; Kramer et al., 2013). Effective trauma screening protocols provide critical entry points for initiating trauma-informed care and decision-making, and child welfare workers in this study appeared capable of facilitating this process.

The implementation of trauma screening protocols in child welfare poses significant challenges. Previous research has cited implementation barriers such as lacking training on administration of screenings and how to utilize screening information, having insufficient time to administer the screening tools, and being concerned about secondary traumatic stress from asking children about their trauma histories (Conradi, Wherry, \& Kisiel, 2011). First, trauma-informed training for child welfare workers should be made available not only to promote effective screening practices and demonstrate the need for providing this service, but also to educate them on how to utilize this information to guide decision-making in a manner appropriate to their scope of practice. Some important training issues to promote effective trauma screening in child welfare include the impact 
of trauma on children and child development, trauma reminders, creating psychological safety to reduce the impact of trauma, ways service delivery may exacerbate trauma's effects on children, how to facilitate access to specialized mental health services for children when indicated, and how to communicate trauma information to caregivers and others involved in the child's life (Conners-Burrow et al., 2013; Conradi, Wherry, \& Kisiel, 2011; Kramer et al., 2013; NCTSN, 2015). Based on the findings of the present study, it appears an additional focus of training should be on issues of co-morbidity and how to accurately screen for the different symptomatic presentations of traumatic stress. A specific focus on indicators of arousal and how these symptoms manifest differently in children is indicated. Workers should be advised to consider temporal sequencing with regard to trauma exposure and onset of symptomatology to help distinguish between the behavioral indicators of arousal and the externalizing symptoms of other conditions.

There also appears to be a need to include information regarding the prevention and management of secondary traumatic stress given that this has been identified as a concern with regard to conducting trauma screenings and is a particularly salient issue for child welfare workers in general. One study found that workers reported issues of secondary traumatic stress and burnout were so significant that they prevented them from being able to focus on learning new protocols and integrating the trauma paradigm as they were operating in "survival mode" (Henry et al., 2011). The supportive training cited in this study was revised in response to this finding to start with addressing secondary traumatic stress and related concerns in order to increase staff responsiveness to issues of trauma and how to integrate them into their work. Another recommendation from the field is to provide workers a forum for discussing their experiences of conducting trauma 
screenings, especially in the early stages of implementing a trauma screening protocol (Chadwick Center for Children and Families, 2013). This has not only been found to provide clarity regarding trauma screening practices and increase fidelity, but also to address any potential secondary traumatic stress or related concerns workers may experience as a result.

There are other practical concerns that need to be addressed in order to promote effective implementation of trauma screening protocols in child welfare. Helping workers integrate trauma screening questions into current practices and utilize existing datasets is indicated given the time and resource constraints prevalent in this system that would likely prohibit protocol expansion and increased documentation demands. Also, helping workers use trauma information to communicate caregiving needs, provide related psychoeducation to foster parents and help children access needed trauma interventions from an established database of trained clinicians may reduce time spent on managing multiple placement disruptions and treatment failures (Chadwick Center for Children and Families, 2014; Conradi, Wherry, \& Kisiel, 2011). However, even with extensive training and advisement on restructuring current protocols, child welfare workers would benefit from ongoing consultation to assist them with effectively utilizing data gathered from the trauma screening process. Collaboration and coaching from knowledgeable mental health providers or consultants can facilitate the application and use of trauma data not only to connect children to comprehensive assessments and evidence-based interventions if necessary, but also to enhance decision-making in numerous areas that potentially support or undermine a child's ability to recover from trauma and the prevention of future maltreatment. These areas include evaluating and intervening with the caregiving system 
in order to determine goodness of fit, and ultimately making trauma-informed decisions about placement, visitation and reunification with these child factors in mind (Conradi et al., 2011; Henry et al., 2011).

Perhaps most importantly, implementing trauma screening protocols would allow for a greater focus on the child well-being aspect of the child welfare system's three part mission to promote safety, permanency and well-being (Samuels, 2011). At least one study has shown that the use of trauma-informed instruments and screening tools in child welfare facilitates increased use of trauma-language and helped incorporate this information into decision making across domains (Henry et al., 2011). In essence, creating a trauma-informed system would promote child resiliency by increasing children's interactions with individuals who understand, support and believe in them (Chadwick Center for Children and Families, 2013). Promoting resiliency is the desired outcome of implementing trauma-informed care, all beginning with the necessary screening of the child's trauma exposure history and its impact to guide the complex series of decisions and interactions that follow the identification of maltreatment.

\section{Policy Implications}

There are implications from this study for child welfare policies to support the implementation of trauma-informed care and associated trauma screening protocols. The Adoption and Safe Families Act of 1997 (P.L. 105-89) is the federal legislation that currently organizes the structure and function of child welfare systems operating at the state level, and its adoption signaled a greater focus on child well-being. ASFA clarifies the reasonable efforts standard regarding reunification of families and delineates high risk situations when such efforts to reunify should be waived, reduces lengths of stays in 
foster care by imposing stricter timelines and provides resources to promote successful foster-adoptions (Adoption and Safe Families Act, 1997; Gordon, 1998; Barth, Wulczyn $\&$ Crea, 2005). The prioritization of child well-being represented in these policy changes indicates a shift from the cultural legacy of viewing children as property of their parents and protecting the family from an intrusive state, a protection specifically offered under the Fourteenth Amendment of the Constitution (Hart, 1991; Wilkinson-Hagen, 2004). Previous child welfare policies reflected the former emphasis on parental rights to the detriment of child well-being. ASFA was designed to address these harms by preventing children from being returned to unsafe environments and addressing the needs of the growing number waiting in foster care while prolonged efforts were made to rehabilitate their biological families (Barth, Wulczyn \& Crea, 2005).

The creation of a trauma-informed child welfare system has the potential to further ASFA's agenda by supporting these goals and promoting child well-being in a meaningful way. Helping children recover from the trauma of abuse and neglect and increasing awareness of the child factors that contribute to maltreatment risk should greatly enhance the system's efforts to achieve safety, permanency and well-being for maltreated children. Creating healthier children supports placement stability whether they reside with biologic or foster-adoptive caregivers, and a trauma-informed system would also recognize the direct and secondary effects of trauma on the caregivers themselves and support their recovery needs as well, thus reducing risks for maltreatment or placement disruption (Chadwick Center for Children and Families, 2013). A traumainformed child welfare system could help bridge the ever widening gap between parental and child rights and facilitate interventions that target the collective needs of families. 
The enactment of trauma-informed care appears to be a logical next step in the evolution of the modern child welfare system.

In order to implement this systemic change toward trauma-informed care, organizational support is critical. The revision of child welfare policies and assignment of funding to support the integration of trauma-informed care including universal trauma screening is needed. Recent estimates of the fiscal cost of childhood abuse and neglect in the U.S. are in excess of 100 billion dollars including foster care and residential treatment experiences (Wang \& Holton, 2007). While it may be difficult to redirect any of the scarce funding available to the current training and service programs of the child welfare system toward trauma initiatives, this should be conveyed as an important fiscal and practical investment in the future well-being of the families served. Given the proven potential of trauma-informed practices to serve as effective recovery strategies for individuals and secondary prevention pathways for maltreatment, the risk of such an investment seems justifiable.

Child welfare policy-makers should consider including provisions for the essential elements of a trauma-informed child welfare system as identified by the researchers of the National Child Traumatic Stress Network. These include the following: "to maximize physical and psychological safety for children and families, enhance family well-being and resilience, partner with youth and families, identify trauma-related needs of children and families, enhance child well-being and resilience, enhance the well-being and resilience of those working in the system, and partner with agencies and systems that interact with children and families" (Chadwick Center for Children and Families, 2013, pg. 20). Sustainable strategies should be developed otherwise there is a risk that child 
welfare workers, clients and others assumed within this system will confuse implementation failures with the efficacy of the evidence based practices of traumainformed care.

In order to achieve successful implementation of trauma-informed care including universal trauma screening protocols, child welfare systems will need to engage in intentional, multi-level change processes. The National Implementation Science Network (NIRN) has identified the essential stages of an implementation process as including exploration and adoption, program installation, initial implementation, full operation, innovation and sustainability (Fixsen, Naoom, Blase, Friedman, \& Wallace, 2005). To move through these stages effectively, resources will need to be leveraged to develop implementation drivers or processes that "improve competence and create a more hospitable organizational and systems environment" for the adoption of the evidencebased practices of trauma-informed care (Fixsen, Blase, Naoom, \& Duda, 2015, p. 3). NIRN has described these implementation drivers in the categories of competency, organization and leadership drivers. Child welfare systems will need to develop competency drivers to support the selection, training and coaching of staff and supervisors. In fact, the Child Welfare Trauma Referral Tool and related trainings could serve as key competency drivers given the operationalization of terms and decision-tree included in this instrument specifically designed for child welfare workers, as well as data supporting its utility. Additionally, leadership drivers that promote adaptive change and provide technical guidance throughout the implementation process, and organization drivers that support the development of a climate conducive to these practices and structures to collect and utilize data to guide decision- making are also needed (Fixsen et 
al., 2015). Given the resource challenges faced by most systems, public child welfareuniversity partnerships or collaborations with other organizations that can provide additional technical expertise seems to be a necessary strategy for achieving these implementation goals.

\section{Implications for Social Work Education}

In much the same manner suggested for policy changes in the child welfare system, there is increasing support for the need to integrate trauma training into social work education at both the undergraduate and graduate levels. Surveys show that social workers comprise approximately one-third of the child welfare workforce and provide the majority of mental health services offered in this country (Child Welfare League of America, 2015; National Association of Social Workers, 2015). In both workplace settings, social workers will be providing services to a high percentage of individuals affected by trauma and traumatic stress. Educators are acknowledging a growing obligation to include trauma training as a standard component of all social work and other mental health curriculums due to the recent dramatic increase in science and technology related to understanding the widespread incidence of trauma exposures, long-term outcomes of unmitigated trauma and strategies for effective intervention (Strand, Abramaovitz, Layne, Robinson, \& Way, 2014). It has been presented as an ethical obligation to acquire trauma training in order to remain current in one's practice and provide the most professional level of care. This also extends to bachelor's level professionals who often work in direct practice settings with highly traumatized clients such as child welfare systems, hospitals and homeless shelters. Social workers in all capacities should be prepared for addressing the issues of secondary traumatic stress 
inherent to this challenging work. It is necessary to present basic trauma theory and related information in order to more fully explain and address this phenomenon (Strand et al., 2014).

The National Child Traumatic Stress Network is currently developing the Core Curriculum on Childhood Trauma, a portion of which has been tested as part of a graduate social work curriculum (Layne et al., 2011). This problem-based learning approach to teaching the core concepts identified to support understanding and intervening with children affected by trauma has been found to be an effective educational approach for social work students (Layne et al., 2011; Strand et al., 2014). The 12 core concepts specifically address the complexity of trauma, variability of reactions to trauma, potential for secondary adversities, effects on development and neurobiology, and the potential for distress in trauma services providers as well as other related topics. Further utilization and study of this approach to integrating trauma training into social work education appears indicated particularly in graduate programs. Further development of ways to integrate trauma training into bachelor's level social work education, particularly in public child welfare partnership programs such as those created under Title IV-B funding, is also indicated and represents a current gap in the literature.

\section{Conclusion}

In sum, this study lends further support for the integration of trauma-informed policies and practices in child welfare. The children in this study were found to experience high rates of trauma exposure and traumatic stress symptoms when screened by their child welfare workers. The child welfare workers were found to generally be as effective in screening for trauma as the children's caregivers, who are used as informants in this 
process routinely in mental health settings. This suggests that child welfare workers present an underutilized resource in identifying maltreated children in need of traumafocused assessment and intervention services to assist with their recovery. Furthermore, having child welfare workers identify the effects of trauma on maltreated children has the potential for many other important benefits such as enhancing the system's overall capacity to provide a supportive, trauma recovery environment and a promoting a greater focus on child well-being. While further research in this area is needed, changes in child welfare policies and practices seem indicated to support efforts to include universal trauma screening and a movement toward providing trauma-informed care. Training and education are critical factors in the successful implementation of trauma informed care in child welfare.

Copyright $\odot$ Adrienne Whitt-Woosley 2016 


\section{Appendix A. Child Welfare Trauma Referral Tool (CWTRT) (Taylor, Steinberg, \& Wilson, 2006)}

Module 4, Activity 4F; Module 4, Activity 4G

\section{Child Welfare Trauma Referral Tool}

This measure is designed to help child welfare workers make more trauma-informed decisions about the need for referral to trauma-specific and general mental health services. It is to be completed by the child welfare worker through record review and key informants (i.e., natural parent, foster parent, child therapist, school-aged children or adolescents if appropriate, and other significant individuals in the child's life).

Section A allows the child welfare worker to document history of exposure to a variety of types of trauma and indicate the age range over which the child experienced each trauma. Section B allows the child welfare worker to document the severity of the child's traumatic stress reactions. Section $\mathrm{C}$ allows the child welfare worker to document attachment problems. Section D allows the child welfare worker to document behaviors requiring immediate stabilization. Section E allows the child welfare worker to document the severity of the child's other reactions/behaviors/functioning. Section F provides strategies for making recommendations to general or trauma-specific mental health services by linking the child's experiences to their reactions.

Form Completed by (Name/Title/ID Code): Date:

Child's Name: Age: Number of Months in Current Placement:

Reason for Current Evaluation (check all that apply):

$\square$ Baseline Assessment: New client $\quad \square$ New Trauma Reported $\quad \square$ Problematic Reactions/Behaviors Reported

$\square$ Change in Placement (Specify): $\square$ Other (Specify):

Instructions: Please flll out Sections A through $\mathrm{E}$ below by checking the box that corresponds to your answer:

- If there is absolutely NO information about the trauma factor in the vignette, you must answer UNKNOWN.

- If there is SOME information about the trauma factor in the vignette, you have three choices:

- YES, if the information suggests that this trauma factor likely occurred,

- No, if the information suggests this trauma factor did not occur,

- SUSPECTED, if the information suggests that this trauma factor could have occurred but more information is needed for a decision. 


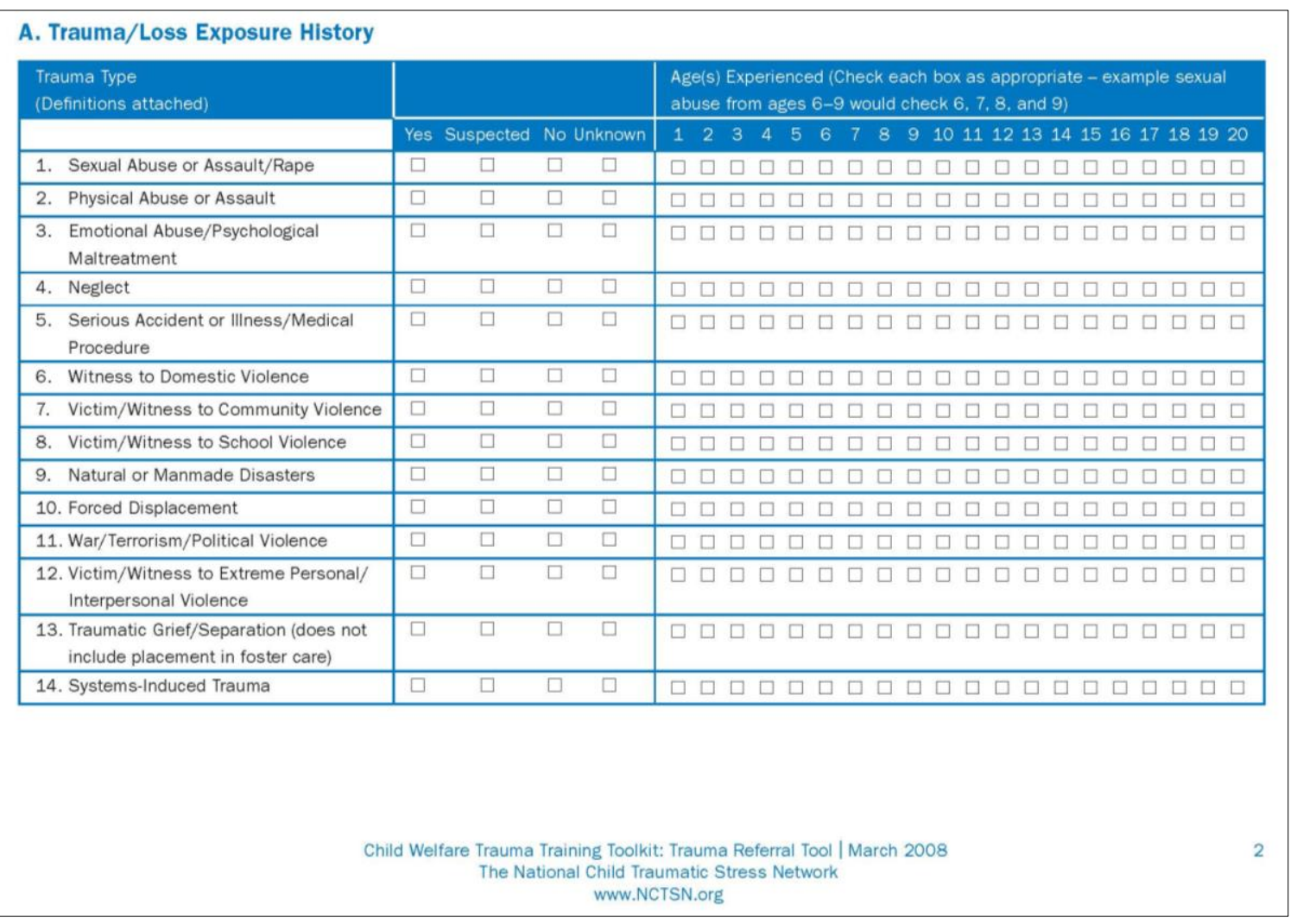

\begin{tabular}{|c|c|c|c|c|}
\hline & & Suspected N & No Unknown & $\begin{array}{l}\text { Definition } \\
\text { (Check Yes if child presents with any of the descriptors listed below) }\end{array}$ \\
\hline 1. Re-experiencing & $\square$ & $\square$ & $\square$ & $\begin{array}{l}\text { These symptoms consist of difficulties with intrusive memories or reminders of } \\
\text { traumatic events, including nightmares, flashbacks, intense reliving of the events, } \\
\text { and repetitive play with themes of specific traumatic experiences. Also included is } \\
\text { pronounced reactivity to trauma or loss reminders. These symptoms are part of the } \\
\text { DSM-IV criteria for PTSD. }\end{array}$ \\
\hline 2. Avoidance & $\square$ & $\square$ & $\square$ & $\begin{array}{l}\text { These symptoms include efforts to avoid stimuli associated with traumatic experiences. } \\
\text { The child may avoid certain places or people, or avoid discussing the specifics of the } \\
\text { trauma. These symptoms are part of the DSM-IV criteria for PTSD. }\end{array}$ \\
\hline 3. Numbing & $\square$ & $\bar{\square}$ & $\bar{\square}$ & $\begin{array}{l}\text { These symptoms include numbing responses that are part of the DSM-IV criteria for } \\
\text { PTSD. These responses were not present before the trauma. Numbing symptoms } \\
\text { include feelings of detachment or estrangement from others, restricted range of } \\
\text { emotion (e.g., unable to have loving feelings), feeling out of sync with others, or having } \\
\text { a sense of a foreshortened future. }\end{array}$ \\
\hline 4. Arousal & $\square$ & $\square$ & $\square$ & $\begin{array}{l}\text { These symptoms consist of difficulties with hypervigilance (an exaggerated awareness } \\
\text { of potential dangers), difficulty concentrating, exaggerated startle reactions, difficulties } \\
\text { falling or staying asleep, and irritability or outbursts of anger. Children with these } \\
\text { symptoms often seem distractible, impulsive and inattentive, leading to a common } \\
\text { misdiagnosis of ADHD. }\end{array}$ \\
\hline
\end{tabular}




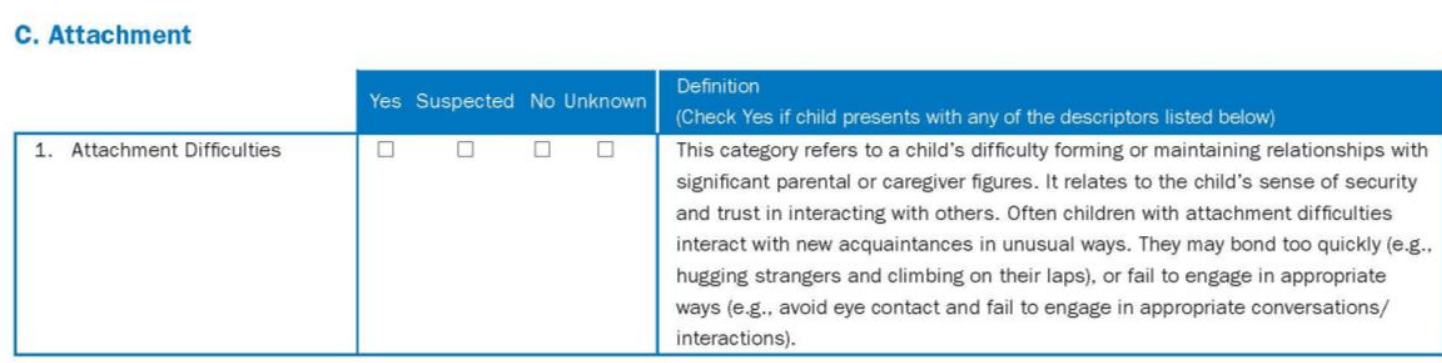

D. Behaviors Requiring Immediate Stabilization

\begin{tabular}{|l|llll|}
\cline { 2 - 4 } \multicolumn{1}{l|}{} & Yes Suspected & No Unknown \\
\hline 1. Suicidal Intent & $\square$ & $\square$ & $\square$ & $\square$ \\
\hline 2. Active Substance Abuse & $\square$ & $\square$ & $\square$ & $\square$ \\
\hline 3. Eating Disorder & $\square$ & $\square$ & $\square$ & $\square$ \\
\hline 4. Serious Sleep Disturbance & $\square$ & $\square$ & $\square$ & $\square$ \\
\hline
\end{tabular}

\section{E. Current Reactions/Behaviors/Functioning (Answer questions E1-E12 in reference to the current situation only)}

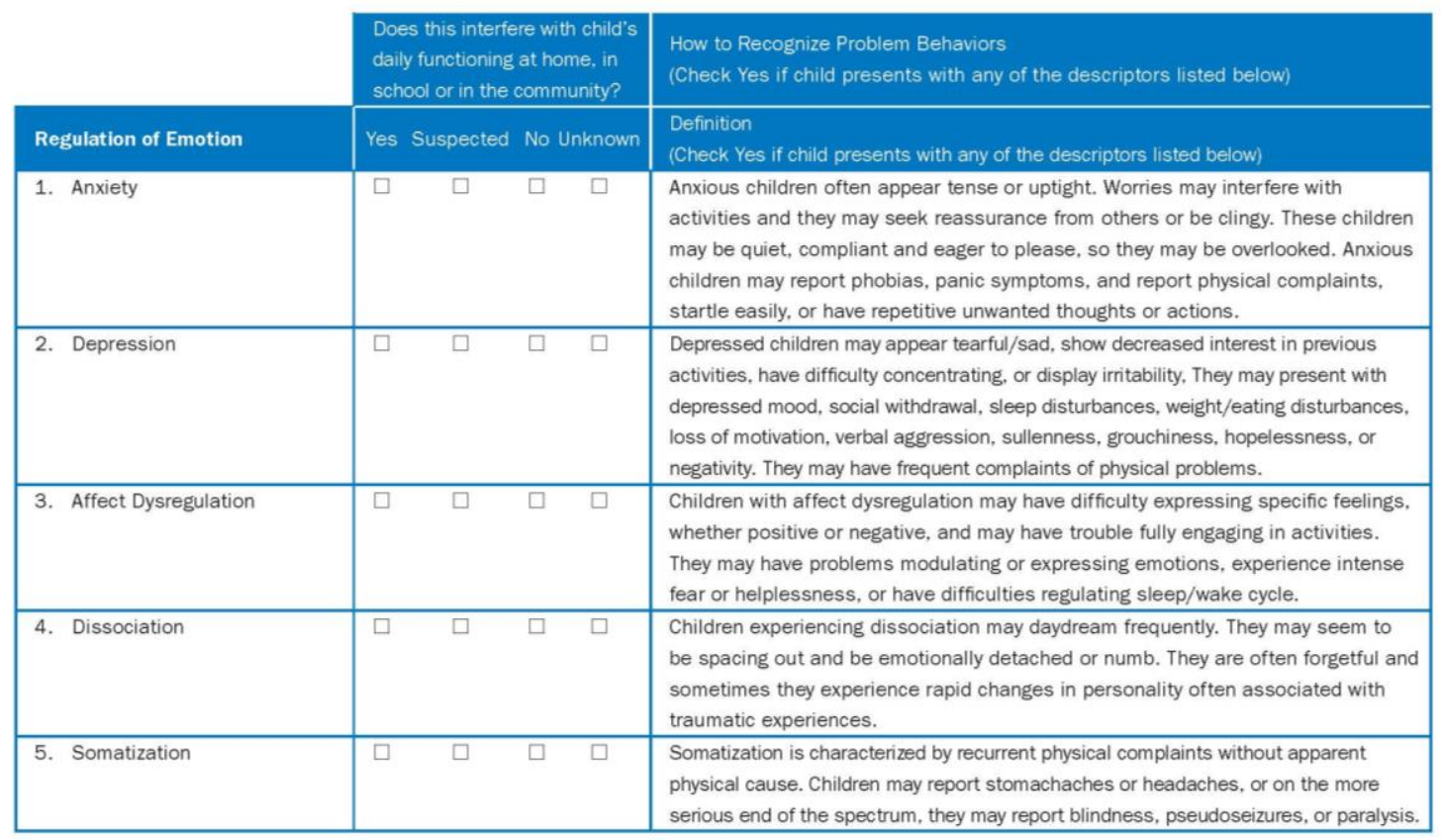




\begin{tabular}{|c|c|c|c|c|}
\hline 6. Attention/Concentration & $\square$ & $\square$ & $\square$ & $\begin{array}{l}\text { Children with problems with attention, concentration and task completion often } \\
\text { have difficulty completing schoolwork or may have difficulty forming strong peer } \\
\text { relationships. }\end{array}$ \\
\hline Regulation of Behavior & Yes & Suspected No & Vo Unknown & $\begin{array}{l}\text { Definition (Includes risky behaviors) } \\
\text { (Check Yes if child presents with any of the descriptors listed below) }\end{array}$ \\
\hline 7. Suicidal Behavior & $\square$ & $\square$ & $\square$ & $\begin{array}{l}\text { Includes both superficial and more serious actions with potentially life-threatening } \\
\text { consequences. Examples include overdosing, deliberately crashing a car, or } \\
\text { slashing wrists. }\end{array}$ \\
\hline 8. Self-Harm & $\square$ & $\square$ & $\square$ & $\begin{array}{l}\text { When someone deliberately harms him or herself. Includes cutting behaviors, } \\
\text { punching oneself, pulling out hair or eyelashes, picking skin causing sores, } \\
\text { burning, inhaling or overdosing on medications. }\end{array}$ \\
\hline 9. Regression & $\square$ & $\square$ & $\square$ & $\begin{array}{l}\text { Child ceases using previously adaptive behaviors. Child may begin wetting or } \\
\text { soiling themselves after they had been potty trained, and may begin using baby } \\
\text { talk or refusing to sleep alone when these skills were previously mastered. }\end{array}$ \\
\hline 10. Impulsivity & $\square$ & $\square$ & $\square$ & Acting or speaking without first thinking of the consequences. \\
\hline 11. Oppositional Behaviors & $\square$ & $\square$ & $\square$ & $\begin{array}{l}\text { Defined by negativistic, hostile and defiant behaviors. Child may lose temper } \\
\text { frequently, argue with adults, and refuse to comply with adult rules. Child may } \\
\text { deliberately annoy people and blame others for mistakes or misbehaviors. }\end{array}$ \\
\hline 12. Conduct Problems & $\square$ & $\square$ & $\square$ & $\begin{array}{l}\text { Defined by a variety of different conduct problems. Child may be physically or } \\
\text { verbally aggressive to other people or animals. Children with conduct problems } \\
\text { may destroy property, steal, break the law, or start fires. They may run away from } \\
\text { home or act in a sexually promiscuous or aggressive fashion. }\end{array}$ \\
\hline \multicolumn{5}{|c|}{$\begin{array}{l}\text { F. Given the information provided in the vignette, what is the appropriate next step? (Please circle one answer.) } \\
\begin{array}{l}\text { a. Trauma-informed mental health referral } \\
\begin{array}{l}\text { b. General mental health referral } \\
\text { d. No mental health referral }\end{array} \\
\text { Child Welfare Trauma Training Toolkit: Trauma Referral Tool | March } 2008 \\
\text { The National Child Traumatic Stress Network } \\
\text { www.NCTSN.org }\end{array}\end{array}$} \\
\hline
\end{tabular}




\section{Appendix B. TSCC-A and TSCYC Permission Letter}

Apr. 4. $201611: 29$ AM

\section{PAR}

Creating Connections. Changing Lives.
No. 6584 P. 2

16204 N. FLORIDR AVENUE • LUTZ, FLORIDA 33549

Telephone: 813.968:3003 * Fax; 813.968.2598 - Web: Www.parinc.com

Sent Via Email: adrienne.whitt-woosiey@uky.edu

March 28, 2016

Adrienne L. Whitt-Woosky

University of Kentucky

Center on Trauma \& Children

3470 Blazer Pkwy, Suite 100

Lexington, KY 40509

Dęar Adrienne:

In response to your recent request, permission is hereby granted to you to include up to a total of three (3) sample items from the Trauma Symptom Checkiist for Children (TSCC-A) and the Trauma Symptom Checklist for Young Children (TSCYC) in the appendix of your dissertation entitled, Identifying the Trauma Recovery Needs of Maltreated Children: An Examination of Child Welfare Workers' Effectiveness in Screening for Traumatic Stress. If additional material is needed or further publication of your dissertation in a Journal or other media, it will be necessary to write to PAR for further permission.

This Agreement is subject to the following restrictions:

(1) Any and all materials used will contain the following credit line:

\section{TSCC-A:}

"Adapted and reproduced by special permission of the Publisher, Psychological Assessment Resources, Inc., 16204 North Florida Avenue, Lutz, Florida 33549, from the Trauma Symptom Checklist for Children by John Briere, PhD, Copyright 1989, 1995 by PAR. Further reproduction is prohibited without permission from PAR."

\section{TSCYC:}

"Adapted and reproduced by special permission of the Publisher, Psychological Assessment Resources, Inc., 16204 North Florida Avenue, Lutz, Florida 33549, from the Trauma Symptom Checklist for Young Children by John Briere, PhD, Copyright 1999, 2005 by PAR. Further reproduction is prohibited without permission from PAR."

TSCC-A TSCYC Whitt-Woosky Sample Items only in đissertation - 3-28-2016 


\section{PAR}

Creating Connections. Changing Lives.

16204 N. FLORIDA AVENUE • LUTZ, FLORIDA. 33549

Telephone: 813.968.3003 - Fax: 813.968.2598 • Web: Www.parinc com

(2) None of the material may be sold, given away, or used for purposes other than those described above.

(3) Payment of a permission fee will be waived.

(4) One copy of any of the material reproduced will be sent to PAR to indicate that the proper credit line has been used.

TWO COPIES of this Permission Agreement should be signed and returned to me to indicate your agreement with the above restrictions. I will then sign it for PAR and return a fully executed copy to you for your records.

Sincerely,

Vicki M. McFadden

Permissions Specialist

vmark@parinc.com

1-800-331-8378 (phone)

1-800-727-9329 (fax)

ACCEPTED AND AGREED:

BY:

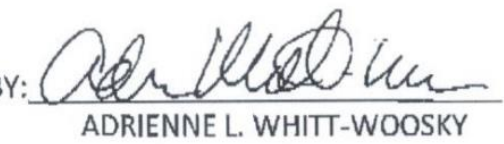

DATE: $4 / 3 / 16$
ACCEPTED AND AGREED:

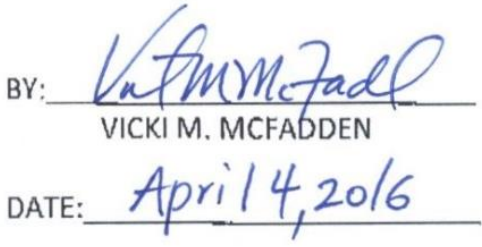




\section{References}

Aarons, G. A., \& Palinkas, L. A. (2007). Implementation of evidence-based practice in child welfare: Service provider perspectives. Administration and Policy in Mental Health and Mental Health Services Research, 34(4), 411-419.

Ai, A.L., Jackson Foster, L.J., Pecora, P.J., Delaney, N., \& Rodriguez, W. (2013). Reshaping child welfare's response to trauma assessment, evidence-based intervention, and new research perspectives. Research on Social Work Practice, 23(6), 651-668.

Agaibi, C. E., \& Wilson, J. P. (2005). Trauma, PTSD, and resilience: A review of the literature. Trauma, Violence, \& Abuse, 6(3), 195-216.

American Psychiatric Association. (2000). Diagnostic and statistical manual of mental disorders, $4^{\text {th }}$ ed TR. Arlington, VA: American Psychiatric Association.

American Psychiatric Association. (2013). Diagnostic and statistical manual of mental disorders. $5^{\text {th }}$ ed. Arlington, VA: American Psychiatric Association.

American Psychological Association. (2015). Policy statement on evidence-based practice in psychology. Retrieved from http://www.apa.org/practice/guidelines/evidencebased-statement.aspx on July 1, 2015.

Anda, R. F., Felitti, V. J., Bremner, J. D., Walker, J. D., Whitfield, C. H., Perry, B. D., ... $\&$ Giles, W. H. (2006). The enduring effects of abuse and related adverse experiences in childhood. European Archives of Psychiatry and Clinical Neuroscience, 256(3), 174-186.

Antle, B. F., Barbee, A. P., \& van Zyl, M. A. (2008). A comprehensive model for child welfare training evaluation. Children and Youth Services Review, 30(9), 1063-1080.

Armenian, H. K., Morikawa, M., Melkonian, A. K., Hovanesian, A., Akiskal, K., \& Akiskal, H. S. (2002). Risk factors for depression in the survivors of the 1988 earthquake in Armenia. Journal of Urban Health, 79(3), 373-382.

Becker-Blease, K. A., \& Freyd, J. J. (2008). A preliminary study of ADHD symptoms and correlates: do abused children differ from nonabused children?. Journal of Aggression, Maltreatment \& Trauma, 17(1), 133-14

Beidas, R. S., \& Kendall, P. C. (2010). Training therapists in evidence-based practice: a critical review of studies from a systems-contextual perspective. Clinical Psychology: Science and Practice, 17(1), 1-30.

Bogar, C. B., \& Hulse-Killacky, D. (2006). Resiliency determinants and resiliency processes among female adult survivors of childhood sexual abuse. Journal of Counseling and Development: JCD, 84(3), 318. 
Bonanno, G. A. (2004). Loss, trauma, and human resilience: have we underestimated the human capacity to thrive after extremely aversive events?. American Psychologist, 59(1), 20 .

Breslau, N. (2009). The epidemiology of trauma, PTSD, and other posttrauma disorders. Trauma, Violence, \& Abuse, 10(3), 198-210.

Breslau, N., Chilcoat, H. D., Kessler, R. C., \& Davis, G. C. (2014). Previous exposure to trauma and PTSD effects of subsequent trauma: results from the Detroit Area Survey of Trauma. American Journal of Psychiatry, 6, 902-907.

Breslau, N., Davis, G. C., Andreski, P., \& Peterson, E. (1991). Traumatic events and posttraumatic stress disorder in an urban population of young adults. Archives of General Psychiatry, 48(3), 216-222.

Breslau, N., Kessler, R. C., Chilcoat, H. D., Schultz, L. R., Davis, G. C., \& Andreski, P. (1998). Trauma and posttraumatic stress disorder in the community: the 1996 Detroit Area Survey of Trauma. Archives of General Psychiatry, 55(7), 626-632.

Breslau, N., Wilcox, H. C., Storr, C. L., Lucia, V. C., \& Anthony, J. C. (2004). Trauma exposure and posttraumatic stress disorder: a study of youths in urban America. Journal of Urban Health, 81(4), 530-544.

Briere, J.N. (1992). Child abuse trauma: Theory and treatment of the lasting effects. Newbury Park, CA: Sage Publications.

Briere, J. (1996). The trauma symptom checklist for children. Odessa, FL: Psychological Assessment Resources.

Briere, J. (2004). Psychological assessment of adult posttraumatic states:

Phenomenology,diagnosis, and measurement. Washington, DC: American Psychological Association.

Briere, J. (2005). The trauma symptom checklist for young children. Odessa, FL: PsychologicalAssessment Resources.

Briere, J., Johnson, K., Bissada, A., Damon, L., Crouch, J., Gil, E., ... \& Ernst, V. (2001). The Trauma Symptom Checklist for Young Children (TSCYC): Reliability and association with abuse exposure in a multi-site study. Child Abuse \& Neglect, 25(8), $1001-1014$.

Briere, J., \& Elliott, D. (2000). Prevalence, characteristics, and long-term sequelae of natural disaster exposure in the general population. Journal of Traumatic Stress, 13(4), 661-679. 
Briere, J., \& Scott, C. (2006). Principles of trauma therapy: A guide to symptoms, evaluation, and treatment. Thousand Oaks, CA: Sage Publications.

Brewin, C. R., Andrews, B., \& Valentine, J. D. (2000). Meta-analysis of risk factors for posttraumatic stress disorder in trauma-exposed adults. Journal of Consulting and Clinical Psychology, 68(5), 748.

Brook, J., McDonald, T.P., \& Yan, Y. (2012). An analysis of the impact of the Strengthening Families Program on family reunification in child welfare. Children and Youth Services Review, 34, 691-695.

Brown, A.D., McCauley, K., Navalta, C.P., \& Saxe, G.N. (2013). Trauma Systems Therapy in residential settings: Improving emotion regulation and the social environment of traumatized children and youth in congregate care. Journal of Family Violence, 28, 693-703.

Bryant, R. A., \& Guthrie, R. M. (2005). Maladaptive appraisals as a risk factor for posttraumatic stress: A study of trainee firefighters. Psychological Science, 16(10), 749752.

Burns, B. J., Phillips, S. D., Wagner, H. R., Barth, R. P., Kolko, D. J., Campbell, Y., \& Landsverk, J. (2004). Mental health need and access to mental health services by youths involved with child welfare: A national survey. Journal of the American Academy of Child \& Adolescent Psychiatry, 43(8), 960-970.

Butcher, F., Kretschmar, J. M., Lin, Y., Flannery, D. J., \& Singer, M. I. (2013). Analysis of the validity scales in the Trauma Symptom Checklist for Children. Research on Social Work Practice, 1049731513516803.

Cabana, M. D., Rand, C. S., Powe, N. R., Wu, A. W., Wilson, M. H., Abboud, P. A. C., \& Rubin, H. R. (1999). Why don't physicians follow clinical practice guidelines?: A framework for improvement. JAMA, 282(15), 1458-1465.

Cahill, S. P., \& Foa, E. B. (2007). Psychological theories of PTSD. Handbook of PTSD: Science and Practice, 55-77.

Carrion, V. G., Weems, C. F., Ray, R., \& Reiss, A. L. (2002). Toward an empirical definition of pediatric PTSD: The phenomenology of PTSD symptoms in youth. Journal of the American Academy of Child \& Adolescent Psychiatry, 41(2), 166-173.

Chadwick Trauma-Informed Systems Project. (2013). Creating trauma-informed child welfare systems: A guide for administrators ( $2^{\text {nd }}$ ed.). San Diego, CA: Chadwick Center for Children and Families.

Child Welfare Information Gateway. (2015). Foster care statistics 2013. Retrieved from https://www.childwelfare.gov/pubPDFs/foster.pdf 
Chu, J. A. (2011). Rebuilding shattered lives: Treating complex PTSD and dissociative disorders. Hoboken, NJ: John Wiley \& Sons.

Cicchetti, D. E., \& Toth, S. L. (1997). Developmental perspectives on trauma: Theory, research, and intervention. Rochester, NY: University of Rochester Press.

Cloitre, M., Stolbach, B. C., Herman, J. L., Kolk, B. V. D., Pynoos, R., Wang, J., \& Petkova, E. (2009). A developmental approach to complex PTSD: Childhood and adult cumulative trauma as predictors of symptom complexity. Journal of Traumatic Stress, 22(5), 399-408.

Cohen, J. A., \& Scheeringa, M. S. (2009). Post-traumatic stress disorder diagnosis in children: Challenges and promises. Dialogues in Clinical Neuroscience, 11(1), 91-99.

Cohen, J. A., Mannarino, A. P., \& Deblinger, E. (2006). Treating trauma and traumatic grief in children and adolescents. New York: Guilford Press.

Collin-Vezina, D., Coleman, K., Milne, L., Sell, J., \& Daigenault, I. (2011). Trauma experiences,maltreatment-related impairments, and resilience among child welfare youth in residential care. International Journal of Mental Health and Addiction, 9, 577-589.

Copeland, W. E., Keeler, G., Angold, A., \& Costello, E. J. (2007). Traumatic events and posttraumatic stress in childhood. Archives of General Psychiatry, 64(5), 577-584.

Conners-Burrow, N. A., Kramer, T. L., Sigel, B. A., Helpenstill, K., Sievers, C., \& McKelvey, L. (2013). Trauma-informed care training in a child welfare system: Moving it to the front line. Children and Youth Services Review, 35(11), 1830-1835.

Conradi, L., Wherry, J., \& Kisiel, C. (2011). Linking child welfare and mental health using trauma-informed screening and assessment practices. Child Welfare, 90(6), 129.

Conway, F., Oster, M., \& Szymanski, K. (2011). ADHD and complex trauma: A descriptive study of hospitalized children in an urban psychiatric hospital. Journal of Infant, Child, and Adolescent Psychotherapy, 10(1), 60-72.

Costello, E. J., Erkanli, A., Fairbank, J. A., \& Angold, A. (2002). The prevalence of potentially traumatic events in childhood and adolescence. Journal of Traumatic Stress, 15(2), 99-112.

Creamer, M., Burgess, P., \& McFarlane, A. C. (2001). Post-traumatic stress disorder: findings from the Australian National Survey of Mental Health and Well-being. Psychological Medicine, 31(07), 1237-1247.

Crossley, M. (2000). Introducing narrative psychology. McGraw-Hill Education (UK). 
Crosson-Tower, C. (2012). Exploring child welfare: A practice perspective. Pearson Higher Ed.

Davidson, J. R., Hughes, D., Blazer, D. G., \& George, L. K. (1991). Post-traumatic stress disorder in the community: an epidemiological study. Psychological medicine, 21(03), 713-721.

De Bellis, M. D., \& Van Dillen, T. (2005). Childhood post-traumatic stress disorder: An overview. Child and adolescent psychiatric clinics of North America, 14(4), 745-772.

DePanfilis, D., \& Salus, M.K. (2003). Child protective services: A guide for caseworkers. Washington, DC: U.S. Department of Health and Human Services, Administration for Children and Families, Children's Bureau.

Dekel, R., Solomon, Z., Elklit, A., \& Ginzburg, K. (2004). World assumptions and combat-related posttraumatic stress disorder. The Journal of social psychology, 144(4), 407-420.

DePrince, A. P., Chu, A., \& Visvanathan, P. (2006). Dissociation and posttraumatic stress disorder. PTSD Research Quarterly, 17(1), 1-3.

Dorsey, S., Burns, B. J., Southerland, D. G., Cox, J. R., Wagner, H. R., \& Farmer, E. M. (2012). Prior trauma exposure for youth in treatment foster care. Journal of Child and Family Studies, 21(5), 816-824.

Eccles, M. P., \& Mittman, B. S. (2006). Welcome to implementation science. Implement Science, 1(1), 1-3.

Edelbrock, C., Costello, A. J., Dulcan, M. K., Kalas, R., \& Conover, N. C. (1985). Age differences in the reliability of the psychiatric interview of the child. Child development, $265-275$.

Elliott, D. M., \& Briere, J. (1994). Forensic sexual abuse evaluations of older children: Disclosures and symptomatology. Behavioral Sciences \& the Law, 12(3), 261-277.

English, D.J., \& Pecora, P.J. (1994). Risk assessment as a practice method in child protective services. Child Welfare, 73, 451-472.

Fairbank, J. A., \& Fairbank, D. W. (2009). Epidemiology of child traumatic stress. Current Psychiatry Reports, 11(4), 289-295.

Fairbank, J. A., Putnam, F. W., \& Harris, W. W. (2007). The prevalence and impact of child traumatic stress. Handbook of PTSD: Science and Practice, 229-251. 
Falsetti, S. A., \& Resnick, H. S. (1997). Frequency and severity of panic attack symptoms in a treatment seeking sample of trauma victims. Journal of Traumatic Stress, 10(4), 683689.

Felitti, V.J., Anda, R.F., Nordenberg, D., Williamson, D.F., Spitz, A.M., Edwards, V. \& Marks, J.S. (1998). Relationship of childhood abuse and household dysfunction to many of the leading causes of death in adults: The adverse childhood experiences (ACE) study. American Journal of Preventive Medicine, 14(4), 245-258.

Finkelhor, D., Ormrod, R. K., \& Turner, H. A. (2009). Lifetime assessment of polyvictimization in a national sample of children and youth. Child Abuse \& Neglect, 33(7), 403-411.

Fixsen, D., Blase, K., Naoom, S., \& Duda, M. (2015). Implementation drivers: Assessing best practices. Chapel Hill, NC: University of North Carolina Chapel Hill, Frank Porter Graham Child Development Institute.

Fixsen, D. L., Naoom, S. F., Blase, K. A., Friedman, R. M. \& Wallace, F. (2005). Implementation research: A synthesis of the literature. Tampa, FL: University of South Florida, Louis de la Parte Florida Mental Health Institute, The National Implementation Research Network (FMHI Publication \#231).

Ford, J. D., Racusin, R., Ellis, C. G., Daviss, W. B., Reiser, J., Fleischer, A., \& Thomas, J. (2000). Child maltreatment, other trauma exposure, and posttraumatic symptomatology among children with oppositional defiant and attention deficit hyperactivity disorders. Child Maltreatment, 5(3), 205-217.

Ford, J.D., Chapman, J., Connor, D.F., \& Cruise, K.R. (2012). Complex trauma and aggression in secure juvenile justice settings. Criminal Justice and Behavior, 39(6), 694724.

Freedman, S. A., Gluck, N., Tuval-Mashiach, R., Brandes, D., Peri, T., \& Shalev, A. Y. (2002). Gender differences in responses to traumatic events: a prospective study. Journal of Traumatic Stress, 15(5), 407-413.

Friedman, M. (2006). Post-traumatic and acute stress disorders: The latest assessment and treatment strategies. Kansas City, MO: Compact Clinicals.

Friedman, M. (2014). PTSD history and overview (revised). National Center for PTSD. http://www.ptsd.va.gov/professional/PTSD-overview/ptsd-overview.asp

Fusco, R. A., \& Cahalane, H. (2013). Young children in the child welfare system: what factors contribute to trauma symptomology?. Child welfare, 92(5), 37. 
Giaconia, R. M., Reinherz, H. Z., Silverman, A. B., Pakiz, B., Frost, A. K., \& Cohen, E. (1995).Traumas and posttraumatic stress disorder in a community population of older adolescents. Journal of the American Academy of Child \& Adolescent Psychiatry, 34(10), 1369-1380.

Gilbert, A. M. (2004). Psychometric properties of the Trauma Symptom Checklist for Young Children. Unpublished doctoral dissertation, Alliant University, San Diego, CA.

Glisson, C., \& Green, P. (2005). The effects of organizational culture and climate on the access to mental health care in child welfare and juvenile justice systems. Administration and Policy in Mental Health and Mental Health Services Research, 33(4), 433-448.

Goldstein, R. D., Wampler, N. S., \& Wise, P. H. (1997). War experiences and distress symptoms of Bosnian children. Pediatrics, 100(5), 873-878.

Goldstein, A.L., Wekerle, C., Tonmyr, L., Thornton, T., Waechter, R., Pereira, J., ... MAP Research Team. (2011). The relationship between post-traumatic stress symptoms and substance use among adolescents involved with child welfare: Implications for emerging adulthood. International Journal of Mental Health and Addictions, 9, 507-524.

Green, B. L., Goodman, L. A., Krupnick, J. L., Corcoran, C. B., Petty, R. M., Stockton, P., \& Stern, N. M. (2000). Outcomes of single versus multiple trauma exposure in a screening sample. Journal of Traumatic Stress, 13(2), 271-286.

Greeson, J. K., Briggs, E. C., Kisiel, C. L., Layne, C. M., Ake III, G. S., Ko, S. J., ... \& Fairbank, J. A. (2011). Complex trauma and mental health in children and adolescents placed in foster care: Findings from the National Child Traumatic Stress Network. Child Welfare, 90(6), 91-108.

Griffin, G., McClelland, G., Holzberg, M., Stolbach, B., Maj, N., \& Kisiel, C. (2012). Addressing the impact of trauma before diagnosing mental illness in child welfare. Child Welfare, 90(6), 69-89.

Grol, R., \& Grimshaw, J. (2003). From best evidence to best practice: effective implementation of change in patients' care. The Lancet, 362(9391), 1225-1230.

Grol, R., \& Wensing, M. (2004). What drives change? Barriers to and incentives for achieving evidence-based practice. Medical Journal of Australia, 180(6 Suppl), S57.

Haight, W., Black, J., \& Sheridan, K. (2010). A mental health intervention for rural, foster children from methamphetamine-involved families: Experimental assessment with qualitative elaboration. Children and Youth Services Review, 32, 1486-1457.

Halligan, S. L., \& Yehuda, R. (2000). Risk factors for PTSD. PTSD Research Quarterly, 11(3), 1-3. 
Hamblen, J., \& Barnett, E. (2015). PTSD in children and adolescents. Accessed on July 31,2015

http://www.ptsd.va.gov/professional/treatment/children/ptsd_in_children_and_adolescent s_overview_for_professionals.asp

Harris, W. W., Putnam, F. W., \& Fairbank, J. A. (2006). Mobilizing trauma resources for children. Shaping the future of children's health, AF Lieberman \& R. DeMartino, eds., Johnson \& Johnson Pediatric Institute, Calverton, NY, 311-339.

Heflinger, C. A., Simpkins, C. G., \& Combs-Orme, T. (2000). Using the CBCL to determine the clinical status of children in state custody. Children and Youth Services Review, 22(1), 55-73.

Henry, J., Richardson, M., Black-Pond, C., Sloane, M., Atchinson, B., \& Hyter, Y. (2011). A grassroots prototype for trauma-informed child welfare system change. Child welfare, 90(6), 169.

Herman, J. (1997). Trauma and Recovery. 1992. New York: Basic.

Hoven, C. W., Duarte, C. S., Lucas, C. P., Mandell, D. J., Cohen, M., Rosen, C., et al. (2002). Effects of the World Trade Center attack on NYC public school students-Initial report to the New York City Board of Education. New York: Columbia University Mailman School of Public Health, New York State Psychiatric Institute, \& Applied Research and Consulting.

Howell, D.C. (2007). Statistical methods for psychology (6 $6^{\text {th }}$ ed.). Belmont, CA: Thomson Wadsworth.

Hurlburt, M. S., Leslie, L. K., Landsverk, J., Barth, R. P., Burns, B. J., Gibbons, R. D., ... \& Zhang, J. (2004). Contextual Predictors of Mental Health Service Use Among Children Open to Child Welfare. Archives of General Psychiatry, 61(12), 1217-1224.

Hyams, K. C., Wignall, F. S., \& Roswell, R. (1996). War syndromes and their evaluation: from the US Civil War to the Persian Gulf War. Annals of Internal Medicine, 125(5), $398-405$.

International Society for the Study of Trauma and Dissociation (2015). Dissociation FAQ's fact sheet. http://www.isst-d.org/default.asp? contentID=76\#discause

Jamora, M. S., Brylske, P. D., Martens, P., Braxton, D., Colantuoni, E., \& Belcher, H. M. (2009). Children in foster care: Adverse childhood experiences and psychiatric diagnoses. Journal of Child \& Adolescent Trauma, 2(3), 198-208.

Janoff-Bulman, R. (1989). Assumptive worlds and the stress of traumatic events: Applications of the schema construct. Social Cognition, 7(2), 113-136. 
Jones, E., \& Wessely, S. (2006). Psychological trauma: a historical perspective. Psychiatry, 5(7), 217-220.

Kammerer, N., \& Mazelis, R. (2006, April). After the crisis initiative: Healing from trauma after disasters. In Expert Panel Meeting.-Bethesda, MD (pp. 24-25).

Keane, T. M., Marshall, A. D., \& Taft, C. T. (2006). Posttraumatic stress disorder: etiology, epidemiology, and treatment outcome. Annu. Rev. Clin. Psychol., 2, 161-197.

Kearney, C. A., Wechsler, A., Kaur, H., \& Lemos-Miller, A. (2010). Posttraumatic stress disorder in maltreated youth: A review of contemporary research and thought. Clinical Child and Family Psychology Review, 13(1), 46-76.

Keller, T.E., Salazar, A.M., \& Courtney, M.E. (2010). Prevalence and timing of diagnosable mental health, alcohol, and substance use problems among older adolescents in the child welfare system. Children and Youth Services Review, 32, 626-634.

Kessler, R. C., Sonnega, A., Bromet, E., Hughes, M., \& Nelson, C. B. (1995). Posttraumatic stress disorder in the National Comorbidity Survey. Archives of General Psychiatry, 52(12), 1048-1060.

Kessler, R. C., \& Üstün, T. B. (Eds.). (2008). The WHO World Mental Health Surveys: global perspectives on the epidemiology of mental disorders (pp. 1-580). New York: Cambridge University Press.

Kilpatrick, D. G., Resnick, H. S., Milanak, M. E., Miller, M. W., Keyes, K. M., \& Friedman, M. J. (2013). National estimates of exposure to traumatic events and PTSD prevalence using DSM-IV and DSM-5 criteria. Journal of Traumatic Stress, 26(5), 537547.

Kisiel, C.L., Blaustein, M., Fogler, J., Ellis, H., \& Saxe, G. (2009). Treating children with Traumatic experiences: Understanding and assessing the needs and strengths. In J.S. Lyon \& D.A. Weiner (Eds.), Behavioral health care: Assessment, service planning and total clinical outcomes management. Kingston, NJ: Civic Research Institute.

Ko, S. J., Ford, J. D., Kassam-Adams, N., Berkowitz, S. J., Wilson, C., Wong, M., ... \& Layne, C. M. (2008). Creating trauma-informed systems: child welfare, education, first responders, health care, juvenile justice. Professional Psychology: Research and Practice, 39(4), 396.

Koenen, K. C., Harley, R., Lyons, M. J., Wolfe, J., Simpson, J. C., Goldberg, J., ... \& Tsuang, M. (2002). A twin registry study of familial and individual risk factors for trauma exposure and posttraumatic stress disorder. The Journal of Nervous and Mental Disease, 190(4), 209-218. 
Kolko, D. J., Hurlburt, M. S., Zhang, J., Barth, R. P., Leslie, L. K., \& Burns, B. J. (2010). Posttraumatic stress symptoms in children and adolescents referred for child welfare investigation: a national sample of in-home and out-of-home care. Child Maltreatment, 15(1), 48-63.

Kramer, T. L., Sigel, B. A., Conners-Burrow, N. A., Savary, P. E., \& Tempel, A. (2013). A statewide introduction of trauma-informed care in a child welfare system. Children and Youth Services Review, 35(1), 19-24.

Kutner, M. H., Nachtsheim, C., \& Neter, J. (2004). Applied linear regression models. New York, NY: McGraw-Hill/Irwin.

Landsverk, J. A., Burns, B. J., Stambaugh, L. F., \& Reutz, J. A. R. (2009). Psychosocial interventions for children and adolescents in foster care: Review of research literature. Mental Health Services for Children Placed in Foster Care: An Overview of Current Challenges, $88,1$.

Lanktree, C. B., Gilbert, A. M., Briere, J., Taylor, N., Chen, K., Maida, C. A., \& Saltzman, W. R. (2008). Multi-informant assessment of maltreated children: Convergent and discriminant validity of the TSCC and TSCYC. Child Abuse \& Neglect, 32(6), 621625.

Leon, S.C., Ragsdale, B., Miller, S.A., \& Spacarelli, S. (2008). Trauma resilience among youth in substitute care demonstrating sexual behavior problems. Child Abuse \& Neglect, $32,67-81$.

Leslie, L. K., Gordon, J. N., Meneken, L., Premji, K., Michelmore, K. L., \& Ganger, W. (2005). The physical, developmental, and mental health needs of young children in child welfare by initial placement type. Journal of Developmental and Behavioral Pediatrics: JDBP, 26(3), 177.

Leslie, L. K., Hurlburt, M. S., James, S., Landsverk, J., Slymen, D. J., \& Zhang, J. (2014). Relationship between entry into child welfare and mental health service use. Psychiatric Services.

Levitt, J. M. (2009). Identification of mental health service need among youth in child welfare. Mental Health Services for Children Placed in Foster Care: An Overview of Current Challenges, 88, 1.

Lieberman, A. F., \& Knorr, K. (2007). The impact of trauma: A developmental framework for infancy and early childhood. Pediatric Annals, 36(4), 209.

Lieberman, A. F., \& Van Horn, P. (2004). Don't hit my mommy: A manual for child parent psychotherapy with young witnesses of family violence. Washington, DC: Zero to Three Press. 
Lipschitz, D.S., Winegar, R.K., Hartnick, E., Foote, B., \& Southwick, S.M. (1999). Posttraumatic Stress Disorder in hospitalized adolescents: Psychiatric comorbidity and clinical correlates. Journal of the American Academy of Child and Adolescent Psychiatry, $38,385-392$.

Lloyd, D. A., \& Turner, R. J. (2003). Cumulative adversity and posttraumatic stress disorder:evidence from a diverse community sample of young adults. American Journal of Orthopsychiatry, 73(4), 381.

MacDonald, C., Chamberlain, K., \& Lon, N. (1997). Race, combat, and PTSD in a community sample of New Zealand Vietnam War veterans. Journal of Traumatic Stress, 10(1), 117-124.

Macdonald, G., \& Turner, W. (2008). Treatment foster care for improving outcomes in children and young people. The Cochrane Library, 9, 1-95.

Macklin, M. L., Metzger, L. J., Litz, B. T., McNally, R. J., Lasko, N. B., Orr, S. P., \& Pitman, R. K. (1998). Lower precombat intelligence is a risk factor for posttraumatic stress disorder. Journal of consulting and clinical psychology, 66(2), 323.

Marans, S., Epstein, C., \& Berkowitz, S. (2011). The CFTSI provider manual: Adaptation for children in foster care. New Haven, CT: Yale Childhood Violent Trauma Center.

Margolin, G. (2005). Children's exposure to violence exploring developmental pathways to diverse outcomes. Journal of Interpersonal Violence, 20(1), 72-81.

McCauley, J., Kern, D. E., Kolodner, K., Dill, L., Schroeder, A. F., DeChant, H. K., ... \& Bass, E. B. (1997). Clinical characteristics of women with a history of childhood abuse: unhealed wounds. JAMA, 277(17), 1362-1368.

McCrae, J. S., \& Barth, R. P. (2008). Using cumulative risk to screen for mental health problems in child welfare. Research on Social Work Practice, 18(2), 144-159.

McFarlane, A.C., Yehuda, R.A.. van der Kolk, B.A. (Ed); McFarlane, A.C. (Ed); Weisaeth, Lars (Ed). (1996). Traumatic stress: The effects of overwhelming experience on mind, body, and society. , (pp. 155-181). New York, NY, US: Guilford Press, xxv, $596 \mathrm{pp}$.

McGee, R. A., Wolfe, D. A., \& Wilson, S. K. (1997). Multiple maltreatment experiences and adolescent behavior problems: Adolescents' perspectives. Development and Psychopathology, 9(01), 131-149.

McIntyre, A., \& Keesler, T. Y. (1986). Psychological disorders among foster children. Journal of Clinical Child Psychology, 15(4), 297-303. 
McMillen, J.C., Zima, B.T., Scott, L.D., Auslander, W.F., Munson, M.R., Ollie, M.T., \& Spitznagel, E. (2005). Prevalence of psychiatric disorders among older youths in the foster care system. Journal of the American Academy of Child and Adolescent Psychiatry, 44(1), 88-95.

Milne, L., \& Collin-Vézina, D. (2014). Disclosure of Sexual Abuse among Youth in Residential Treatment Care: A Multiple Informant Comparison. Journal of Child Sexual Abuse, 23(4), 398-417.

Mizuta, I., Ikuno, T., Shimai, S., Hirotsune, H., Ogasawara, M., Ogawa, A., ... \& Inoue, Y. (2005). The prevalence of traumatic events in young Japanese women. Journal of Traumatic Stress, 18(1), 33-37.

Mollica, R. F., Poole, C., \& Tor, S. (1998). Symptoms, functioning, and health problems in a massively traumatized population: The legacy of the Cambodian tragedy.

Monson, C. M., Friedman, M. J., \& La Bash, H. A. (2007). A psychological history of PTSD. Handbook of PTSD: Science and Practice, 37-52.

National Center for PTSD (2015). DSM-5 criteria for PTSD. Retrieved from http://www.ptsd.va.gov/professional/PTSD-overview/dsm5_criteria_ptsd.asp

National Child Traumatic Stress Network, Child Welfare Collaborative Group. (2008). Child welfare trauma training toolkit. Los Angeles, CA: National Child Traumatic Stress Network.

National Child Traumatic Stress Network. (2015). Assessment of complex trauma. Retrieved from http://www.nctsn.org/trauma-types/complex-trauma/effects-of-complex$\underline{\text { trauma }}$

National Child Traumatic Stress Network. (2015). Effects of complex trauma. Retrieved fromhttp://www.nctsn.org/trauma-types/complex-trauma/effects-of-complex-trauma

Norris, F.H. (2002). Psychological consequences of disasters. PTSD Research Quarterly, 13(2), 1.

Norris, F. H. (1992). Epidemiology of trauma: frequency and impact of different potentially traumatic events on different demographic groups. Journal of Consulting and Clinical Psychology, 60(3), 409.

Norris, F. H., Murphy, A. D., Baker, C. K., Perilla, J. L., Rodriguez, F. G., \& Rodriguez, J. D. J. G. (2003). Epidemiology of trauma and posttraumatic stress disorder in Mexico. Journal of Abnormal Psychology, 112(4), 646.

Norris, F. H., \& Slone, L. B. (2007). The epidemiology of trauma and PTSD. Handbook of PTSD: Science and practice, 78-98. 
Norris, F. H., Friedman, M. J., Watson, P. J., Byrne, C. M., Diaz, E., \& Kaniasty, K. (2002). 60,000 disaster victims speak: Part I. An empirical review of the empirical literature, 1981-2001. Psychiatry, 65(3), 207-239.

Norris, F. H., \& Slone, L. B. (2013). Understanding research on the epidemiology of trauma and PTSD. PTSD Research Quarterly, 24(2-3), 1.

O'Donovan, A., Epel, E., Lin, J., Wolkowitz, O., Cohen, B., Maguen, S., ... \& Neylan, T. C. (2011). Childhood trauma associated with short leukocyte telomere length in posttraumatic stress disorder. Biological Psychiatry, 70(5), 465-471.

Ozer, E. J., Best, S. R., Lipsey, T. L., \& Weiss, D. S. (2008, August). Predictors of posttraumatic stress disorder and symptoms in adults: a meta-analysis. In Annual Meeting of the International Society for Traumatic Stress Studies, 14th, Nov, 1998, Washington, $D C, U S$; This article is based on a paper presented at the aforementioned meeting. (No. 1, p. 3). Educational Publishing Foundation.

Pecora, P. J. (1997). A profile of youth placed with the Casey Family Program using the Child Behavior Checklist/4-18 and the Teachers Report Form. Seattle, WA: The Casey Family Program, Research Department.

Pecora, P. J., Jensen, P. S., Romanelli, L. H., Jackson, L. J., \& Ortiz, A. (2009). Mental health services for children placed in foster care: An overview of current challenges. Child Welfare, 88(1), 5.

Pecora, P. J., White, C. R., Jackson, L. J., \& Wiggins, T. (2009). Mental health of current and former recipients of foster care: A review of recent studies in the USA. Child \& Family Social Work, 14(2), 132-146.

Perkonigg, A., Kessler, R. C., Storz, S., \& Wittchen, H. U. (2000). Traumatic events and post-traumatic stress disorder in the community: prevalence, risk factors and comorbidity. Acta psychiatrica scandinavica, 101(1), 46-59.

Proctor, E. K., Landsverk, J., Aarons, G., Chambers, D., Glisson, C., \& Mittman, B. (2009). Implementation research in mental health services: An emerging science with conceptual, methodological, and training challenges. Administration and Policy in Mental Health and Mental Health Services Research, 36(1), 24-34.

Pynoos, R. S., Steinberg, A. M., \& Piacentini, J. C. (1999). A developmental psychopathology model of childhood traumatic stress and intersection with anxiety disorders. Biological Psychiatry, 46(11), 1542-1554.

Reynolds, M., Mezey, G., Chapman, M., Wheeler, M., Drummond, C., \& Baldacchino, A. (2005). Co-morbid post-traumatic stress disorder in a substance misusing clinical population. Drug and Alcohol Dependence, 77(3), 251-258. 
Resnick, H. S., Kilpatrick, D. G., Dansky, B. S., Saunders, B. E., \& Best, C. L. (1993). Prevalence of civilian trauma and posttraumatic stress disorder in a representative national sample of women. Journal of Consulting and Clinical Psychology, 61(6), 984.

Resnick HS, Yehuda R, Pitman RK, Foy DW (1995): Effect of previous trauma on acute plasma cortisol level following rape. American Journal of Psychiatry, 152,1675-1677.

Ribbe, D. (1996). Psychometric review of traumatic event screening instrument for children (TESI-C). In B.H. Stamm (Ed.), Measurement of stress, trauma, and adaptation (pp. 386-387). Lutherville, MD: Sidran Press.

Richardson, G. E. (2002). The metatheory of resilience and resiliency. Journal of Clinical Psychology, 58(3), 307-321.

Rittner, B. (2002). The use of risk assessment instruments in child protective services case planning and closures. Children and Youth Services Review, 24, 189-207.

Rosenbach M, Lewis K, Quinn B. Health Conditions, Utilization, and Expenditures of Children in Foster Care: Final Report. Washington DC.: Sep, 2000. Submitted to Office of the Assistant Secretary for Planning and Evaluation MPR Reference Number 8551600.

Romanelli, L. H., Landsverk, J., Mass, J., Levitt, L. K. L., Hurley, M. M., Bellonci, C., ... \& Peter, S. (2009). Best practices for mental health in child welfare: Screening, assessment, and treatment guidelines. Mental Health Services for Children Placed in Foster Care: An Overview of Current Challenges, 88, 1.

Salmon, K., \& Bryant, R. A. (2002). Posttraumatic stress disorder in children: The influence of developmental factors. Clinical Psychology Review, 22(2), 163-188.

Saxe, G.N., Ellis, B.H., \& Kaplow, J.B. (2007). Collaborative treatment of traumatized children and teens: The trauma systems therapy approach. New York, NY: Guilford Press.

Scheeringa, M. S., \& Zeanah, C. H. (2001). A relational perspective on PTSD in early childhood. Journal of Traumatic Stress, 14(4), 799-815.

Schmid, M., Petermann, F., \& Fegert, J. M. (2013). Developmental trauma disorder: pros and cons of including formal criteria in the psychiatric diagnostic systems. $B M C$ psychiatry, 13(1), 3.

Schultz, D., Barnes-Proby, D., Chandra, A., Jaycox, L. H., Maher, E. \& Pecora, P. (2010). Toolkit for adapting cognitive behavioral intervention for trauma in schools (CBITS) or supporting students exposed to trauma (SSET) for implementation with youth in foster care. TR722. Santa Monica, CA: RAND Corporation. 
Schwarz, E. D., \& Perry, B. D. (1994). The post-traumatic response in children and adolescents. Psychiatric Clinics of North America, 17(2), 311-326.

Shalev, A. Y., Peri, T., Canetti, L., \& Schreiber, S. (1996). Predictors of PTSD in injured trauma survivors: a prospective study. American Journal of Psychiatry, 153(2), 219-225.

Silver, S. E., Duchnowski, A. J., Kutash, K., Friedman, R. M., Eisen, M., Prange, M. E., ... \& Greenbaum, P. E. (1992). A comparison of children with serious emotional disturbance served in residential and school settings. Journal of Child and Family Studies, 1(1), 43-59.

Scott, K., Smith, D., \& Ellis, P. (2010). Prospectively ascertained child maltreatment and its association with DSM-IV mental disorders in young adults. Archives of General Psychiatry, 67, 712-719.

Seedat, S., Nyamai, C., Njenga, F., Vythilingum, B., \& Stein, D. J. (2004). Trauma exposure and post-traumatic stress symptoms in urban African schools Survey in CapeTown and Nairobi. The British Journal of Psychiatry, 184(2), 169-175.

Shear, M. K., \& Smith-Caroff, K. (2002). Traumatic loss and the syndrome of complicated grief. PTSD Research Quarterly, 13(1), 1-8.

Silverman, W. K., Saavedra, L. M., \& Pina, A. A. (2001). Test-retest reliability of anxiety symptoms and diagnoses with the Anxiety Disorders Interview Schedule for DSM-IV: child and parent versions. Journal of the American Academy of Child \& Adolescent Psychiatry, 40(8), 937-944.

Southam-Gerow, M. A., Flannery-Schroeder, E. C., \& Kendall, P. C. (2003). A psychometric evaluation of the parent report form of the State-Trait Anxiety Inventory for Children-Trait Version. Journal of Anxiety Disorders, 17(4), 427-446.

Southwick, S. M., Davis, L. L., Aikins, D. E., Rasmusson, A., Barron, J., Morgan, C. A., ... \& Resick, P. A. (2007). Neurobiological alterations associated with PTSD. Handbook of PTSD: Science and Practice, 166-189.

Sprang, G., Silman, M., Whitt-Woosley, A. \& Mau, A. (2015). Translational research in child maltreatment: Innovations in assessing and managing risk. In Jared Jaworski (Ed.) Advances in Sociological Research, 39-62.

Stein, M. B., Walker, J. R., Hazen, A. L., \& Forde, D. R. (1997). Full and partial posttraumatic stress disorder: findings from a community survey. American Journal of Psychiatry, 154(8), 1114-1119. 
Stein, B., Zima, B., Elliott, M., Burnam, M., Shahinfar, A., Fox, N., \& Leavitt, L.A. (2001). Violence Exposure among school-age children in foster care: Relationship to distress symptoms. Journal of the American Academy of Child and Adolescent Psychiatry, 40(5), 588-594.

Steinberg, A.M., Brymer, M.J., Decker, K.B., \& Pynoos, R.S. (2004). The University at Los Angeles post-traumatic stress disorder reaction index. Current Psychiatry Reports, 6 , 96-100.

Stewart, S. H., Pihl, R. O., Conrod, P. J., \& Dongier, M. (1998). Functional associations among trauma, PTSD, and substance-related disorders. Addictive Behaviors, 23(6), $797-$ 812.

Substance Abuse and Mental Health Services Administration. SAMHSA's Concept of Trauma and Guidance for a Trauma-Informed Approach. HHS Publication No. (SMA) 14-4884. Rockville, MD: Substance Abuse and Mental Health Services Administration, 2014.

Szymanski, K., Sapanski, L., \& Conway, F. (2011). Trauma and ADHD-Association or diagnostic confusion? A clinical perspective. Journal of Infant, Child, and Adolescent Psychotherapy, 10(1), 51-59.

Tabachnick, B.G., \& Fidell, L.S. (2007). Using multivariate statistics (5 ${ }^{\text {th }}$ ed.). Boston, MA: Allyn and Bacon.

Tarren-Sweeney, M. (2013a). The Assessment Checklist for Adolescents- ACA: A scale for measuring the mental health of young people in foster, kinship, residential and adoptive care. Children and Youth Services Review, 35, 384-393.

Tarren-Sweeney, M. (2013b). The Brief Assessment Checklists (BAC-C, BAC-A): Mental health screening measures for school-aged children and adolescents in foster, kinship, residential and adoptive care. Children and Youth Services Review, 35, 771-779.

Taylor, N., Steinberg, A., \& Wilson, C. (2006). The child welfare trauma referral tool. San Diego, CA: Chadwick Center for Children and Families, Rady Children's.

Teicher, M. H., Andersen, S. L., Polcari, A., Anderson, C. M., Navalta, C. P., \& Kim, D. M. (2003). The neurobiological consequences of early stress and childhood maltreatment. Neuroscience \& Biobehavioral Reviews, 27(1), 33-44.

Thabet, A. A. M., Abed, Y., \& Vostanis, P. (2004). Comorbidity of PTSD and depression among refugee children during war conflict. Journal of Child Psychology and Psychiatry, 45(3), 533-542. 
Thienkrua, W., Cardozo, B. L., Chakkraband, M. S., Guadamuz, T. E., Pengjuntr, W., Tantipiwatanaskul, P., ... \& Tappero, J. W. (2006). Symptoms of posttraumatic stress disorder and depression among children in tsunami-affected areas in southern Thailand. JAMA, 296(5), 549-559.

Trickey, D., Siddaway, A. P., Meiser-Stedman, R., Serpell, L., \& Field, A. P. (2012). A meta-analysis of risk factors for post-traumatic stress disorder in children and adolescents. Clinical Psychology Review, 32(2), 122-138.

Tucker, P., Pfefferbaum, B., Nixon, S. J., \& Dickson, W. (2000). Predictors of posttraumatic stress symptoms in Oklahoma City: Exposure, social support, peri-traumatic responses. The Journal of Behavioral Health Services \& Research, 27(4), 406-416.

Tyrka, A. R., Price, L. H., Kao, H.-T., Porton, B., Marsella, S. A., \& Carpenter, L. L. (2010). Childhood Maltreatment and Telomere Shortening: Preliminary Support for an Effect of Early Stress on Cellular Aging. Biological Psychiatry, 67(6), 531-534.

Doi:10.1016/j.biopsych.2009.08.014

Ullman, S. E., \& Filipas, H. H. (2001). Predictors of PTSD symptom severity and social reactions in sexual assault victims. Journal of Traumatic Stress, 14(2), 369-389.

U.S. Department of Health and Human Services, Administration for Children and Families, Children's Bureau. (2013). Child Maltreatment 2012. Available from http://www.acf.hhs.gov/programs/cb/research-data-technology/statistics-research/childmaltreatment

U.S. Department of Health and Human Services, Administration for Children and Families, Children's Bureau. (2014). Trends in foster care and adoption FFY 2002-FFY 2013. Washington, DC: Author. Retrieved from http://www.acf.hhs.gov/programs

van der Kolk, B.A. (1989). The compulsion to repeat the trauma: Re-enactment, revictimization, and masochism. Psychiatric Clinics of North America, 12(2), 389-411.

Van der Kolk, B. A. (1996). The complexity of adaptation to trauma: Self-regulation, stimulus discrimination, and characterological development. (pp. 182-213). New York, NY: Guilford Press, xxv, 596 pp.

Van der Kolk, B. A., McFarlane, A. C., \& Weisaeth, L. (Eds.). (2012). Preface. Traumatic stress: The effects of overwhelming experience on mind, body, and society. New York, NY: Guilford Press.

Vogt, D. S., King, D. W., \& King, L. A. (2007). Risk pathways for PTSD. Handbook of PTSD: Science and Practice, 99-115. 
Weathers, F.W., \& Keane, T.M. (2007). The criterion A problem revisited: Controversies and challenges in defining and measuring psychological trauma. Journal of Traumatic Stress, 20, 107-121.

Wherry, J.N., Graves, L.E., \& Rhodes, H.M. (2008). The convergent validity of the trauma symptom checklist for young children for a sample of sexually abused outpatients. Journal of Child Sexual Abuse, 17(1), 38-50.

White, C.R., Havalchak, K., Jackson, L.J., O’Brien, K., \& Pecora, P.J. (2007). Mental health, ethnicity, sexuality, and spirituality among youth in foster care: Findings from the Casey Field Office Mental Health Study. Seattle, WA: Casey Family Programs. Retrieved January11, 2007 from www.casey.org.

Widom, C. S., DuMont, K., \& Czaja, S. J. (2007). A prospective investigation of major depressive disorder and comorbidity in abused and neglected children grown up. Archives of general psychiatry, 64(1), 49-56.

Yehuda, R. (2004). Risk and resilience in posttraumatic stress disorder. Journal of Clinical Psychiatry.1: p. 29-36.

Yehuda, R., Resnick, H. S., Schmeidler, J., Yang, R. K., \& Pitman, R. K. (1998). Predictors of cortisol and 3-methoxy-4-hydroxyphenylglycol responses in the acute aftermath of rape. Biological Psychiatry, 43(11), 855-859.

Copyright (C) Adrienne Whitt-Woosley 2016 


\section{Adrienne Whitt-Woosley, MSW, LCSW Place of Birth: Lexington, KY}

Vita

\section{Education}

2007-Present

1999-2000

1994-1999

1993-1994
Doctoral Candidate, College of Social Work University of Kentucky, Lexington, Kentucky Dissertation: Identifying the Trauma Recovery Needs of Maltreated Children: An Examination of Child Welfare Workers' Effectiveness in Screening for Traumatic Stress

Dissertation successfully defended April 20, 2016

Master of Social Work, College of Social Work University of Kentucky, Lexington, KY

Bachelor of Arts in Social Work, College of Social Work University of Kentucky, Lexington, KY

Centre College

Danville, KY

\section{Research Experience}

Associate Director, Center on Trauma and Children, University of Kentucky (July 2012present).

Project Director, Behavioral Health Disaster Response Project, University of Kentucky (December 2003- July 2008).

\section{Peer-Reviewed Publications}

Whitt-Woosley, A., \& Sprang, G. (2015). Analysis of the Adoption and Safe Families Act of 1997 and the justice challenge of balancing the rights of parents and children in a culture of inequality. Child Welfare, 93,3.

Sprang, G., Choi, M., Eslinger, J. G., \& Whitt-Woosley, A. (2015). The pathway to grandparenting stress: trauma, relational conflict, and emotional well-being. Aging \& Mental Health, 19(4), 315-324.

Whitt-Woosley, A., Sprang, G., \& Gustman, B. D. (2014). Lives at risk: Uncovering factors associated with fatal child maltreatment. Children and Youth Services Review, 47, 307-313. 
Clark, J., Sprang, G., Freer, B., \& Whitt-Woosley, A. (2010). "Better than nothing" is not good

enough: Challenges to introducing evidence based approaches for traumatized populations. Journal of Evaluation in Clinical Practice,(2), 352-359.

Freer, B., Whitt-Woosley, A., \& Sprang, G. (2010). Narrative coherence and the trauma experience: A mixed-method analysis. Victims and Violence, 25, 743-755.

Sprang, G., Kaak, H.O., Staton-Tindall, M., Clark, J., Hubbard, K., Whitt-Woosley, A., Mau, A., Combs, A., Risk, H. (2009). A response from the field: Perspectives on translating neuroscience to clinical practice. Journal of Loss and Trauma, 14, 315-346.

Sprang, G., Whitt-Woosley, A., \& Clark, J. (2007). Compassion fatigue, compassion satisfaction and Burnout: Factors impacting a professional's quality of life. Journal of Loss and Trauma, 12, 259-280.

\section{Other Publications}

Whitt-Woosley, A., Eslinger, J.G., \& Sprang, G. (In publication, 2016). Partners in Child Protection: A Trauma-Informed Approach to Assessment in Child Welfare. In Virginia Strand \& Ginny Sprang (Eds.) Developing Trauma-Informed Child Welfare Agencies and Services.

Sprang, G., Silman. M., Whitt- Woosley, A., \& Mau, A. (In Publication, 2016). Translational Research in Child Maltreatment: Innovations in Assessing and Managing Risk. In Jared Jaworski (Ed.) Advances in Sociological Research.

\section{Professional Presentations}

Whitt-Woosley, A., \& Sprang, G. (2015). Identifying the Trauma Recovery Needs of Maltreated Children: An Examination of Child Welfare Workers' Effectiveness in Screening for Traumatic Stress. Poster presentation at the International Society for Traumatic Stress Studies Annual Meeting, New Orleans, LA. November 2015.

Whitt-Woosley, A., \& Swanson, L. (2014). Community Healing and Cultural Preservation Through Architecture and Arts Programming: A Case Study of the Renovation of the Historic Lyric Theatre. Paper presentation at the Arts and Society Conference, Rome, Italy. June 2014.

Whitt-Woosley, A., \& Sprang, G. (2014). Secondary Traumatic Stress, Burnout and Compassion Satisfaction: An Investigation of Risk and Protective Factors. Paper presentation at the fourteenth International Conference on Social Stress Research, Vancouver, BC. June 2014. 
Whitt-Woosley, A., \& Sprang, G. (2013). The Emotional Experiences of Social Science Researchers of Trauma-Exposed Populations. Poster presentation at the International Society for Traumatic Stress Studies Annual Meeting, Philadelphia, PA. November 2013.

Whitt-Woosley, A., \& Sprang, G. (2013). Lives at Risk: Factors Associated with Fatal Child Maltreatment. Poster presentation at the International Society for Traumatic Stress Studies Annual Meeting, Philadelphia, PA. November 2013.

Whitt-Woosley, A., \& Sprang, G. (2013). The Emotional Experiences of Social Science Researchers of Trauma-Exposed Populations. Paper presentation at the American Professional Society for Abused Children Conference, Las Vegas, NV. June 2013.

Whitt-Woosley, A., \& Sprang, G. (2012). Lives at Risk: Factors Associated with Fatal Child Maltreatment. Paper presentation at the American Professional Society for Abused Children Conference, Chicago, IL. June 2012.

Whitt-Woosley, A., \& Sprang, G. (2012). Lives at Risk: Factors Associated with Fatal Child Maltreatment. Paper presentation at the National Conference on Child Abuse and Neglect, Washington, DC. April 2012.

\section{Funding/Awards}

Research Mini-Grant (2014), Kentucky Humanities Council.

Doctoral Student Research Funding (2014), University of Kentucky College of Social Work.

Martha Davis Scholar Award (1999-2000), University of Kentucky College of Social Work.

Day Scholar Award (1993-1994), Centre College.

\section{Teaching Experience}

Trainer of State Certified Foster Care Trainers, Kentucky Cabinet for Health and Family Services. (2014- present).

Trainer, University of Kentucky, Center on Trauma and Children. (2003-present).

Practicum Supervisor, University of Kentucky, College of Social Work. (2003-present).

Adjunct Faculty, University of Kentucky, College of Social Work. (2003-2008). 


\section{Specialized Training}

Trauma-Focused Cognitive Behavioral Therapy (TF-CBT). Pre-meeting Training Institute, American Professional Society on the Abuse of Children. (June 2008).

Parent-Child Interaction Therapy (PCIT). University of Cincinnati. (August 2005).

\section{Practice Experience}

Clinician for the Center on Trauma and Children, University of Kentucky College of Medicine- Department of Psychiatry, Lexington, KY. (2000- present).

Mental Health Consultant for Child Protective Services, Kentucky Cabinet for Health and Family Services, Frankfort, KY. (2012- present).

\section{Professional Licensure}

Licensed Clinical Social Worker, Kentucky (2003- present).

\section{Social Work Supervision}

Provision of clinical supervision to certified social workers for clinical social work licensure (2007- present). 